\title{
Cooperative breeding and anti-predator strategies of the azure-winged magpie (Cyanopica cyanus Pallas, 1776) in northern Mongolia
}

\author{
Dissertation \\ to acquire the doctoral degree in mathematics and natural science \\ the degree 'Doctor of Philosophy' \\ at the Georg-August-University Goettingen
}

in the doctoral degree programme 'Biological Diversity and Ecology' at the Georg-August University School of Science (GAUSS)

Submitted by

Gantulga Bayandonoi

from Dornogobi, Mongolia

Goettingen, 2016 


\section{Thesis Committee}

Univ.-Prof. i.R. Dr. Michael Muehlenberg

Honorary Professor Conservation Biology, Workgroup on Endangered Species, Department of Animal Ecology, Johann-Friedrich-Blumenbach Institute of Zoology \& Anthropology, Georg-August University, Goettingen

Prof. Dr. Peter M. Kappeler

Department of Sociobiology/Anthropology, Johann-Friedrich-Blumenbach Institute of Zoology \& Anthropology, Georg-August University, and Behavioural Ecology \& Sociobiology Unit, German Primate Center (DPZ), Goettingen, Germany

Prof. Dr. Eckhard W. Heymann

Department of Sociobiology/Anthropology, Johann-Friedrich-Blumenbach Institute of Zoology \& Anthropology, Georg-August University, and Behavioural Ecology \& Sociobiology Unit, German Primate Center (DPZ), Goettingen, Germany

Members of the examination board:

Referee: Univ.-Prof. i.R. Dr. Michael Muehlenberg

Co-referee: Prof. Dr. Peter M. Kappeler

Second Co-referee: Prof. Dr. Eckhard W. Heymann

Other members of the Examination Board:

Prof. Dr. Stefan Scheu

Department of Animal Ecology, Johann-Friedrich-Blumenbach-Institut für Zoologie und Anthropologie, Georg-August University, Goettingen

Prof. Dr. Rainer Willmann

Abteilung Morphologie, Systematik, Evolutionsbiologie Johann-Friedrich-Blumenbach-Institut für Zoologie und Anthropologie, Georg-August University, Goettingen

PD. Dr. Matthias Waltert

Workgroup on Endangered Species, Department of Animal Ecology, Johann-FriedrichBlumenbach Institute of Zoology \& Anthropology, Georg-August University, Goettingen

Date of the oral examination: 11.07.2016 


\section{CONTENTS}

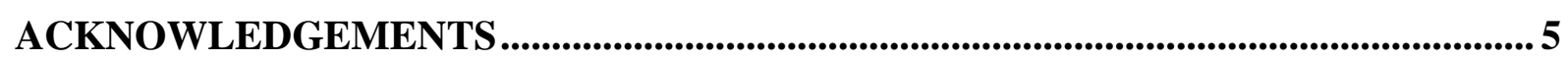

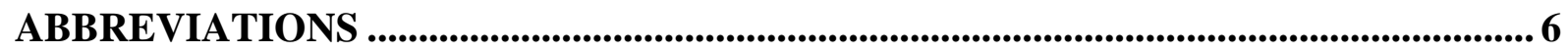

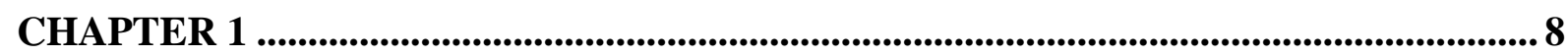

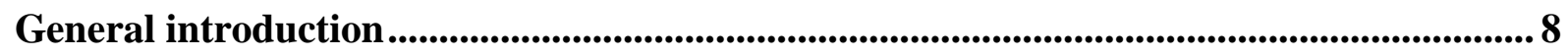

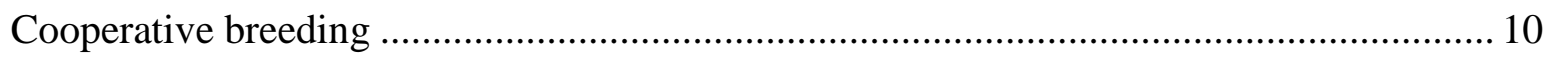

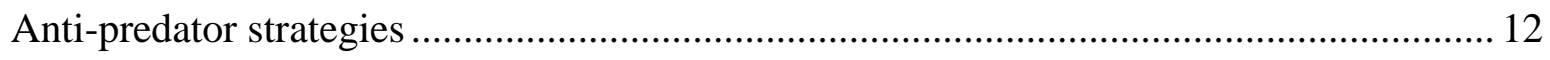

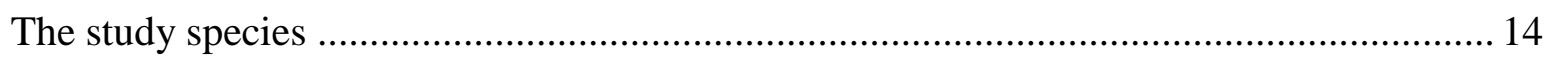

Cooperative breeding in the azure-winged magpie .................................................. 17

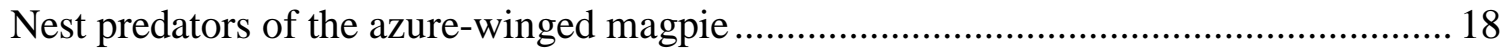

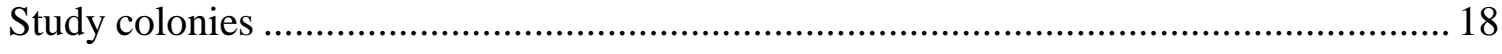

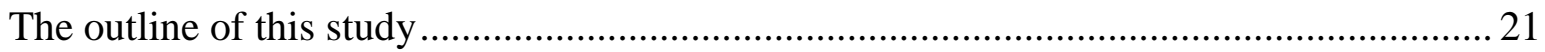

CHAPTER 2 ................................................................................................................................... 24

Helping behaviour affects nestling condition and nest predation in a facultative cooperative breeding bird, the azure-winged magpie ..................................................................... 24

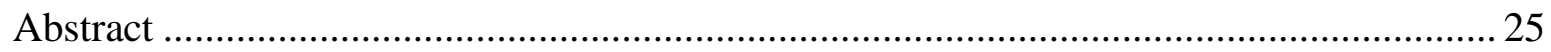

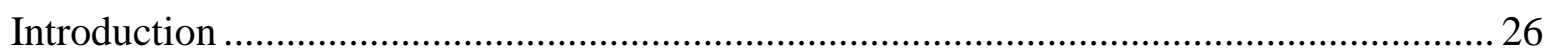

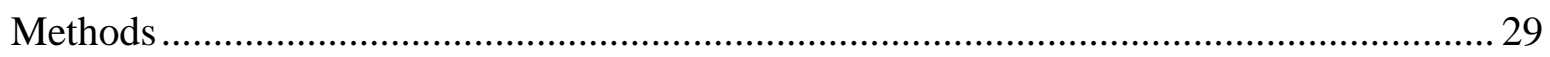

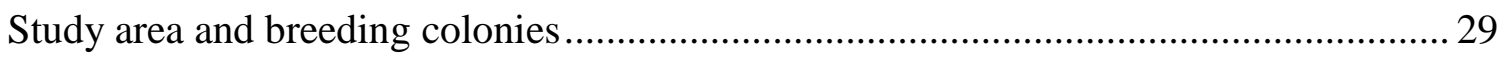

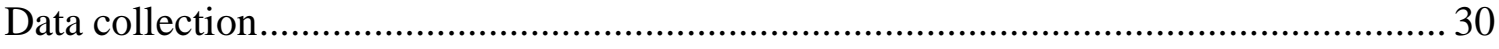

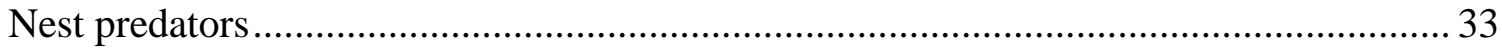

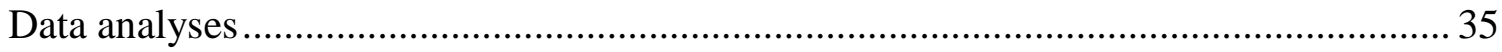

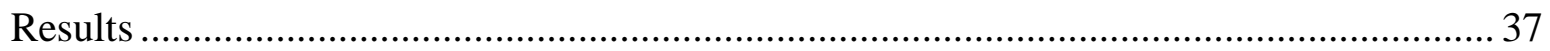

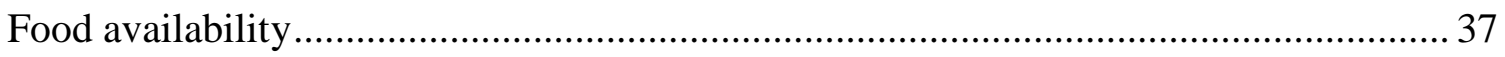

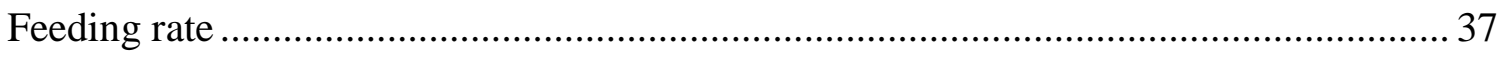

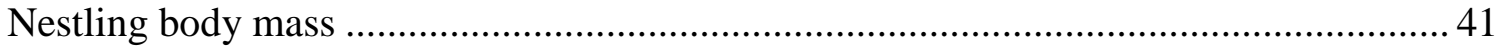

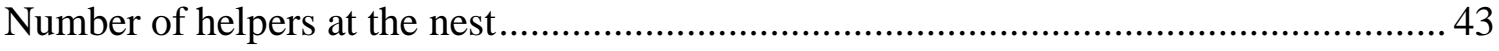

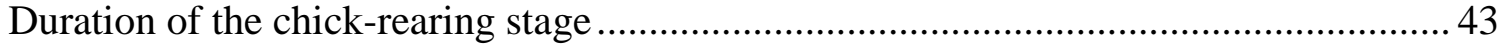

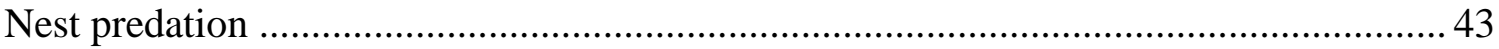




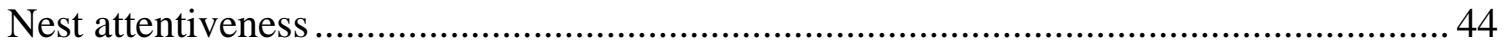

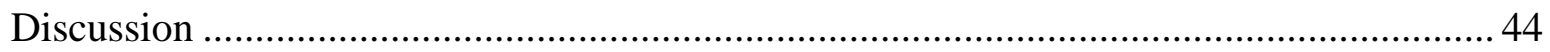

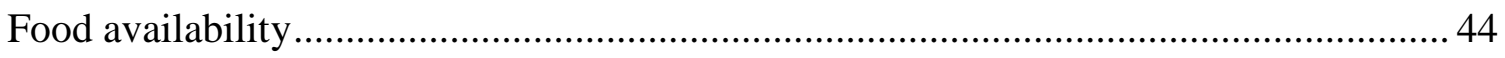

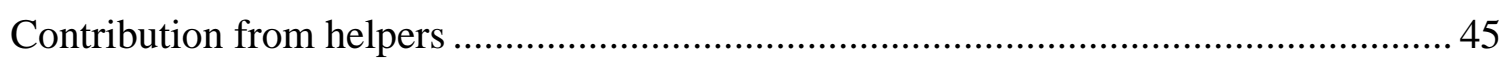

Selective factors promoting cooperative breeding ................................................. 47

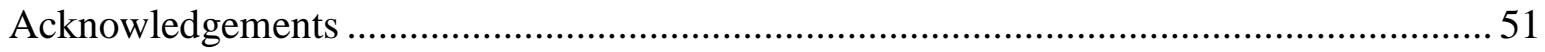

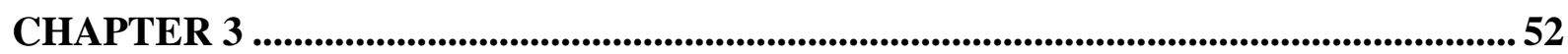

\section{Responsive adaptation to anti-predator strategies of the Azure-winged magpie}

(Cyanopica cyanus Pallas, 1776) breeding colonies in northern Mongolia ........................52

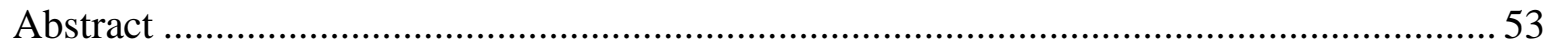

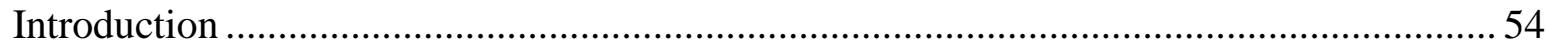

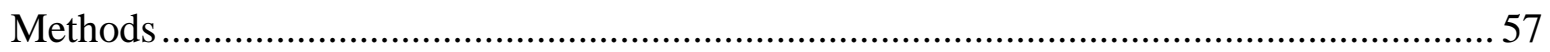

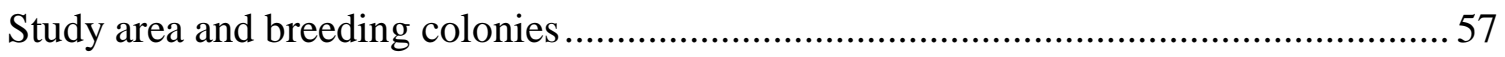

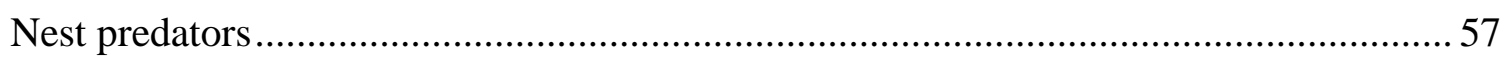

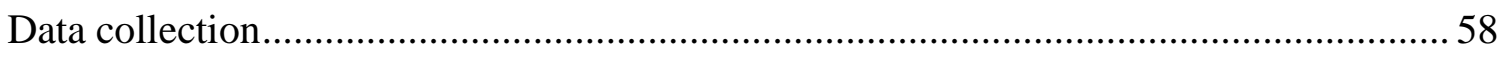

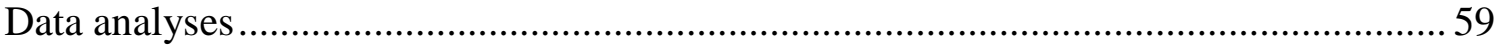

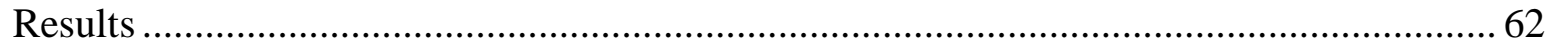

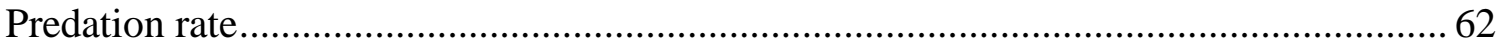

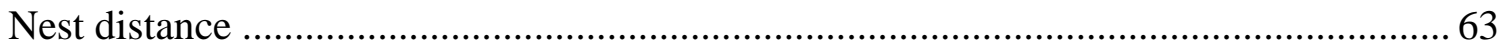

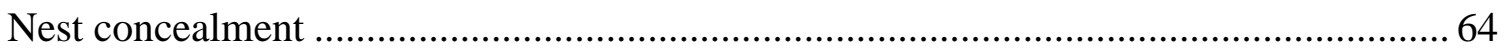

Effect of breeding pair experience on anti-predator strategies...................................... 64

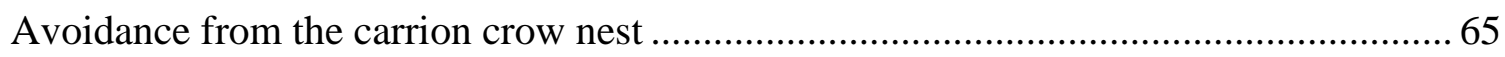

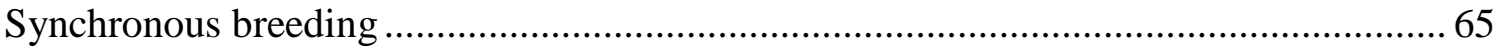

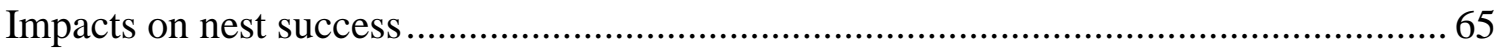

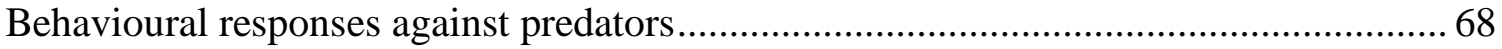

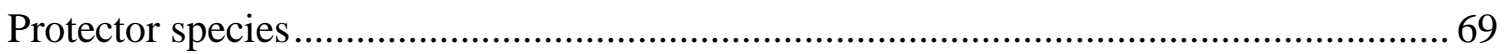

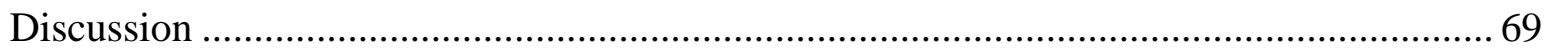

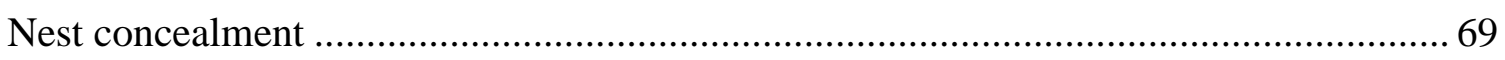

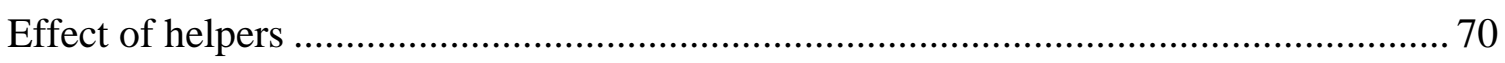

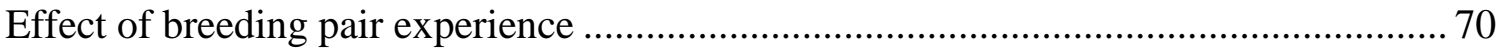

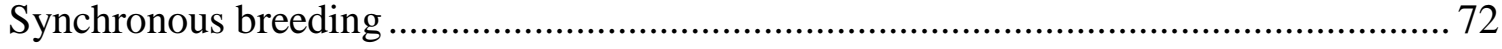

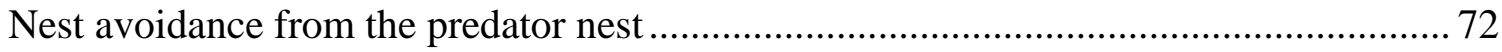

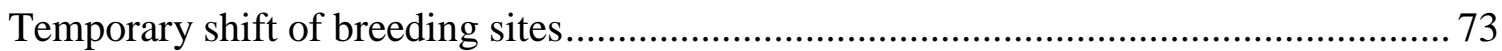




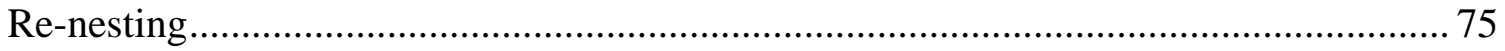

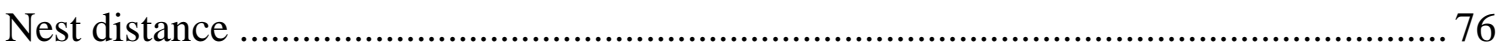

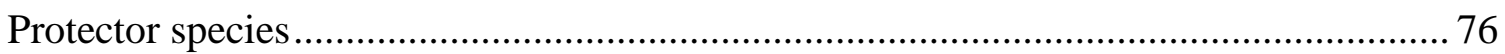

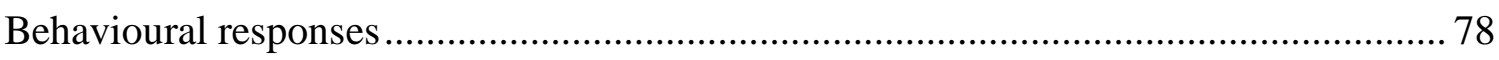

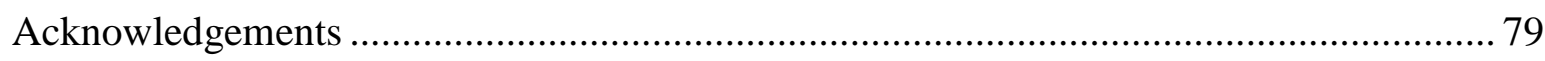

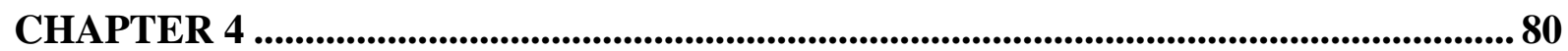

Nesting close together and splitting in sub-colonies as adaptive anti-predator strategies of the Azure-winged magpie (Cyanopica cyanus Pallas, 1776) .............................................. 80

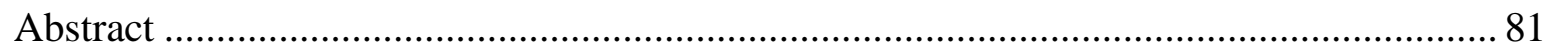

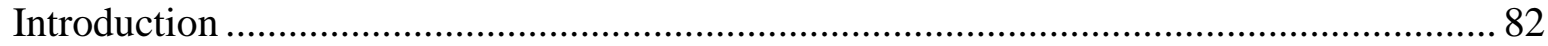

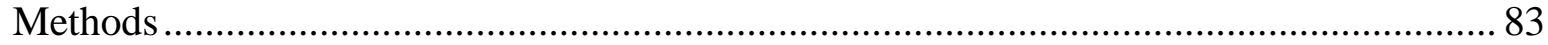

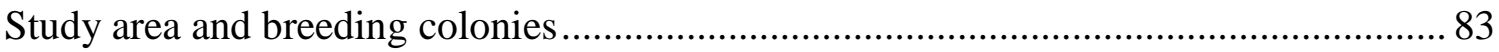

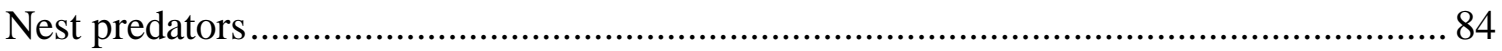

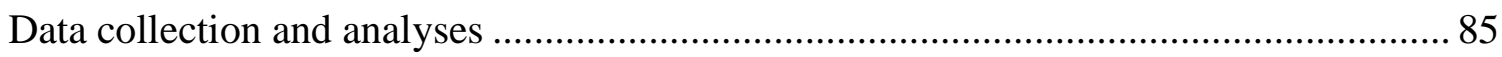

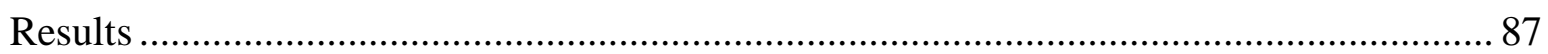

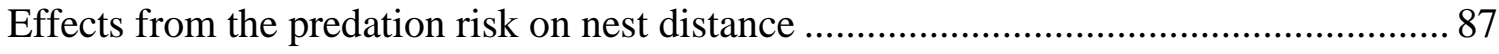

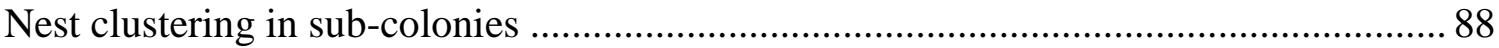

Effects from nest distance on nest success ................................................................ 90

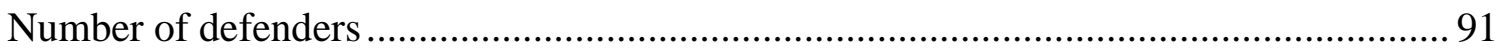

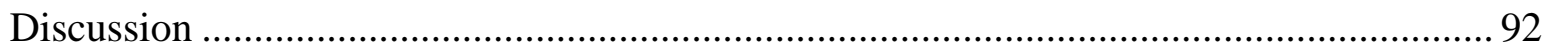

Nest distance in respect to the predation risk and predator types ................................. 92

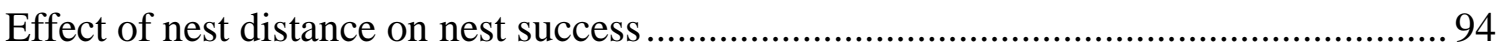

Effect of nest clustering in sub-colonies .................................................................... 95

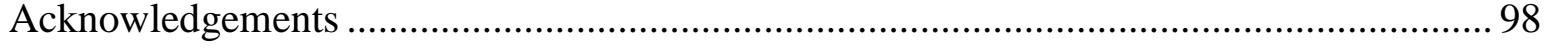

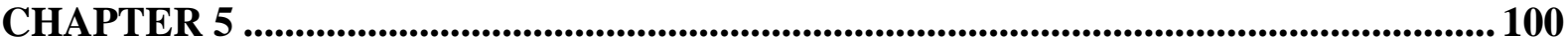

SUMMARY OF THE MAIN FINDINGS AND CONCLUSION .................................100

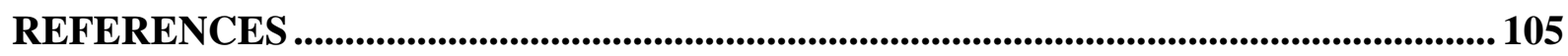

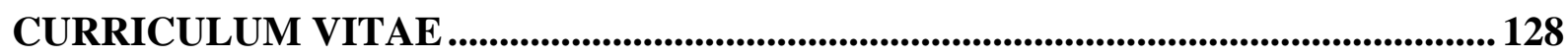




\section{ACKNOWLEDGEMENTS}

I especially want to thank my supervisor, Prof. Dr. Michael Muehlenberg, for his enormous support to study the azure-winged magpie in the Khonin Nuga field station, his encouragement to pursue PhD study and direction over the course of the study. I also thank my committee members, Prof. Dr Peter M. Kappeler and Prof. Dr. Eckhard W. Heymann, for their genuine support and ongoing insightful help to write scientific papers. I am grateful to the camp manager Enkhmaa Ayush for her encouragement and true support during field work at the Khonin Nuga Field Station and field station staff. I want to thank my teacher, Gombobaatar Sundev, for his long-lasting support and direction for me to become ornithologist, and Mongolian Ornithological Society for providing me with field equipment and logistic supports. Fellow graduate students at National University of Mongolia, Mongolian State University of Education, Mongolian University of Life Sciences, GeorgAugust University Goettingen, Jena University in Germany, Sterling College in USA, especially for Erdenezul Jargalsaikhan and Kayla Scheimreif for assistance in field work. This work could not have been done without students and my field team and driver, Altantsooj Enkhee, who kept running car and field equipment in order. Funding was provided by the German Academic Exchange Service (DAAD) and Mike Madder's Field Research Award. Finally, I have to thank my family for their continuous support. 


\section{ABBREVIATIONS}

\begin{tabular}{|c|c|}
\hline $\mathrm{KhN}$ & Khonin Nuga breeding colony \\
\hline SUG & Sugnugur breeding colony \\
\hline SON & Songino breeding colony \\
\hline SON-1 & Songino- 1 breeding colony \\
\hline SON-2 & Songino- 2 breeding colony \\
\hline $\mathrm{KWU}$ & Kruskal-Wallis $U$-test \\
\hline GLM & Generalized Mixed Model \\
\hline GLMMs & Generalized Linear Mixed Models \\
\hline NA & Nestling age \\
\hline $\mathrm{BC}$ & Breeding colony \\
\hline CS & Colony size \\
\hline $\mathrm{SC}$ & Sub-colony \\
\hline $\mathrm{BS}$ & Breeding season \\
\hline $\mathrm{B}$ & Brood size \\
\hline $\mathrm{H}$ & Helpers at the nest \\
\hline $\mathrm{NH}$ & Number of helpers at the nest \\
\hline $\mathrm{RF}$ & Relative feeding at day 9 post-hatching \\
\hline ND & Nest distance between azure-winged magpies nests \\
\hline MD & Mean distance of each nest of the azure-winged magpie to neighbouring nests \\
\hline RD & Relative distance between azure-winged magpie nests \\
\hline DC & Distance from azure-winged magpie to carrion crow nest \\
\hline $\mathrm{NC}$ & Nest concealment \\
\hline $\mathrm{PE}$ & Pair experience \\
\hline ID & Identity \\
\hline $\mathrm{AIC}_{\mathrm{c}}$ & Akaike Information Criterion with a correction \\
\hline$\Delta_{i}$ & Akaike weight \\
\hline e.g. & exempli gratia, "for example" \\
\hline i.e. & id est, "that is" \\
\hline $\mathrm{h}$ & hour \\
\hline
\end{tabular}




\section{CHAPTER 1}

GENERAL INTRODUCTION 


\section{GENERAL INTRODUCTION}

Evolution of intelligence has always been fascinated researchers. Studies have found that the comparatively high intelligence is evolved independently in several vertebrate groups including the bird family Corvidae (corvids) (Seed et al. 2009). Some corvids and parrots are superior in intelligence to other bird species (Emery and Clayton 2004). The complex social behaviour of corvids has been studied relatively well (Ekman and Ericson 2006). Recent studies have found that the corvids have exceptional cognitive ability and intelligence levels, for example, an episodic-like memory (Emery and Clayton 2004), ability to plan future (Raby et al. 2007), visual perspective of conspecifics (Dally et al. 2006), cooperative problem solving (Seed et al. 2008), creating and using a tool for problem solving (Weir et al. 2002). Interestingly, the cooperative breeding has been reported in exceptionally higher percentage of the corvid species than in any other avian family (Cockburn 1996). Social structure likely to demand significant cognitive ability from individuals, consequently, complex social behaviours are observed more frequently in cooperatively breeding birds than asocial species (Iwaniuk and Arnold 2004).

The azure-winged magpie is a corvid species with a flexible facultative cooperative breeding system (Valencia et al. 2003), which makes it an ideal subject to study as well cooperative breeding and its cognitive capacity as adaptive responses to environmental changes, such as nest predation risk. In this study, I present the potential selective factors of the cooperative breeding system of the azure-winged magpie, its cognitive ability to assess the predation risk and adaptive anti-predator strategies. 


\section{COOPERATIVE BREEDING}

In cooperatively breeding species individuals that apparently able to reproduce on their own delay breeding and instead assist others in their parental duties (Skutch 1935). Cooperative breeding involves both non-breeding related (usually offspring from the previous years) and unrelated individuals or co-breeders that assist the breeding pairs or show parentlike behaviour towards the young (Brown 1987, Ekman and Ericson 2006). Cooperative breeding is present in around 9\% of extant bird species (Cockburn 2006).

Over last few decades, several influential but not mutually exclusive hypotheses were developed to explain the evolution of cooperative breeding, such as the kin-selection (Hamilton 1964), the ecological constraints (Emlen 1982), the broad constraints (Hatchwell and Komdeur 2000), the benefits of philopatry (Stacey and Ligon 1991), the life-history (Arnold and Owens 1998, 1999), adaptive delayed dispersal (Covas and Griesser 2007), the group augmentation (Kokko et al. 2001, Kingma et al. 2014), the temporal variability (Rubenstein and Lovette 2007, Jetz and Rubenstein 2011) and the nest predation hypotheses (Poiani and Pagel 1997).

Kin-selection hypothesis predicts that cooperative breeding should arise between relatives since they share similar genes, thus altruistic individuals can increase their own indirect fitness (Hamilton 1964). However, this hypothesis was questioned in two ways: it could just be a consequence of demographic viscosity that in most species helpers are delayed offspring of the breeding birds (Clutton-Brock 2002, Baglione 2003, Canestrari et al. 2005) and helpers from several cooperative breeding birds care non-kin juveniles (e.g. Dickinson 2004, Canestrari et al. 2005). Therefore, kin-selection cannot fully explain the evolution of cooperative breeding. Hamilton (1964)'s argument that both delayed or limited dispersal in viscous populations will increase the opportunities to interact with kin has provided the 
background for all adaptive hypotheses of the evolution of cooperative breeding (Hatchwell 2009).

One of those adaptive hypotheses based on Hamilton (1964)'s idea is the ecological constraints hypothesis. Emlen (1982) developed the ecological constraints hypothesis which is either in predictable or unpredictable environments the ecological constraints restrict young individuals to breed independently, thus some individuals or offspring remain at the natal group and assist the breeding pairs. This hypothesis was the foundation for the establishment of following influential hypotheses since its broad and unspecific definition of constraints can accommodate great variety of constraints.

Most widely recognized hypothesis is the life-history hypothesis, which argues that low annual mortality leads to overcrowded population, which in turn limits breeding opportunity and promotes delayed dispersal and cooperative breeding (Arnold and Owens 1998). Broad constraints and adaptive delayed dispersal hypotheses are based on life-history hypothesis that both agrees the role of low mortality rates but, in addition, they predicts that ecological factors work along with low mortality rates to predispose certain lineages in the direction of cooperative breeding (Koenig and Dickinson 2016). The broad constraints hypothesis focuses on importance of the life-history factors acting together to generate constraints and delayed dispersal (Hatchwell and Komdeur 2000, Koenig and Dickinson 2016). Whereas, the adaptive delayed dispersal hypothesis focuses on mutual benefits of delayed dispersal for philopatry youngs and parents that would overweight the relative costs of dispersal in a long term (individual's lifetime) rather than short term (Covas and Griesser 2007, Hatchwell 2009).

The benefits of philopatry hypothesis proposes that the net of benefits of staying in natal territory lead to cooperative breeding (Stacey and Ligon 1991). The temporal variability hypothesis argues that the environmental uncertainty challenges the individuals to have 
flexible reproductive strategy that promotes social benefits of delayed dispersal and cooperation to maximize their fitness, resulting in cooperative breeding. The group augmentation hypothesis argues that individuals survive and reproduce better in large groups, thus, the group augmentation favours the evolution of cooperative breeding provided that helpers in group increase reproductive success of the group (Kokko et al. 2001, Kingma et al. 2014). The nest predation hypothesis proposes that helpers reduce nest predation, thus, it favours cooperative breeding (Poiani and Pagel 1997). Nest predation is the main cause of nest failure in great variety of bird species (Martin 1995a, Hanski et al. 1996, Poiani and Pagel 1997) and it can be a constant selective force over evolutionary time. Perhaps, the nest predation hypothesis is the least discussed one among above mentioned hypotheses. Although, none of those hypotheses can exclusively explain the evolution of cooperative breeding, most authors agree that some of these hypotheses play an important role in conjunction with each other for the evolution of cooperative breeding.

Here, I put emphasis on nest predation hypothesis using data from four breeding colonies of the azure-winged magpie in northern Mongolia (see chapter 2).

\section{ANTI-PREDATOR STRATEGIES}

Animals have evolved many morphological, physiological and behavioural traits to reduce predation since predation is a major selective force of natural selection (Caro 2005, Lima 2009, Morosinotto et al. 2010). It is also the primary cause of reproductive failure in a majority of bird species (Ricklefs 1969, Martin 1995a). Birds have evolved various antipredator strategies that affect many aspects of behavioural and reproductive decision making (Lima 2009). Perhaps the most common anti-predator strategies regarding nest predation are group living during breeding season, changing nest site location after predation, re-nesting, 
concealing the location for the nest, elaboration of nest design and behavioural adjustments in breeding biology (Lima 2009).

Some birds, sspecially passerines, have several breeding attempts during a breeding season to have successful reproduction because nest predation is often very high (Ricklefs 1969). Re-nesting is often considered as a common anti-predator strategy, since it will definitely increase the likelihood of successful reproduction during the breeding season (Jackson et al. 1989, Martin 1992a). Re-nesting facilitates several other anti-predator strategies, such as nest site selection within breeding season and behavioural adjustments.

Birds should select specific nest sites to reduce nest predation provided that nest predation is the highest cause of nest failure in great extent of the bird species (Klett et al. 1988, Pitman et al. 2006, Perkins and Vickery 2007, Borgo 2008, Lima 2009). A substantial number of studies found that birds disperse further to new breeding area after experiencing nest predation (e.g. Dow and Fredgat 1983, Sonerud 1985, Doligez et al. 1999, Hakkarainen et al. 2001) and birds change nest site at small scale to the seemingly safe place within breeding territory (Marzluff 1988, Eggers et al. 2006, Schmidt et al. 2006, Emmering and Schmidt 2011). Predation-related adjustment to nest site selection is also observed in some species (Lima 2009, see Fontaine et al. 2007, Peluc et al. 2008). Another important nest site selection strategy is the spatial scale avoidance from the predator species. Several studies showed that birds prefer to nest in places further from or absence of the predator species (Møller 1988, Finney et al. 2003, Roos and Pärt 2004, Fontaine and Martin 2006a).

A most common nest site selection strategy is the preference of the greater concealed nest location by birds. Well concealed locations should reduce the likelihood of nest detection by vision-oriented predators, thus, birds are expected to choose greater nest concealment (Lima 2009). Nest concealment is likely one of the common anti-predator strategies also in other animal groups, surprisingly, little 'ecological time' work exists concerning this strategy 
(Lima 2009). Generally, predators use two main sensory stimuli, visual and olfactory cues, to locate nest (Borgo 2008). They usually rely on single type of sensor heavily, though they may use other type of sensors to locate nests (Wells and Lehner 1978). The effectiveness of nest concealment may depend on type of predators, for example, it can be ineffective against olfactory-oriented predators. Although, experimental studies using artificial nests generally support the positive effect of nest concealment (Martin 1992a, Weidinger 2002, Remeš 2005), it is often not the case in studies on natural nests (Götmark et al. 1995, Howlett and Stutchbury 1996, Remeš 2005, reviewed in Lima 2009 and Borgmann and Conway 2015). The lack of nest concealment effect in natural nests may be compensated by breeding bird's behavioural responses (Cresswell 1997, Remeš 2005, Goławski and Mitrus 2008, Lima 2009). Nest concealment has its own drawbacks, such as obstructed view for the parents and less optimal microclimate for the eggs and nestlings (Lima 2009).

Extensive predation pressure is a major ecological cause of group living in animals (Rubenstein 1978, Krause and Ruxton 2002). Therefore, nesting in colony may also be an effective anti-predator strategy in some species (Lima 2009). However, it largely depends on predator and prey type (Hogstad 1995, Lima 2009). Some studies found positive effects of colony nesting in high density on lowering nest predation (Ritschel 1985, Picman et al. 1988, Hogstad 1995, Ringelman et al. 2012).

Here, I investigate the adaptive responses and complexity of the anti-predator strategies of azure-winged magpies associated with predation risk (see chapter 3 and 4).

\section{THE STUDY SPECIES}

The study was conducted on the azure-winged magpie (Cyanopica cyanus Pallas 1776), known as a cooperative breeding species. The azure-winged magpie (family Corvidae) is currently the only recognized species in its genus. The species has a remarkably disjunct 
distribution (Fig. 1): the birds are present in Iberian Peninsula (central and southern Spain and Portugal) and in north-eastern Asia (Goodwin 1986).

Within Asian region the azure-winged magpie is restricted to areas south and east of Lake Baikal. In Mongolia, the species is present along the northern Mongolian river systems, especially in the Yuruu, Orkhon and Selenge river basins (Tugarinov 1929, Kozlova 1930, Bold 1973, 1977, Boldbaatar 1999, 2006).

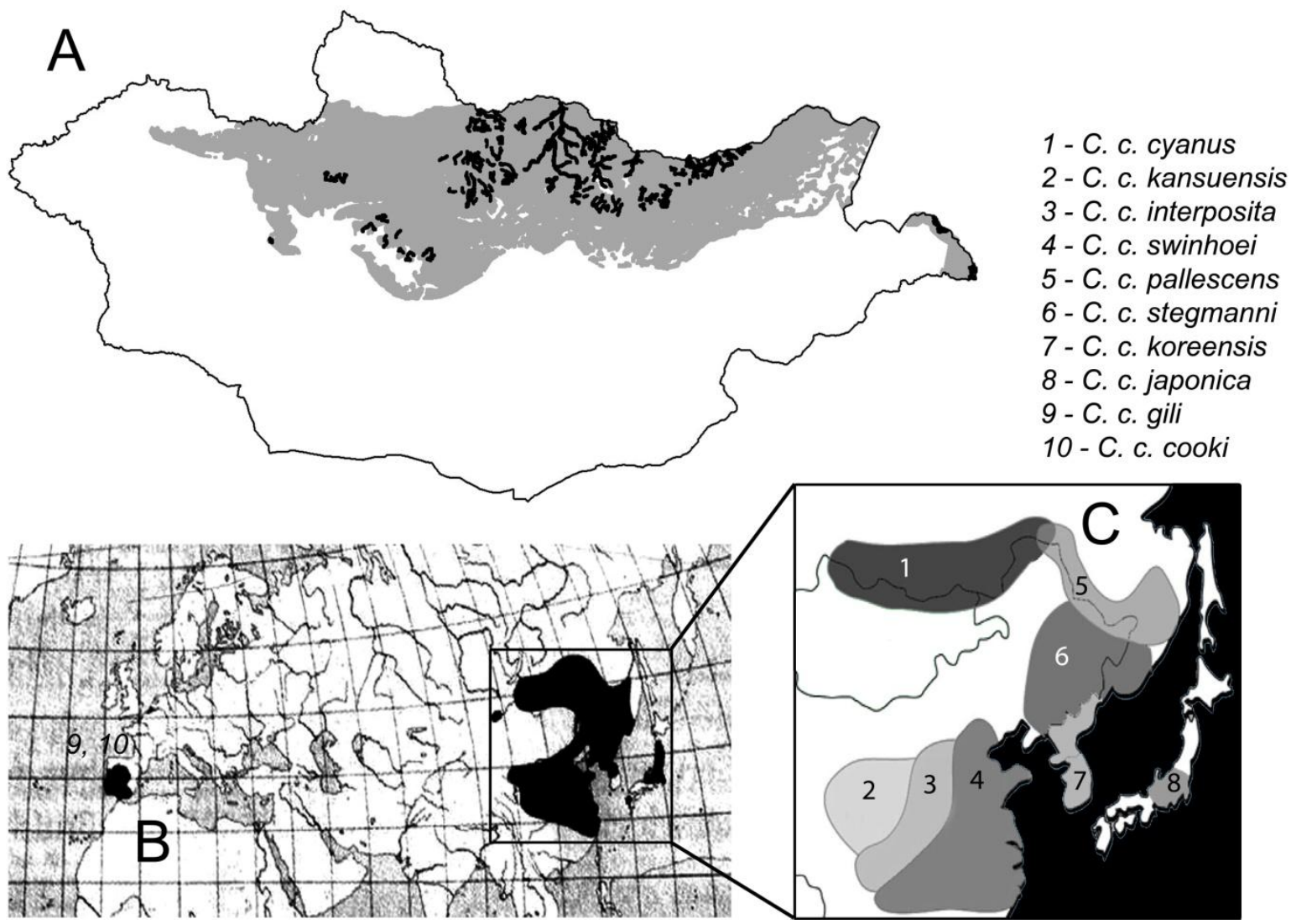

Figure. 1 Geographical distribution of the azure-winged magpie (shaded areas) showing the geographical distribution of the European (B) and Asiatic subspecies (C) and its range in Mongolia (A). On the map of Mongolia (A): breeding area is shown in black, non-breeding area is shown in grey. Map A is from Gombobaatar and Monks (2011), B is from Voous (1960) and C is from Fok et al. (2002). 
There are ten proposed subspecies characterized by morphological differences and geographical distribution that two of them in Iberian Peninsula, the rest are in Asia (Fig. 1B and 1C, Vaurie 1959). Recent studies suggested that the Asian and Iberian populations should be regarded as separate species based on mitochondrial DNA, phylogenetic and morphometric analyses. Therefore, it is recommended to name Asian population as Cyanopica cyanus Pallas, 1776 and Iberian population as Cyanopica cooki Bonaparte, 1850 (Fok et al. 2002, Kryukov et al. 2004). However, their study results did not support the current classification of the two subspecies of Iberian population, while only C.c.japonica was recognized as subspecies from eight subspecies according to Vaurie (1959) in Asian population.

Azure-winged magpies mainly feed on insects and other invertebrates as well as fruits, berries and seeds obtained while foraging in trees, shrubs, and on the ground (Hosono 1966a, Komeda et al. 1987, Álvarez and Aguilera 1988, Cramp and Perrins 1994). Food caching is observed in the azure-winged magpies (acorns, olives, pine seeds) under the ground (Snow et al. 1997). Azure-winged magpies inhabit open woodlands and cultivated or open country with groves of trees in Japan (Komeda et al. 1987). In Iberia they predominantly inhabit managed habitats like, dehesa (open holm oak Quercus ilex woodland) (Valencia et al. 2000). Azurewinged magpie is sexually monomorphic in plumage and nearly monomorphic in size (Cramp and Perrins 1994, Alarcos et al. 2007). This species is highly gregarious throughout the year, and breeds in sparse colonies (Komeda et al. 1987, Cramp and Perrins 1994). Breeding colony in Asian populations are tight colonies that consists of an average of 20 individuals in Japanese (Hosono 1968, Komeda et al. 1987) and 25 individuals in Mongolian (in this study). Whereas, Iberian magpies have relatively large breeding colonies that consists on average of 33 breeding pairs (Valencia et al. 2002). Only females incubate eggs and brood young nestlings (Hosono 1966b, Goodwin 1986, Komeda et al. 1987). They are generally singlebrooded, though second broods have occasionally been reported in Spain (Valencia et al. 
2000) and Asia (Madge and Burn 1994). Re-nesting after failed breeding attempt is common in this species (Valencia et al. 2000). Nests are generally close to one another and egg-laying relatively synchronous, although there may be two or even three phases of nesting, with nests close together and synchronous within each phase. Pairs are monogamous, but may receive help from other conspecifics (Valencia et al. 2003). Clutch size is usually five to six eggs (range 2-9) (Jesus M. Aviles 2004, Bayandonoi et al. 2013). Breeding season is between April and July in Iberian populations (Valencia et al. 2002), while it is around one month late (MayJuly) in Asian populations (Komeda et al. 1987, Bayandonoi et al. 2013).

\section{Cooperative breeding in the azure-winged magpie}

Cooperative breeding is more common in the family Corvidae than in most other groups of birds (Ekman and Ericson 2006) suggesting a strongly conserved evolutionary trait in the corvids (Arnold and Owens 1998, Ekman and Ericson 2006). Within the Corvidae cooperative breeding has been found to improve reproductive success in many species, for example, azure-winged magpie (Valencia et al. 2003, Canario et al. 2004, Bayandonoi et al. 2013), Florida scrub-jay Aphelocoma coerulescens (Woolfenden 1975) and carrion crow Corvus corone (Canestrari et al. 2008a, 2009). Cooperative breeding has been reported in the Iberian (Araujo 1975, Cruz 1988, Valencia et al. 2000, 2003), Japanese (Hosono 1983, Komeda et al. 1987) and Mongolian populations of the azure-winged magpie (Bayandonoi et al. 2013). Azure-winged magpies (Cyanopica cyanus) may perform a flexible cooperative breeding system (Valencia et al. 2002, 2003). The frequency of helpers in the colony is $25.2 \%$ on average in Iberian studied colonies (Valencia et al. 2003), 22\% in this study, and up to $50 \%$ in Japanese studied colony (Komeda et al. 1987). Helpers in the azure-winged magpie colonies may contribute to nest building, provisioning incubation or brooding females, 
feeding nestlings and fledglings, removing faecal sacs, and mobbing predators (Komeda et al., 1987, Valencia et al., 2003).

\section{Nest predators of the azure-winged magpie}

Nest predators of the azure-winged magpies vary between populations. The great spotted cuckoo Clamator glandarius is the common nest predator and nest parasite in Iberian population (Avilés and Parejo 2006), while jungle crows Corvus macrorhynchos are the main nest predator in the Japanese population (Hosono 1983, Ueta 1994). The carrion crow Corvus corone and the common magpie Pica pica are the most common nest predators in the Mongolian population (Gantulga Bayandonoi, see chapter 2). Nest predation is the most common cause of nest failure in the azure-winged magpie breeding populations because $56 \%$ of all nests from breeding colonies in Mongolian preyed by predators (see Chapter 3). While it is also high in other populations that it account to $68 \%$ of the nests in Japanese (Ueta 1998a), and up to $80 \%$ of nests in one study (Cruz et al. 1990), 32\% of nests in another (Canario et al. 2004) and 45\% of nests (Valencia et al. 2003) in Iberian populations. Potential predatory species of the azure-winged magpies that recorded in breeding colonies in this study are short-eared owl (Asio flammeus), sparrow hawk (Accipiter nisus), goshawk (A. gentilis), common cuckoo (Cuculus canorus), oriental cuckoo (C. saturatus), hobby (Falco subbuteo), halys pit viper (Gloydius halys), Steppe's rat snake (Elaphe dione), red fox (Vulpes vulpes), sable (Martes zibellina), other small mustelids (Mustelidae), red squirrel (Scirius vularis) and Siberian chipmunk (Tamias sibiricus). However, these species seem to have far less impact on predation rate than the impact from corvids in breeding sites of this study.

\section{Study colonies}

Study was carried out on four different breeding colonies, namely Khonin Nuga $(\mathrm{KhN})$, Songino-1, Songino-2 (referred as one breeding site along with Songino-1) and 
Sugnugur (SUG). Breeding colonies are located in the southern Siberian mountain taiga forest, along the Yuruu, Tuul and Sugnugur river basins (Figure 2). The habitats are the riparian woodland, surrounded by mountain dry steppe, meadow steppe and wet grassland (Muehlenberg et al. 2000). The climate in these habitats is continental with hot summers and cold, severe winters. Average annual temperature is $0.7^{0} \mathrm{C}$. In the coldest month, January, the average temperature is $-22.1^{\circ} \mathrm{C}$ (min. $-51^{\circ} \mathrm{C}$ in January 2010 in $\mathrm{KhN}$, local ranger Myagmarsuren. D, personal observation) and in the warmest month, July, the average temperature is $19^{\circ} \mathrm{C}\left(\max .36 .4^{\circ} \mathrm{C}\right)$ (von Velsen-Zerweck 2002). Mean temperature during breeding season in 2014 ranged from 13.8 to $14^{\circ} \mathrm{C}$ at the three breeding sites, while mean precipitation ranged from 147.2 to $202.8 \mathrm{~mm}$. Snow covers the ground from early October to mid-April.

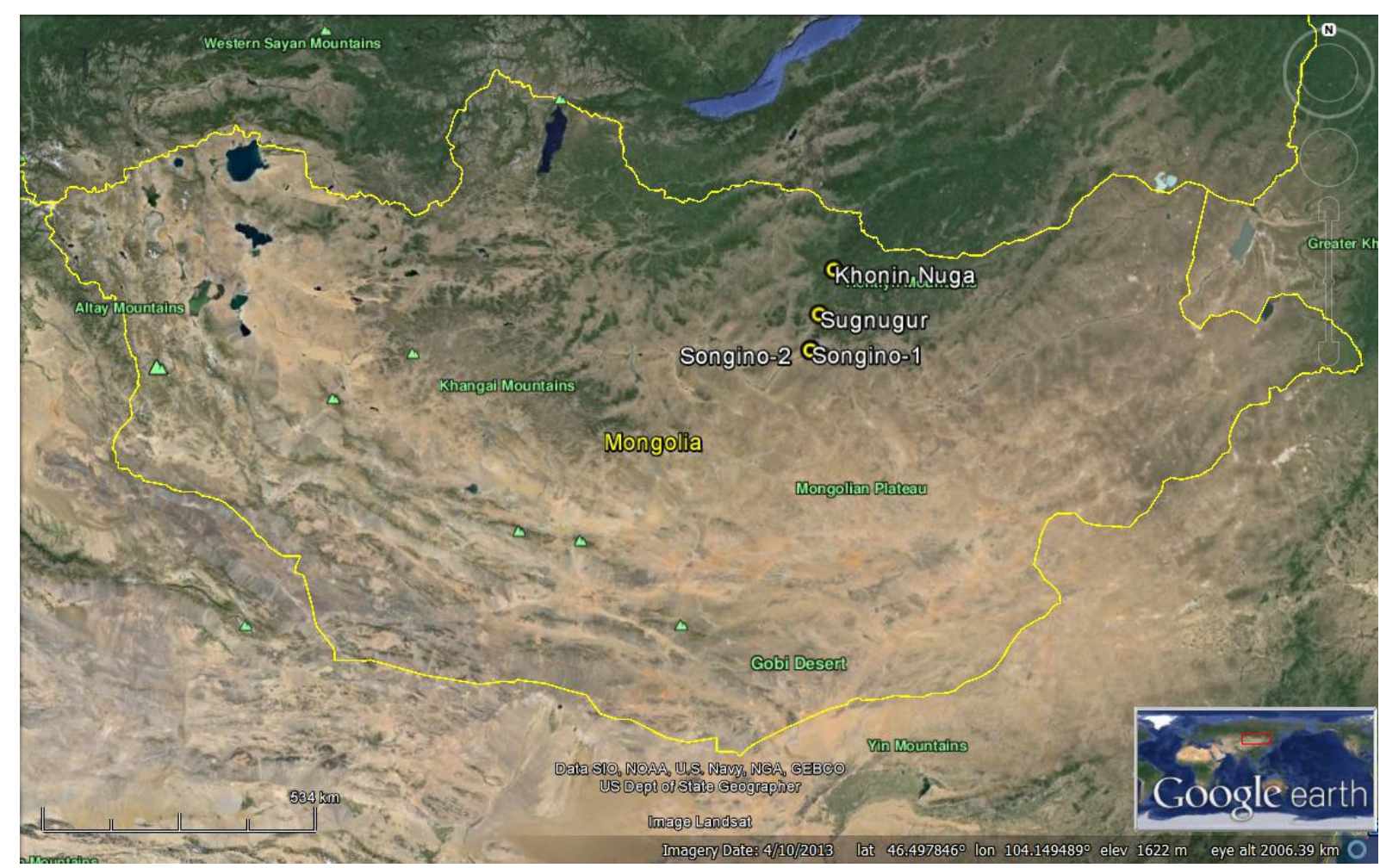

Figure 2. Location of the breeding colonies of the azure-winged magpies in Northern Mongolia. 
Khonin Nuga site has a rich invertebrate fauna thus potential food items are varied. However, the main food source of the Khonin Nuga breeding colony is annually a two-week swarm of stoneflies (Coleoptera) during egg-laying and early incubation stages, while it is the adult gypsy moths (Lymantria dispar) and berries after breeding season. Gypsy moths were the main food source for the azure-winged magpies during incubation and chick rearing stages (see chapter 2) and these moths with its fluctuating populations were abundant in the breeding site between 2001 and 2006 (Gantigmaa 2004, Michael Muehlenberg personal comment), peaking again in 2007 (Tiralla 2007, Magsarjav Altantsegtseg unpubl.data).

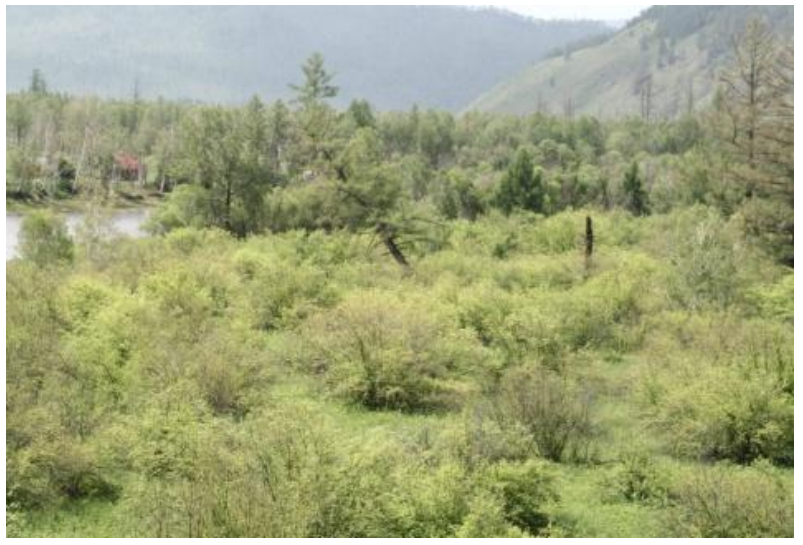

Khonin Nuga

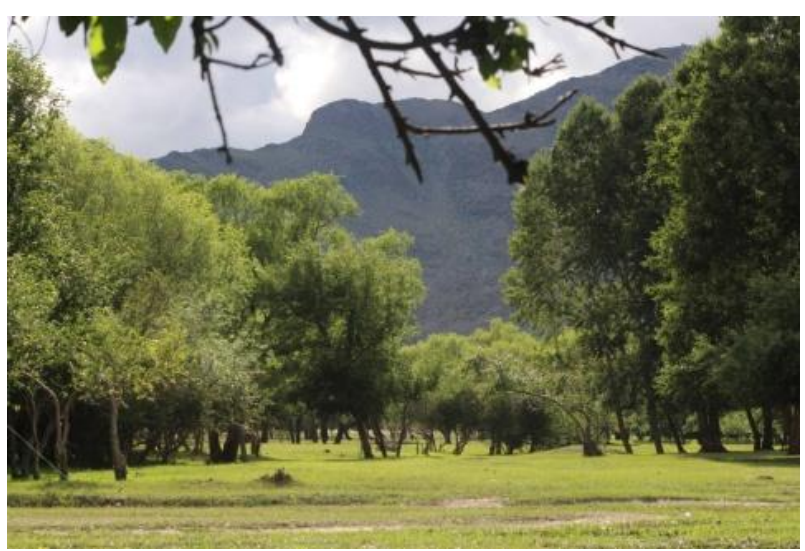

Songino-1

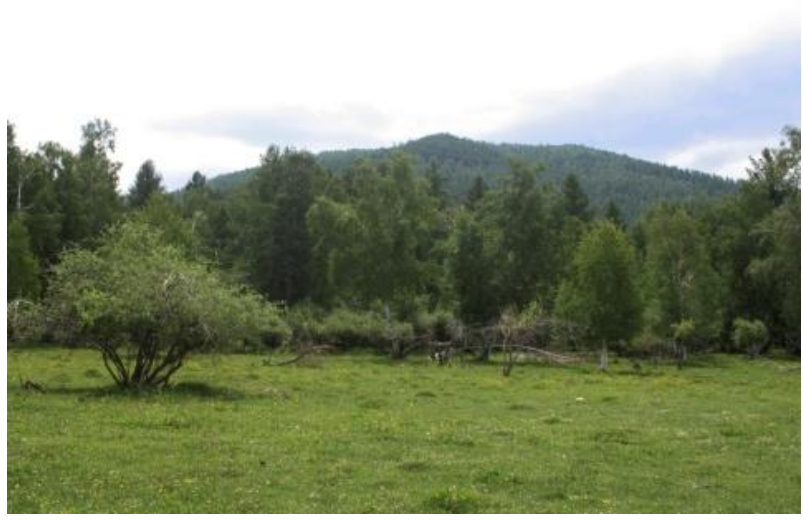

Sugnugur

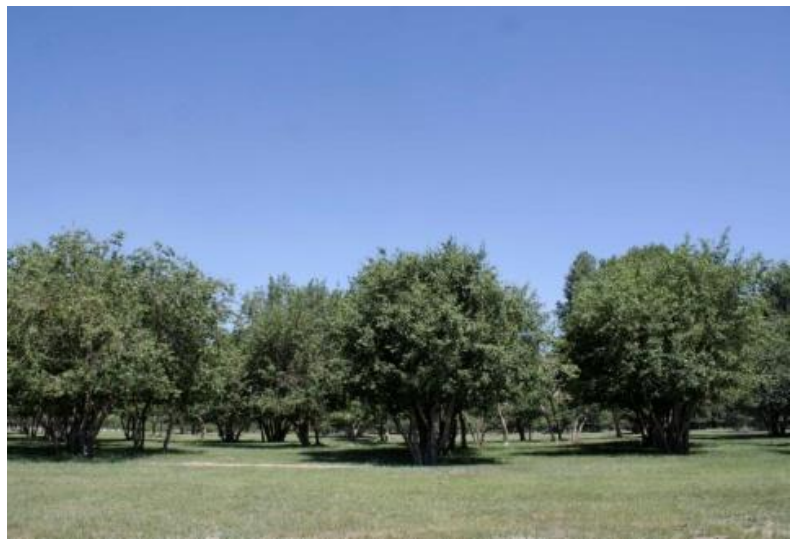

Songino-2

Figure 3. Breeding habitat views of the four breeding colonies 
Habitat of the Sugnugur breeding colony is similar to the habitat of the Khonin Nuga as well as it has high abundance of the gypsy moths. Likewise in Khonin Nuga, gypsy moths are the most important food source in Sugnugur breeding colony (see chapter 2). The habitats of the Songino-1 and Songino-2 breeding colonies have been settled by humans for decades with intensive cattle grazing activities that resulted in more homogenous vegetation and invertebrate fauna.

A large anthropogenic fire broke out in May 2009, and devastated about 70,000 ha in and around the Khonin Nuga valley (Oyunsanaa B, pers. comm.). The magpie's breeding site was burnt on 25 May, at the beginning of the breeding season. All vegetation was affected, but some small pockets were remained intact along the river (Haojin 2011).

\section{THE OUTLINE OF THIS STUDY}

Cooperative breeding system of the azure-winged magpie has been studied in the Iberian and Japanese populations; however, there has been little research elsewhere in Asia and no prior study in the taiga forests of northern Mongolia or southern Siberia which constitute the northern and western edges of their Asian range. The frequency of helping behaviour and its characteristics are expected to be different among populations assuming that the species is found in geographically isolated populations with distinct environmental conditions (Komeda et al. 1987, Valencia et al. 2003, Bayandonoi et al. 2013). Therefore, I conducted the study on distantly located four breeding colonies in northern Mongolia to represent a northern Mongolian population of the azure-winged magpie. For eight years (2007-2014), I studied cooperative breeding system of the azure-winged magpie and its antipredator strategies. This study provides first in-depth knowledge of the lesser-known Asian subspecies, C.c.cyanus, in this region. Although, there is still much to learn about its biology and ecology, the study primarily focused on understanding the underlying mechanisms of the 
cooperative breeding and the adaptive responses and flexibility of the anti-predator strategies of the azure-winged magpies under different ecological conditions, especially the predation risk.

This study aimed at analysing the characteristics of the cooperative breeding system, the relation between helping behaviour and predation risk, and the effects of anti-predator strategies on the breeding ecology of the azure-winged magpie.

Chapter 2 investigates the effect of food availability and nest predation risk on cooperative breeding behaviour. Ecological conditions have been the main focus for the influential hypotheses to explain the evolution of helping behaviour in birds (e.g. Selander 1964; Stacey and Ligon 1991; Koenig et al. 1992; Cockburn 1998; Hatchwell and Komdeur 2000; Covas and Griesser 2007). Although, the main cause of nest failure is the nest predation in a great range of bird species (Martin 1995a, Hanski et al. 1996), implying it's possible substantial evolutionary force for the cooperative breeding, nest predation has not received much attention in this context.

By this chapter, I emphasize the importance of both nest predation and food availability on dynamics of helping behaviour. The hypothesis was tested that both low food availability and high risk of predation on eggs and nestlings lead to increased benefits of helping behaviour, thus increasing the likelihood that non-dispersing individuals show helping behaviour.

Chapter 3 investigates the plasticity of the anti-predator strategies of this species regarding nest predation under varying predation risk in different breeding colonies. Recent studies suggest that breeding birds have a notable ability to assess and respond predation risk (Lima 2009). Birds often employ different anti-predator strategies to reduce predation rates effectively depending on predation risk, habitat and predator types (reviewed in Lima 2009). 
In this chapter, I examined the complexity of different anti-predator strategies and their relative contribution to reduced predation rate in the Mongolian population. The strategies, such as nest concealment, nest site changes, spatial avoidance from the predator species, nest clustering, protective nesting association and recruiting helpers are investigated comprenhensively and also separately to assess the effectiveness and compound effects of multiple strategies. I also investigated the cogntive capacity and adaptive responses of the azure-winged magpies caused by various predation risk.

Chapter 4 addresses effects of the nest distance and nest clustering regarding nest predation risk. Aggregation has likely positive effects on reduced predation, probably as a result of increased vigilance, joint group defense, dilution and confusion effects (reviewed in: Krause and Ruxton 2002; Caro 2005). Therefore, high density in group living birds may reduce the predation rate (Wittenberger and Hunt 1985, Picman et al. 1988). So far, empirical evidence to support the hypothesis that the birds assess and adjust their nest density and spacing of nests in accordance with nest predation risk and type of predators is relatively rare (Lima 2009).

This chapter tests this hypothesis using data on nest distance and nest clustering of the azure-winged magpie. I investigate whether azure-winged magpies decrease the distance between their nests under high predation risk, and after recent predation incidences on earlier nests within and between breeding seasons.

Chapter 5 concludes the main findings and contribution of this study to current knowledge of the cooperative breeding and anti-predator strategies. 


\section{CHAPTER 2}

\section{HELPING BEHAVIOUR AFFECTS NESTLING CONDITION AND NEST PREDATION IN A FACULTATIVE COOPERATIVE BREEDING BIRD, THE AZURE-WINGED MAGPIE}

Gantulga Bayandonoi, Matthias Waltert, Peter M. Kappeler, Eckhard W. Heymann, Denis Kupsch, Gombobaatar Sundev, Michael Mühlenberg

Submitted to the Journal of Avian Biology on 10.03.2016 


\section{ABSTRACT}

Previous studies have identified resource availability and predictability as factors favouring cooperative breeding in birds, but little is known about the role of nest predation in maintaining helping behaviour. We studied four different breeding colonies of a facultative cooperative breeder, the azure-winged magpie (C. cyanus) in northern Mongolia to assess the effects of nest predation on helping behaviour. We compared feeding rates of breeding birds and helpers from different breeding colonies in three sites as well as between helped and unhelped nests based on data from $404 \mathrm{~h}$ of nest observations in 2014. At one site, food supply was almost 6.4 times higher, and both feeding rates and nestling body mass were considerably higher than at the two other breeding sites. Under these favourable conditions, feeding rates at the nest and nestling body mass at day 9 post-hatching were unrelated to the presence of helpers. In contrast, at the two other sites, feeding rates were 1.5 - 3.8 times higher and nestlings were 16.5 - 22\% heavier in helped nests compared to unhelped nests. Per capita provisioning rates were consistently higher in nests with helpers at all sites. Food provisioning by helpers did not differ between the breeding colonies even though food supply differed considerably across sites. Importantly, the chick-rearing stage was significantly shorter and nest predation was $32 \%$ lower in nests with helpers compared to those of nests without. The mean number of helpers per nest was highest in high predation risk site and small in low predation risk site, whereas, percentage of helpers in colonies and provisioning rate from helpers remained constant. Our study suggests that the helpers' contribution does not only result in improved nestling body condition, but also improves nest defense. The contribution of helpers to nest defense should therefore receive more attention because it is likely to be one of the selective factors promoting cooperative breeding in birds.

Key words: azure-winged magpie, helping, cooperative breeding, provisioning, food availability, predation, nest defense 


\section{INTRODUCTION}

Cooperative breeding is a phenomenon characterized by allo-parental care that individuals other than parents, commonly referred to as helpers, and multiple co-breeders with shared nest show parent-like behaviour toward non-descendant young (Brown 1987, Haydock et al. 2001). The evolution of cooperative breeding in birds has proven to be difficult to explain by any single hypothesis or obvious ecological correlates alone (Arnold and Owens 1998, Koenig and Dickinson 2016). Although cooperative breeding in birds has received much attention from the perspective of kin selection (Hamilton 1964), ecological constraints (Emlen 1982), broad constraints (Hatchwell and Komdeur 2000), the benefits of philopatry (Stacey and Ligon 1991), life-history (Arnold and Owens 1998, 1999), adaptive delayed dispersal (Covas and Griesser 2007), group augmentation (Kokko et al. 2001, Kingma et al. 2014) and temporal variability hypotheses (Rubenstein and Lovette 2007, Jetz and Rubenstein 2011), it is still unclear which factors promote the evolution of cooperative breeding and which contribute to its maintenance (Gonzalez et al. 2013). Much research has focused on ecological conditions that may affect helping behaviour in birds (e.g. Selander 1964; Stacey and Ligon 1991; Koenig et al. 1992; Cockburn 1998; Hatchwell and Komdeur 2000; Covas and Griesser 2007). Despite the fact that predation is the main cause of nest failure in many bird species (Martin 1995a, Hanski et al. 1996), indicating its possible evolutionary importance for group living and cooperative breeding, it did not receive much attention in previous studies. The effect of helpers on nest predation has been studied intensively showing that helpers have a positive effect on reproductive success (e.g. Brown 1987, Emlen and Wrege 1991, Innes and Johnston 1996, Hatchwell 2004, Lloyd et al. 2009), but only a few studies have addressed the role of nest predation as a selective factor in modulating helping behaviour (Ford et al. 1988, Du Plessis et al. 1995, Poiani and Pagel 1997). Since predation risk also plays an important role in social complexity (Groenewoud et al. 2016), it may affect the frequency and characteristics of helping behaviour. 
Delayed dispersal of young birds and the individual decision to help are the two vital steps towards cooperative breeding (Koenig and Dickinson 2016). Some authors have considered predation risk faced by young birds as an ecological constraint limiting their dispersal (Emlen 1982; Koenig et al. 1992; Kokko \& Ekman 2002). If dispersal is costly and breeding in the natal territory is not an option, young birds may be 'forced' to stay in their natal territory (Emlen 1982). It remains unclear what exactly triggers the final decision of birds to help when ecological and social conditions favour helping behaviour. Cooperative breeding is not homogeneous under varying environmental conditions (Koenig and Stacey 1990). For example, Baglione et al. (2002a) found that cooperative breeding of carrion crows (Corvus corone) varied both across and within populations, reflecting variation in environmental conditions. Therefore, studies on different populations of the same cooperatively breeding species may therefore reveal underlying factors that trigger the expression and affect the frequency of cooperative breeding.

The azure-winged magpie (Cyanopica cyanus) has a large geographical distribution, ranging from Western Europe to Eastern Asia (Goodwin 1986). Because the species is found in geographically isolated populations with distinct environmental conditions, the frequency of cooperative behaviour is expected to differ among populations (Komeda et al. 1987, Valencia et al. 2003, Bayandonoi et al. 2013). Also, the cooperative breeding behaviour of the azure-winged magpie is known to be flexible (Valencia et al. 2003).

Here, we investigate the effect of food availability and nest predation risk on cooperative breeding behaviour in a northern Mongolian population of the azure-winged magpie. Valencia et al. (2003) have shown that high temperature and low food availability (indirectly measured by rainfall) were associated with high frequencies of helpers. We hypothesize that not only low food availability but also high risk of predation on eggs and nestlings lead to increased benefits of helping behaviour, and thus increase the likelihood that non-dispersing individuals will help. 
If increasing the food supply to nestlings is the primary driver of helping behaviour, we expect that individuals will more likely to help when food availability is low regardless of predation risk. If reducing the nest predation risk is the primary driver of helping behaviour, we expect that the number of helpers will also be large when nest predation risk is high, regardless of food availability. Because increased group size is often associated with decreased predation risk (Krause and Ruxton 2002, Canestrari et al. 2008a, see also Kingma et al. 2014), the recruitment of more helpers should be favoured under high risk of predation. Previous work also suggested that helpers' feeding effort may respond to food availability (e.g. Valencia et al. 2006b, Canestrari et al. 2008b) and nest predation risk in cooperative breeding vertebrates (e.g. Heg and Taborsky 2010). Under conditions of high resource availability, helpers increase the feeding effort to nestlings (Eden 1987, Boland et al. 1997, Clutton-Brock et al. 2002). In carrion crow, both helpers and parents reduced the feeding effort under food supplementation only during the breeding season (Canestrari et al. 2007), whereas, helpers increased, but breeders maintained similar feeding effort under year-round food supplementation (Canestrari et al. 2008a). Canestrari et al. (2008b) concluded that individual responses to resource availability are likely to vary depending on their status (breeder or helper) due to the necessity of their self-maintenance in regard to survival and reproduction. We predict that provisioning rates are higher at sites with higher food availability because both the costs of achieving self-maintenance of breeders and helpers as well as food provisioning to nestlings are expected to be low (Weimerskirch et al. 2001, Velando and Alonso-Alvarez 2003). According to the model by Carranza et al. (2008), breeding birds should not reduce but instead respond with additional provisioning if expectations for future success of offspring increase because of the helpers' presence by means of reduced predation (Hatchwell 1999, Koenig and Dickinson 2004) and increased offspring quality (Hatchwell 2004, Valencia et al. 2006b). Therefore, we would expect that breeders of the azure-winged magpie should increase their feeding effort when assisted by 
helpers under conditions of high predation risk, but under the condition that feeding visits have a negligible effect on nest predation where probability of attracting predators due to increased visits at the nest should well be compensated by successful nest defense.

\section{METHODS}

\section{Study area and breeding colonies}

We define a breeding colony as a year-round cohesive group consisting of multiple breeding pairs and non-breeders co-residing within a single breeding territory during the breeding season. All members of the breeding colony participate in territory defense and use the area around the nests equally, while pairs do not have their own defined small territories within a colony except the single tree their nests are located in. The breeding season of the azure-winged magpie in northern Mongolia starts mid-May and ends around mid-July. In northern Mongolia, azure-winged magpies are only found along river basins. Due to their specific habitat requirements, breeding colonies are often relatively isolated from each other. Our studied sites of breeding colonies were 63-143 km apart from one another. We studied one breeding colony $(\mathrm{KhN})$ in Khonin Nuga valley between May and July from 2007 until 2014. During the 2013 and 2014 breeding seasons, three other distantly located breeding colonies, namely Songino-1, Songino-2 (here after together Songino breeding colonies, SON, referred as one breeding site) and Sugnugur (SUG) along the Yuruu, Sugnugur and Tuul river basins in West Khentii Mountains in northern Mongolia were incorporated into our study. These four breeding colonies are year-round residents at their respective sites and consist of $26.3 \pm 12.9$ (range 14 - 54) individuals on average during the last two breeding seasons of the study. Breeding colonies were composed of $77 \%$ breeding birds on average, $22 \%$ helpers (few are former breeding birds) and the rest being non-breeders in 2014.

The climate in northern Mongolia is continental with hot summers and cold, severe winters. Mean annual temperature of this region is $0.7^{\circ} \mathrm{C}$, with the coldest month being 
January, reaching $-51{ }^{\circ} \mathrm{C}$, and the hottest being July, with a maximum temperature of $36.4^{0} \mathrm{C}$ (von Velsen-Zerweck 2002). Snow covers the ground from early October to mid-April. Generally, habitats of the breeding colonies are similar to each other and include open river flats, riparian woodland and scrubland. The habitats of the Khonin Nuga and Sugnugur breeding colonies are dominated by Siberian larch (Larix sibirica) and Japanese white birch (Betula platyphylla), with the main shrubs being bird cherries (Padus asiatica), willows (Salix), Siberian hawthorn (Crataegus sanguinea). The vegetation around the Songino-1 and Songino-2 breeding colonies is dominated by laurel-leaf poplar (Populus laurifolia), with the main shrubs being Siberian crabapple (Malus baccata), bird cherries and willows, as it is affected by intense cattle grazing and human presence. The azure-winged magpies nest mostly on Siberian crabapple in Songino breeding colonies and on bird cherries in Khonin Nuga and Sugnugur. Both of these trees are round shaped with dense foliage, which provides excellent concealment.

\section{Data collection}

We trapped birds at the onset and midpoint of the chick rearing stages of the breeding season in Khonin Nuga between 2007 and 2014, and in the remaining three breeding colonies in 2013 (91.6\% of all individuals in four breeding colonies) and 2014 (immigrants and most of the remaining unbanded birds) using mist nets, especially designed for thrushes and middle-sized birds. Birds were ringed with unique combinations of one numbered metal and one or several coloured plastic rings. The ringing process did not result in any nest abandonments or any detectable behavioural changes in newly ringed birds during nest observations. We conducted $498 \mathrm{~h}$ of nest observations in all four breeding colonies in the 2014 breeding season during late incubation ( $94 \mathrm{~h}$ of nest observations for the individual identification and observer training purposes) and chick-rearing (404 h) stages until the fledglings left their nests. We recorded bird identity, activity, number of feeding visits, time, 
duration of stay at the nest, potential predator occurrence and the response towards predators. In total, we observed 16 helped nests with 24 helpers and 14 unhelped nests in 2014. Due to late start of the nest observations at nests, we could not detect helpers' presence at most of the nests preyed during egg-laying and early incubation stages. However, according to the preliminary nest observation during late incubation stage, $71 \%$ (17 individuals) of the helpers were already assisting breeding birds during incubation stage from all breeding colonies in 2014. The rest of the helpers that were first recorded during chick rearing stage might also have started assisting during incubation stage. We conducted nest observations from concealed locations in 15-30 m distance from the nest during the morning (07:00-10:00 $\mathrm{h}$ ), midday (11:00-14:00 h), and late afternoon (16:00-19:00 h). Each observation lasted for $2 \mathrm{~h}$, unless it had to be curtailed due to adverse weather or other unforeseen circumstances. We did not record data 'blind' because our study involved targeted bird nests in the field. However, nests were randomly chosen for observation, following a design aimed at equal observation times at each nest across late incubation and chick-rearing stages as well as time of day. To minimize inter-observer biases, five observers were rotated among breeding colonies every five days. Our nest observation design also meant that the distribution of nests observed was even among observers within and across all breeding colonies to ensure the same amount of involvement from each observer at each nest. Period of day and observer ID had no effect on nest observation data (total feeding rate tested by Kruskal-Wallis test, time difference within day: $\mathrm{H}_{2,202}=1.22, P=0.54$; difference between observers: in $\mathrm{KhN}: \mathrm{H}_{4,62}=1.70, P=0.43$; in SON: $\mathrm{H}_{4,70}=0.003, P=1.00$; in SUG: $\left.\mathrm{H}_{4,70}=3.95, P=0.41\right)$.

We determined the sex of ringed birds based on sex-specific behaviour, such as exclusive female incubation and brooding (Hosono 1966b, Goodwin 1986, Komeda et al. 1987) or the presence of a brood patch. Nests were categorized as helped or unhelped based on at least $6 \mathrm{~h}$ observation at the nest. In most cases, helpers were easily distinguished from breeding males by known history from ringing, since most helpers were offspring of at least 
one of the breeding birds or redirected helpers whose first breeding attempt had failed. In two cases in which it was unclear which bird was the breeding male and which was the helper, we considered the bird that recorded at the nest earlier in the breeding season and visited the nest more regularly to be the breeding male, and the bird that visited the nest rarely to be the helper according to the classification approach of Valencia et al. (2006a).

Nestlings in all nests with and without helpers were weighed in each breeding colony at day 9 post-hatching to determine the helpers' contribution to nestling body condition in 2014. According to results obtained from Khonin Nuga in 2011, body mass differences between nestlings from helped and unhelped nests were highest at day 9 post-hatching. Thus, day 9 post-hatching was chosen because it is likely the best day to reveal body mass differences clearly. After day 9, the body mass of nestlings from helped and unhelped nests converged gradually, but nestlings from unhelped nests still had slightly lower body mass at day 15 post-hatching, the end of the chick-rearing stage (Gantulga Bayandonoi, unpubl. data). The duration of the chick rearing stage refers to the days between the first hatching day and the day that last fledgling left the nest for each nest, not including those days that fledglings stayed around the nest following their departure. We considered nests as successful when at least one fledgling left the nest.

Based on foraging observations around the nest during nest observation and the analyses of food extracted from the crop of 12 breeding birds that were caught for ringing purposes, we found that the larvae of the gypsy moth (Lymantria dispar) was the main food source during the chick rearing stage in Khonin Nuga and Sugnugur breeding colonies in 2014, as well as during previous years in Khonin Nuga (see Bayandonoi et al. 2013). Thus, we counted larvae of moths and butterflies (mostly gypsy moth) from randomly chosen 20 bushes of the dominant species, such as bird cherries and Siberian hawthorn, which were all around 2-3 $\mathrm{m}$ high and 2-3 $\mathrm{m}$ wide, within breeding territories during the middle of the chickrearing stage (around second half of June) in Khonin Nuga and Sugnugur to determine food 
availability. To increase the detection of larvae, two researchers simultaneously started counting larvae within the visual field from the opposite side of each bush by completely circling the bush two times. The highest count of four counts obtained by two researchers was regarded as an actual count.

We obtained temperature and precipitation data between 01 May and 31 July 2014, the entire breeding season, from the weather stations of the National Meteorological Telecommunication Center of Mongolia nearest to the breeding sites (5 - $37 \mathrm{~km}$ away). Mean temperature ranged from 13.8 to $14^{\circ} \mathrm{C}$ and the total rainfall ranged from 147.2 to $202.8 \mathrm{~mm}$ during the breeding season at the three study sites. The temperature and the rainfall data did not differ significantly between sites (Kruskal-Wallis $U$-test, daily temperature: $\mathrm{H}_{2,276}=$ $0.008, P=0.99$; weekly precipitation: $\left.\mathrm{H}_{2,39}=0.88, P=0.64\right)$. We therefore excluded weather data from subsequent analyses.

All food provisioning resulted in actual feeding, except in a few cases in the Sugnugur breeding colony where nestlings' lack of begging resulted in swallowing the food themselves both by the breeding birds and helpers. We excluded those unsuccessful provisioning attempts from our analyses. Feeding rate refers to food delivery (provisioning) to the nest per hour, resulting in actual feeding of nestlings.

\section{Nest predators}

Since 2007, a pair of carrion crows bred close (average distance from the crow nest to each azure-winged magpie nest during eight breeding season: $461 \pm 68 \mathrm{~m}$ ) to the Khonin Nuga breeding colony every year. Three pairs of carrion crows bred nearby the Songino breeding colonies in the 2014 breeding season (distance from the nearest crow nest to each azurewinged magpie nest: $203 \pm 75 \mathrm{~m}$ ). In addition, we regularly observed two resident nonbreeding common magpies (Pica pica) near an azure-winged magpie's breeding site in Songino. The pair of crow was responsible for $91 \%$ (185 out of 203 predator intrusion) of the 
azure-winged magpie responses against predators during five breeding seasons in Khonin Nuga and those of corvids in Songino were responsible for $87 \%$ (26 out of 30 predator intrusion) of intrusion in 2014. We suspect that these carrion crows and common magpies specialized in preying upon azure-winged magpie nests because observers witnessed the crows and common magpies raiding azure-winged magpie nests on five occasions in some of which they were seeing as carrying eggs in their beak and killing all nestlings at the nest only to return next day to collect bodies after nest abandonment by host birds. Some of the nests in which eggs or nestlings disappeared showed signs of predation from carrion crows, such as down feather and fresh faeces of crow around the nest. Other avian predators were rarely observed within azure-winged magpie's breeding territories in both Khonin Nuga and Songino, probably due to the highly aggressive territorial defense activities of the neighbouring resident carrion crows. These resident individuals themselves were the main nest predators of breeding colonies in the Khonin Nuga and Songino.

Unlike in the other three breeding colonies, the Sugnugur breeding colony had no resident predators that bred or stayed regularly close to the breeding site, though other avian predators including carrion crows were common in the area. In Sugnugur, 64\% (9 out of 14 predator intrusion) of the azure-winged magpie responses against predators were towards carrion crows, the rest attributed to raptors. We considered predation risk at each breeding site based on the number of resident predators around breeding territories and the predator occurrence, e.g. number of approaching predators per hour during nest observations (Songino: 0.22 per hour, Khonin Nuga: 0.18 per hour and Sugnugur: 0.10 per hour), as high in Songino, intermediate in Khonin Nuga and low predation risk in Sugnugur for the 2014 breeding season (Gantulga Bayandonoi, unpubl. data). We used actual nest predation for the analyses to see whether presence of helpers affects nest predation. We considered nests as preyed in cases where: 1) entire clutches or broods disappeared on one day, 2) clues of predators or 
remains of nestlings were found at or nearby the nest, or 3) when we witness nest predation directly.

\section{Data analyses}

We combined data from Songino-1 and Songino-2 breeding colonies because of their similarities being essentially in the same habitat that two colonies were located close to each other (nearest nest distance of two colonies was $320 \mathrm{~m}$ apart), timing of breeding and same set of predator individuals. In addition, we observed that three individuals from the Songino-2 breeding colony joined the Songino-1 breeding colony in 2014.

Generalized Linear Mixed Models (GLMMs) were used to analyse data on feeding rate and nestling body mass. We used the glmer function of the R-package 'Ime4' (Bates et al. 2015) with Poisson distribution (link function: $\log$ ) in R (R Core Development Team 2016) for the analyses on feeding rate. We considered nestling age (NA), breeding colony (BC), brood size (B), helpers at the nest $(\mathrm{H})$ as predictor variables for the response variables Total, Male, Female and Helper feeding rates. NA, BC, B and relative feeding rate at day 9 posthatching (RF) were used as predictor variables for nestling body mass using lmer function from the 'Ime4' package since response variable was normally distributed. The nest ID was included in the models as a random factor nested within breeding colony to control for nonindependence of the repeated feeding observations at the same nests for the analyses on feeding rate and non-independent measurements of the body mass of the nestlings from the same nest for the analyses on body mass. Relative feeding rates were calculated by averaging daily feeding rates at each nest, which is associated with corresponding days (1-2 days difference between nests) due to unequal numbers of observations on the respective nestling day at each nest. After that, we ran a regression analysis to describe the relationship between feeding rate and nestling age using data until day 9 post-hatching, the day at which nestling body mass was measured. The regression coefficient was then used to adjust the relative 
feeding rate for each nest at day 9 post-hatching. Nests that failed before completion of minimum $6 \mathrm{~h}$ nest observation to determine helper's presence were excluded from the analyses.

We used Akaike Information Criterion with a correction for finite sample sizes $\left(\mathrm{AIC}_{\mathrm{c}}\right)$ to rank our models from GLMMs analyses, because usage of $\mathrm{AIC}_{\mathrm{c}}$ over $\mathrm{AIC}$ is recommended for small sample sizes, where the relation between the feeding data and fitted parameters $(\mathrm{n} / \mathrm{k})$ is less than 40 (Sugiura 1978, Hurvich and Tsai 1989). We did multi-model inference in the full set of models using MuMIn-package in R, considering that best approximating models cannot explain the results solely in our analyses because of Akaike weight $\left(\Delta_{i}\right)$ lower than 0.9 (Burnham and Anderson 2002, Lukacs et al. 2010, Symonds and Moussalli 2011). We obtained p-values for our analyses using lmerTest-package (Kuznetsova et al. 2016) in R. In order to investigate the differences between helped and unhelped nests, we averaged the feeding rate data of the nestlings by each day and used a Wilcoxon matched-pair test to eliminate the bias that could arise from the increasing provisioning rate with nestling age. Because some of the unhelped nests failed during early chick-rearing stage, a considerable amount of data was collected from the early period of the chick-rearing stage in nests without helpers and less so from the late chick-rearing stage. Thus, data were unevenly distributed throughout the nestling stage between nests with and without helpers. Due to the small number of nests in each breeding colony, we were unable to differentiate between nests with and without helpers with regard to clutch and brood sizes. However, analyses on the pooled data of the breeding colonies did not reveal any statistical difference in clutch and brood sizes between nests with and without helpers (Mann-Whitney $U$-test, Clutch size: $U=189.5, n_{1}=$ 23, $n_{2}=17, P<0.87$; Brood size: $\left.U=62, n_{1}=16, n_{2}=9, P<0.60\right)$. Since variation in brood size (1-7 nestlings in each nest) was masking the exact contribution of the helpers and breeding birds to each nestling, we analysed the feeding rate not only at per nest but per nestling to reveal the importance of the helpers' contribution to nestlings. We tested variables 
for normality and used parametric tests whenever possible. Nonparametric tests were used for non-normal variables. For all analyses, significance levels were set at 5\% and means are reported \pm 1 SD unless otherwise stated.

\section{RESULTS}

\section{Food availability}

We found that larvae of the gypsy moth were the main food source in both Sugnugur and Khonin Nuga during the chick-rearing stage of the 2014 breeding season based on the crop analyses from the breeding birds that larvae of gypsy moth account to $89 \%$ of biomass in food composition in Khonin Nuga (food items from three individuals) and 94\% in Sugnugur (food items from four individuals) breeding colonies. In the Sugnugur breeding colony, we counted almost 6.4 times as many gypsy moth larvae as we did in the Khonin Nuga breeding site (SUG: $120 \pm 20 ; \mathrm{KhN}: 18.8 \pm 2.3$; Mann-Whitney $U$-test: $U=244, n_{1}=20, n_{2}=20, P<$ 0.001). However, the Khonin Nuga breeding site had the highest numbers of gypsy moth larvae in 2014 when compared with the last seven years (2007-2013, on average 7.1 gypsy moth larvae per tree). In contrast, composition of the food source was different in the Songino breeding site where beetles (Coleoptera) and other insects were the main food source (confirmed by observations on foraging activities and food extracted from the crop of five individuals during ringing process that $86 \%$ of biomass belonged to the Coleoptera) whereas the gypsy moths were scarce.

\section{Feeding rate}

The total feeding rate at the nest increased with nestling age and brood size, was higher in nests with helpers and differed slightly among breeding colonies (Tables 1, 2). 
Table 1 Results of the best-ranked models of the feeding rates of the Total, Males, Females and Helpers in three breeding colonies within $\Delta i<2$ range. Full average refers to multi-model inference of the full set of models. $k$ number of parameters, $\Delta i$ difference between the $\mathrm{AIC}_{\mathrm{c}}$ value of the best model and the $\mathrm{AIC}_{\mathrm{c}}$ of the $i$ model, $\mathrm{w}_{i}$ Akaike weight of the $i$ model, acc $\mathrm{w}_{i}$ cumulative Akaike weight, ER evidence ratio

\begin{tabular}{lllllllllllll}
\hline Rank & Best models & $\mathrm{H}$ & $\mathrm{BC}$ & $\mathrm{NA}$ & $\mathrm{B}$ & $\mathrm{k}$ & $\operatorname{logLik}$ & $\mathrm{AICc}$ & $\Delta i$ & $\mathrm{w}_{i}$ & $\mathrm{acc}_{i}$ & $\mathrm{ER}$ \\
\hline Total $^{\mathrm{a}}$ & Full average & 0.376 & 0.261 & 0.055 & 0.069 & 6 & & & & & & \\
1 & H+NA+BC+B & 0.379 & 0.266 & 0.055 & 0.079 & 5 & -493.30 & 999.0 & 0 & 0.85 & 0.85 & \\
Males $^{\mathrm{a}}$ & Full average & -0.026 & 0.248 & 0.067 & 0.032 & 6 & & & & & & \\
1 & NA+BC+B & & 0.275 & 0.066 & 0.061 & 5 & -402.91 & 816.1 & 0 & 0.33 & 0.33 & \\
2 & NA+BC & & 0.245 & & 0.067 & 4 & -404.04 & 816.3 & 0.16 & 0.31 & 0.64 & 1.09 \\
3 & H+NA+BC+B & 0.098 & 0.264 & 0.065 & 0.066 & 6 & -402.66 & 817.8 & 1.64 & 0.15 & 0.78 & 2.27 \\
4 & H+NA+BC & 0.083 & 0.234 & 0.067 & & 5 & -403.88 & 818.1 & 1.95 & 0.13 & 0.91 & 2.66 \\
Females & Full average & 0.098 & -0.248 & 0.045 & 0.031 & 6 & & & & & & \\
1 & NA+BC & & 0.272 & 0.046 & & 4 & -367.18 & 742.6 & 0 & 0.26 & 0.26 & \\
2 & NA+BC+B & & 0.307 & 0.044 & 0.065 & 5 & -366.35 & 743.0 & 0.43 & 0.21 & 0.47 & 1.24 \\
3 & H+NA+BC+B & 0.239 & 0.283 & 0.043 & 0.078 & 6 & -365.35 & 743.1 & 0.56 & 0.20 & 0.67 & 1.32 \\
4 & H+NA+BC & 0.190 & 0.248 & 0.045 & & 5 & -366.57 & 743.4 & 0.88 & 0.17 & 0.84 & 1.55 \\
3 & Full average & & 0.046 & 0.044 & 0.021 & 5 & & & & & & \\
1 & NA & & & 0.052 & & 3 & -249.48 & 505.1 & 0 & 0.42 & 0.42 & \\
\hline & NA+BC & & 0.545 & 0.051 & & 4 & -248.91 & 506.0 & 0.94 & 0.26 & 0.68 & 1.60 \\
\hline
\end{tabular}

NA - nestling age by day, $\mathrm{H}$ - Helped vs unhelped nests, BC - breeding colony, B - brood size

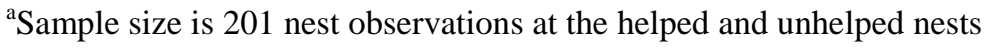

${ }^{\mathrm{b}}$ Sample size is 137 nest observations at the helped nests

Moreover, the total feeding rate at the nest was much higher in Sugnugur than in the other

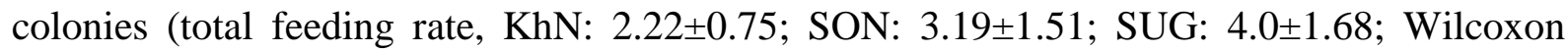
matched-pair test, SUG vs. KhN: $T=3, P=0.001, n=15$; SUG vs. SON: $T=16, P=0.026, n$ $=16$, Fig. 1a). The total feeding rate at the nests with helpers was 1.46 and 3.84 times higher than at nests without helpers in both Khonin Nuga and Songino, respectively (daily feeding 
rate at the nest: Wilcoxon matched-pair test, KhN: $T=6.5, P=0.032, n=10$; SON: $T=0, P=$ $0.012, n=8)$. In contrast, there was no such difference in the Sugnugur breeding colony (Wilcoxon matched-pair test, $T=33, P=0.637, n=12$ ).

Table 2 Result of the All-Subset average estimates of the models within 95\% confidence set for the parameters of GLMM analyses for the feeding rates of the Total, Males, Females and Helpers. Tested by Wald test

\begin{tabular}{|c|c|c|c|c|c|c|c|c|}
\hline & \multicolumn{2}{|c|}{ Total feeding } & \multicolumn{2}{|c|}{ Males' feeding } & \multicolumn{2}{|c|}{ Females' feeding } & \multicolumn{2}{|c|}{ Helpers' feeding } \\
\hline & $n=201$ & & $\mathrm{n}=201$ & & $n=201$ & & $\mathrm{n}=137$ & \\
\hline & $\mathrm{z}$ value & $\operatorname{Pr}(>|z|)$ & $\mathrm{z}$ value & $\operatorname{Pr}(>|z|)$ & $\mathrm{z}$ value & $\operatorname{Pr}(>|z|)$ & $\mathrm{z}$ value & $\operatorname{Pr}(>|z|)$ \\
\hline (Intercept) & 0.529 & 0.597 & 0.619 & 0.536 & 1.007 & 0.314 & 0.670 & 0.5029 \\
\hline Helpers' presence & 3.561 & $0.0004 * * *$ & 0.293 & 0.7693 & 0.616 & 0.5382 & - & - \\
\hline Nestling age & 7.070 & $\mathbf{0 . 0 0 0 0} * * *$ & 6.100 & $0.0000 * * *$ & 3.334 & $0.0009 * * *$ & 1.958 & 0.0502 . \\
\hline Brood size & 1.775 & 0.0759 . & 0.747 & 0.4548 & 0.641 & 0.5218 & 0.246 & 0.8056 \\
\hline Breeding colony & 3.703 & $0.0002 * * *$ & 2.446 & $0.0145 *$ & 1.800 & 0.0719 & 0.231 & 0.8169 \\
\hline
\end{tabular}

However, when comparing the per capita feeding rate (feeding rate at the nest/brood size), nestlings from helped nests enjoyed a higher rate of food delivery compared to nestlings from unhelped nests in all three breeding colonies (per capita feeding rate, tested by day posthatching: Wilcoxon matched-pair test, $\mathrm{KhN}: T=8, P=0.026, n=10$; SON: $T=4, P=0.049$, $n=8$; SUG: $T=2, P=0.002, n=12$; Fig. $4 \mathrm{~b})$. Results from the GLMM analyses showed that the helpers indeed increased the amount of food delivery to each nestling in all breeding colonies, even though breeding birds from Sugnugur slightly compensated their food delivery to helped nests (Fig. 4b, Table 2).

There was no difference in the provisioning rate of helpers between breeding colonies (Mann-Whitney $U$-test, KhN vs. SON: $U=674, n_{1}=60, n_{2}=25, P<0.469$; KhN vs. SUG: $U$ $=534, n_{1}=52, n_{2}=25, P<0.21$; SUG vs. SON: $\left.U=1476, n_{1}=60, n_{2}=52, P<0.627\right)$, as well as brood size (Fig. 4a, Table 2). Helpers feeding rate increased slightly with nestling age, 
but not significantly so (Table 2). The overall average feeding rate of per helper, i.e the average feeding rate of all helpers in a breeding colony divided by number of helpers, were being lowest that is 0.05 (times/per hour) in Songino, 0.09 in Sugnugur and 1.26 in Khonin Nuga.
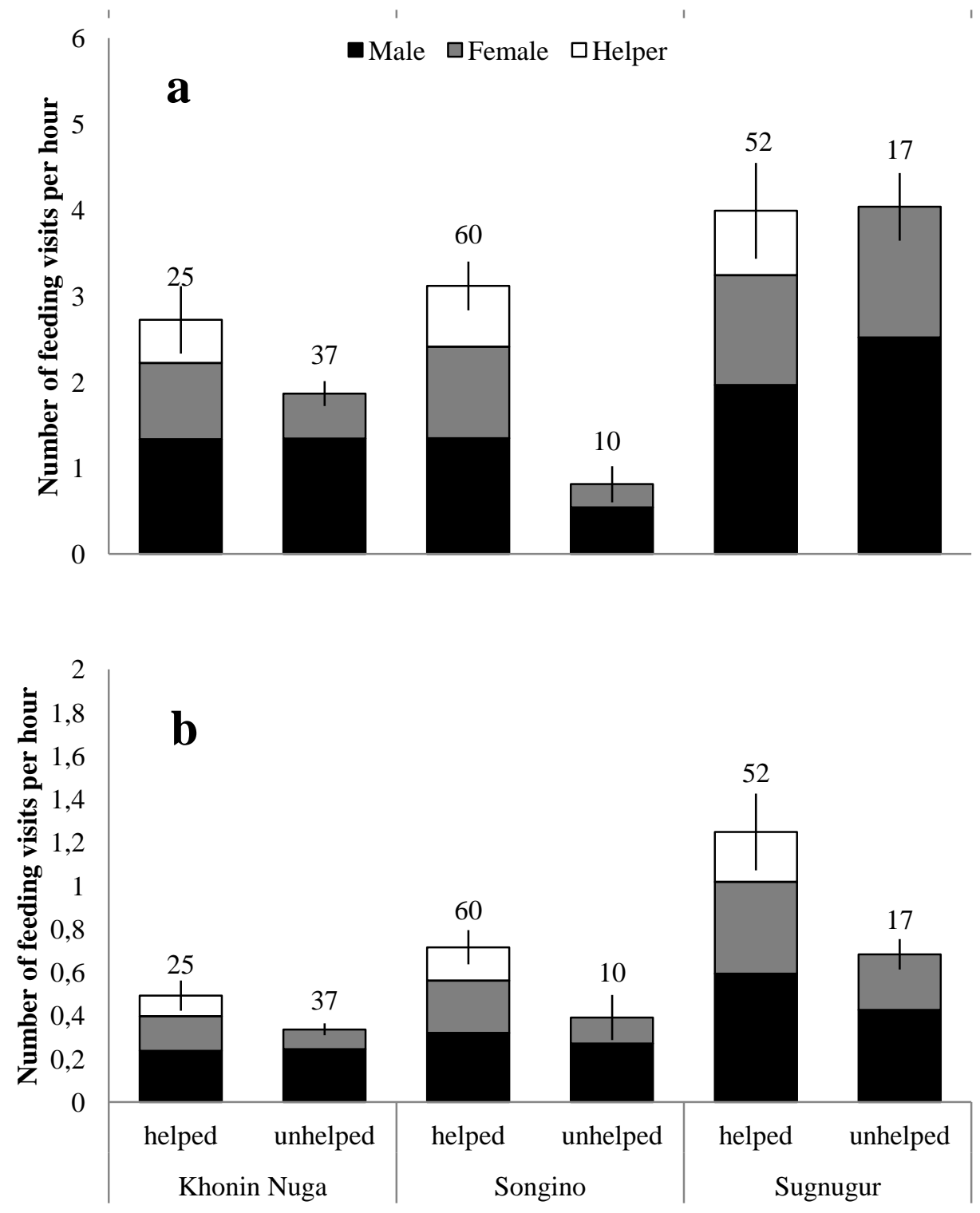

Figure 4 Feeding rate (Mean \pm SE) for per nest (a) and per capita feeding rate (for each nestling, b) of breeding males (black), breeding females (grey) and helpers (white) in helped and unhelped nests in three breeding colonies during the 2014 breeding season. SE refers to total feeding rate. Number of observations $(n)$ are shown above the bars 
In the Songino breeding colonies, breeding birds' feeding rate at the nest from the nests with helpers was higher than in nests without helpers (males: $F_{1,68}=6.64, P=0.012$; females: $F_{1,68}$ $=5.64, P=0.020$; Fig. 4a). There was no difference in feeding rates between breeding birds from helped and unhelped nests in the Khonin Nuga breeding colony (males: $F_{1,60}=0.009, P$ $=0.924$; females: $F_{1,60}=2.68, P=0.107$; Fig. $4 \mathrm{a}$ ). In contrast, breeding males and females slightly, but non-significantly, reduced their feeding rate at the nest in helped nests compared to unhelped nests in Sugnugur (males: $F_{1,67}=3.37, P=0.071$; females: $F_{1,67}=2.98, P=$ 0.089; Fig. 4a).

\section{Nestling body mass}

Mean nestling body mass was significantly different among breeding colonies (Kruskal-Wallis test $\mathrm{H}_{2,102}=12.1, P=0.002$ ).

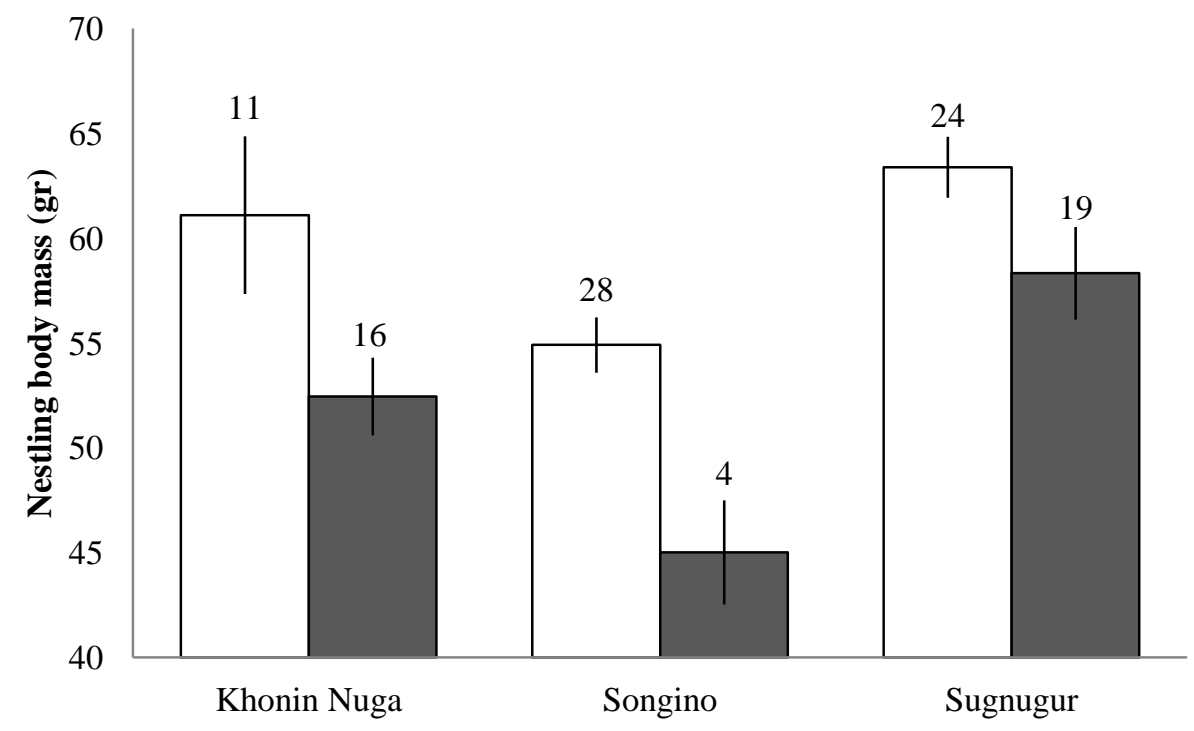

Figure 5 Body mass of the nestlings (Mean \pm SE) at the day 9 post-hatching in helped (white) and unhelped (grey) nests in three breeding colonies, 2014. Number of nestlings (n) are shown above the bars

In particular, nestlings from the Sugnugur breeding colony were heavier than those from the other two breeding colonies (Mann-Whitney $U$-test, SUG vs. KhN: $U=413, n_{1}=43, n_{2}=27$, 
$P<0.043$; SUG vs. SON: $U=362, n_{1}=43, n_{2}=32, P<0.004$; SON vs. KhN: $U=382, n_{1}=$ $32, n_{2}=27, P<0.45$; Fig. 5, Table 4). Body mass of the nestlings in helped nests was higher than for nestlings from unhelped nests at day 9 post-hatching in all three breeding colonies (Mann-Whitney $U$-test, SUG: $9 \%$ heavier, $U=150, n_{1}=24, n_{2}=19$, p < 0.057; SON: $16.5 \%$ heavier, $U=12, n_{1}=28, n_{2}=4, \mathrm{p}<0.009 ; \mathrm{KhN}$ : $22 \%$ heavier, $U=32, n_{1}=17, n_{2}=10, \mathrm{p}<$ 0.007; Fig. 5).

According to GLMMs analyses, both relative feeding rate and whether a nest was helped versus unhelped were associated with nestling body mass: nestlings in helped nests received more food and had higher body mass. Nestling body mass was unaffected by breeding group and brood size (Tables 3, 4).

Table 3 Results of the best-ranked models of the nestling body mass within $\Delta i<2$ range and full average of the full set of models. $k$ number of parameters , $\Delta i$ difference between the $\mathrm{AIC}_{\mathrm{c}}$ value of the best model and the $\mathrm{AIC}_{\mathrm{c}}$ of the $i$ model, $\mathrm{w}_{i}$ Akaike weight indicating the relative support for each of the $i$ model, acc $\mathrm{w}_{i}$ cumulative Akaike weight, ER evidence ratio. Sample size is 103 nestlings.

\begin{tabular}{|c|c|c|c|c|c|c|c|c|c|c|c|c|}
\hline Rank & Best models & $\mathrm{H}$ & $\mathrm{RF}$ & $\mathrm{BC}$ & B & $\mathrm{k}$ & logLik & $\overline{\mathrm{AIC}_{\mathrm{c}}}$ & $\Delta i$ & $\overline{\mathrm{w}_{i}}$ & $\operatorname{acc} \mathrm{w}_{i}$ & ER \\
\hline & Full average & 5.698 & 2.651 & -1.286 & -0.178 & 7 & & & & & & \\
\hline 1 & $\mathrm{H}+\mathrm{RF}+\mathrm{BC}$ & 5.772 & 2.637 & -1.606 & & 6 & -350.71 & 714.3 & 0 & 0.31 & 0.31 & \\
\hline 2 & $\mathrm{H}+\mathrm{RF}+\mathrm{BC}+\mathrm{B}$ & 5.663 & 2.855 & -1.318 & -0.387 & 7 & -349.72 & 714.6 & 0.31 & 0.27 & 0.58 & 1.17 \\
\hline 3 & $\mathrm{H}+\mathrm{RF}$ & 5.529 & 3.281 & & & 5 & -352.64 & 715.9 & 1.60 & 0.14 & 0.72 & 2.24 \\
\hline 4 & $\mathrm{H}+\mathrm{RF}+\mathrm{B}$ & 5.433 & 3.437 & & -0.600 & 6 & -351.60 & 716.1 & 1.77 & 0.13 & 0.84 & 2.43 \\
\hline
\end{tabular}




\section{Number of helpers at the nest}

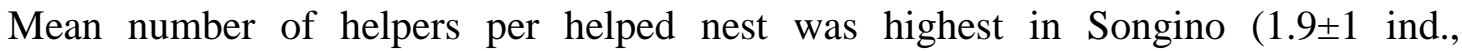

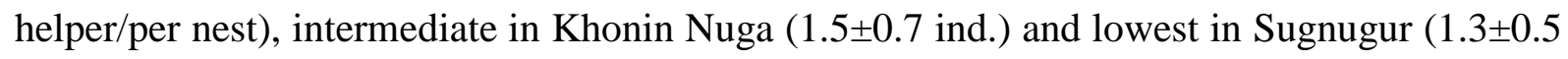
ind.) during the 2014 breeding season.

Table 4 Nestling body mass: result from the GLMM models, All-Subset average estimates of the models within 95\% confidence set. Sample size is 103 nestlings. Tested by Wald test

\begin{tabular}{llllll}
\hline Parameters & Estimate & Std. Error & Adjusted SE & z value & $\operatorname{Pr}(>|z|)$ \\
\hline (Intercept) & 47.337 & 7.945 & 8.017 & 5.905 & $0.000 * * *$ \\
Helpers' presence & 5.698 & 2.805 & 2.840 & 2.006 & $0.045^{*}$ \\
Relative feeding rate & 2.652 & 1.575 & 1.588 & 1.670 & 0.095 \\
Breeding colony & -1.286 & 2.047 & 2.066 & 0.623 & 0.534 \\
Brood size & -0.178 & 0.722 & 0.730 & 0.244 & 0.807 \\
\hline
\end{tabular}

\section{Duration of the chick-rearing stage}

Nestlings from the nests with helpers left their nests almost two days earlier compared to nestlings from the nests without helpers in the 2014 breeding season (pooled data from SUG, SON and KhN, Mann-Whitney $U$-test: $\left.U=8, n_{1}=12, n_{2}=5, \mathrm{p}<0.019\right)$.

\section{Nest predation}

The sole cause of nest failure was nest predation in the 2014 breeding season in all four breeding colonies. Overall, nest predation was responsible for $94 \%$ of all nest failures during our 8-year study in four breeding colonies. Across all breeding colonies in 2014, 60\% (26 out of 43 nests) of the predation occurred during incubation stage, while the rest of the nests (17 nests) were destroyed by predators during chick rearing stage. Nest predation occurred evenly during the incubation stage, while $76 \%$ of the nest predation was accumulated in the first half of the chick rearing stage. Helped nests were more successful 
than unhelped nests (preyed nests: 7 out of 30 nests with helpers vs. 29 out of 42 nests without helpers, Fisher's exact test: $P=0.03$, pooled data from breeding colonies regardless of the year). In the 2014 breeding season, nest predation was the lowest (31\%) in Sugnugur compared to Khonin Nuga (58\%) and Songino (89\%). Nest success (based on nests with at least $6 \mathrm{~h}$ nest observation to classify as helped or unhelped) was 32\% higher in helped nests than unhelped nests across breeding colonies in 2014. If we consider preyed nests before $6 \mathrm{~h}$ observation as unhelped nests, nest success would be $62 \%$ higher in helped nests than unhelped ones.

\section{Nest attentiveness}

Nest attentiveness, i.e. time with at least one adult bird at the nest, was virtually the same between helped and unhelped nests during the incubation stage (data from Khonin Nuga colony over three breeding seasons; helped nests: $50.7 \pm 11.4 \mathrm{~min} /$ hour, unhelped nests: 51.8 $\pm 8.6 \mathrm{~min} /$ hour; Mann-Whitney $U$-test, $\left.U=1197, n_{1}=75, n_{2}=33, P<0.791\right)$. In contrast, it was around 8 minute longer per hour in helped nests during the chick-rearing stage (helped nests: $44.6 \pm 13.6 \mathrm{~min} / \mathrm{h}$, unhelped nests: $36.6 \pm 17.9 \mathrm{~min} / \mathrm{h} ; U=730.5, n_{1}=58, n_{2}=34, P<$ $0.038)$.

\section{DISCUSSION}

\section{Food availability}

This study compared the response of azure-winged magpies' nestling feeding effort to food availability and nest predation risk in three localities. The habitat of the Sugnugur breeding colony was characterized by a high abundance of gypsy moth larvae during the breeding season compared to the breeding site of Khonin Nuga. Under the condition of abundant food, this breeding colony showed small differences in feeding rates of breeding birds in helped versus unhelped nests, heavier nestlings, no significant differences in body 
mass between nestlings of helped and unhelped nests, and no resident predators nearby the breeding site. All of these results suggest that breeding conditions were more favourable than in the two other sites. In addition, in combination with sufficient food sources, a lower predation risk led to higher nest success (nest success, SUG: 69\%; KhN: 42\%; SON: 11\%). Over the eight years of study at Khonin Nuga, there was only one incidence of nestling starvation after an unexpected food shortage because of a forest fire in 2009 (Bayandonoi et al. 2013). Thus, food availability during the 2014 breeding season was likely sufficient for the Khonin Nuga site.

The gypsy moth is extremely rare at the Songino study area due to its isolated location from the main body of forest, the natural habitat of gypsy moth. Moreover, this site was also characterized by low herbaceous vegetation and a more homogeneous plant community compared to other breeding habitats as a result of long-term intense grazing and human activities. Unlike the other two breeding colonies, birds from the Songino breeding colonies foraged mostly on the ground, collecting mainly beetles and some other insects. Unfortunately, we were unable to collect data on food availability for the Songino breeding colonies to compare with other two breeding colonies. Nevertheless, based on the feeding rate and nestling body mass, we can assume that food availability in the Songino breeding colonies was much lower than it was in Sugnugur and comparable to Khonin Nuga. However, nestlings in Songino have probably received less energy from the same amount of food than those in Khonin Nuga because of the higher nutritional value of the gypsy moths common in Khonin Nuga (up to $80 \%$ protein content in dry matter; Finke 2005) relative to the insects consumed in Songino, which had a larger proportion of exoskeleton and thus were likely more difficult to digest.

\section{Contribution from helpers}

Since breeding colony size, structure as well as nest predation events during early breeding stages may affect the individual's helping opportunities, the percentage of helpers in 
breeding colonies as a sole indicator of helping behaviour does not seem to be reliable. Instead the mean number of helper per nest and the average provisioning rate per helper in breeding colonies are more reliable indicators to describe the key role of helpers. While the mean number of helpers per nest was lower, helpers in Sugnugur were contributed to provisioning to a similar extent when compared to the other breeding colonies. Why helpers did not reduce their provisioning towards nestlings under conditions of high food availability, however, is not clear. Some other studies have shown that heavy nestlings from helped nests survive better during the post-fledgling period (Mumme 1992, Ridley 2007, Canestrari et al. 2011). Therefore, even in a breeding colony with a high food supply the extra provisioning from helpers may have a long-term effect on the survival of young birds, while the costs of helping are likely to be relatively low, providing that helpers can collect food easily and replenish their lost energy for provisioning the nestlings in a short time.

In Songino, the predation risk, as well as the mean number of helpers per nest was highest, while the food provisioning per helper was lowest. This suggests that under high predation risk, increasing provisioning towards nestlings by helpers is not as important as augmenting the number of helpers per nest to enhance nest defense and, therefore, reduce nest predation. Indeed, the latter has been shown for several cooperatively breeding bird species (Austad and Rabenold 1985, Emlen and Wrege 1991, Mumme 1992, Schaub et al. 1992, Innes and Johnston 1996, Boland 1998, Cockburn 1998, Valencia et al. 2003, Hatchwell 2004, Lloyd et al. 2009). Since food availability was low in Songino, we would expect to see higher average provisioning rates per helper, but provisioning rates were in fact the lowest compared to the two other breeding colonies. We have not documented any nestling starvation in Songino suggesting that the food was sufficient enough to prevent nestlings from starvation, at least with helpers' provisioning. This may be due to several factors, for example, shortage of food may have resulted in longer foraging time which in turn decreased helpers' 
provisioning rates and high predation risk forced helpers to devote more time for nest defense, also reducing foraging time.

Similarly, Woolfenden (1978) and McGowan and Woolfenden (1990) suggested that the main contribution from helpers in Florida scrub jays (Aphelocoma coerulescens) is not via increased food provisioning but likely through reduced predation on eggs or nestlings and in some instances on fledglings and breeders, possibly by increasing vigilance. When there is an abundant food supply, the helpers' provisioning might become less important for facilitating nestling growth, but their presence around the nest may reduce nest predation. Our results and observations also indicate that helpers carry out a combination of activities which may reduce nest predation, including sentinel behaviour (McGowan and Woolfenden 1989), nest defense and predator mobbing (Reyer 1984, Francis et al. 1989), sharing the feeding task to allow breeding birds to devote more time for nest defense (Rabenold 1984), and shortening the nestling stage by accelerating the development of the nestlings via extra provisioning (O'Brien 1997; Dickinson and Hatchwell 2004).

\section{Selective factors promoting cooperative breeding}

Baglione et al. (2002b) demonstrated experimentally that carrion crow nestlings from a non-cooperatively breeding population exhibited helping behaviour after having been reared in a cooperatively breeding population. They concluded that environmental conditions were responsible for the expression of helping behaviour, though they were unable to identify the specific factor that drives its expression. In our study, the percentage of helpers in a colony was highest in 2009 in Khonin Nuga, being 34\% (14 individuals out of 41). All helpers were recruited just after a forest fire that greatly diminished food sources (Bayandonoi et al. 2013). Considering that there was no confirmed helping behaviour during the previous two years of nest observations at the Khonin Nuga breeding colony, and even though high nest predation had occurred (7\% in 2007 and $47 \%$ of all nest in 2008), we hypothesize that the sudden food 
shortage and/or lack of suitable habitat for independent breeding destroyed by fire were the main cause(s) of the rapid emergence of helping behaviour in 2009.

Nevertheless, the proportion of helpers remained fairly constant (19\% - 21\% of colony members) in the following five years in that breeding colony, even when the food source gradually increased again and surpassed the food availability of the years before forest fire by 2013. This suggests that once helping behaviour is expressed within colony, it tends to be preserved. However, it might still be the case that there is a shortage of suitable breeding habitat that is not fully recovered following five years, leading to an elevated rate of helping behaviour. Regardless of environmental conditions, helpers made up similar proportion in all breeding colonies in the 2014 breeding season (SUG: $28 \%, \mathrm{KhN}$ : $19 \%, \mathrm{SON}$ : $23 \%$ of colony members). Those similar proportions of helpers under conditions of differing food supply in different breeding colonies also suggest that the expression of helping behaviour is not only triggered by food availability.

In our study, both the combination of predation pressure and the unpredictable food availability likely contributed to the maintenance of helping behaviour. Results from other studies indicated that nest predation could be a potential selective factor supporting cooperative breeding (e.g. Vehrencamp 1978; Francis et al. 1989; McGowan and Woolfenden 1989; Rabenold 1990; Mumme 1992; Hailman et al. 1994; Innes and Johnston 1996). However, Poiani and Pagel's (1997) comparative tests on the nest predation hypothesis, i.e. predation can be a selective factor for group living and cooperative breeding, were inconclusive. Nonetheless, these authors agreed that anti-predator behaviours that involved helpers can be effective against nest predation in some species.

In our study colonies in 2014, none of the nestlings starved to death. According to Hatchwell's (1999) assumption, our breeding birds should have reduced their food delivery in helped nests if starvation is not a main cause of nest failure. Valencia et al. (2006b) proposed that compensatory or additive parental strategies may depend on ecological conditions. The 
results of our study do not entirely seem to support this idea, at least under conditions where food availability is different. Compared to unhelped breeding birds, helped parents responded to food availability in various ways: by reducing the nestling feeding rate slightly at per nest when food was available (in SUG), by not showing any response (in $\mathrm{KhN}$ ) when food availability was intermediate, and by increasing provisioning when food was relatively scarce (in SON). Considering the per capita feeding rate instead of the per nest feeding rate in Sugnugur, clearly showed that helped breeding birds delivered food more frequently to each nestling than unhelped breeding birds. This trend was masked due to small brood sizes in helped nests in the comparison of the food delivery rate at per nest (brood size of SUG in helped nests: $3.7 \pm 0.84$ vs. unhelped nests: $5.3 \pm 0.85$ ). Therefore, the weak compensation of breeding birds in Sugnugur was rather a result of workload adjustment to brood size than a response to helpers' contribution (load lightening) during conditions of an abundant food source. In reality, each nestling from helped nests received more food at all times in all breeding colonies regardless of differing food availability. These results are consistent with those from Iberian azure-winged magpies, in which parents increased provisioning in the presence of helpers (Canario et al. 2004, Valencia et al. 2006a).

The response that parents increase provisioning when assisted has not been considered by present theories of cooperative breeding (Valencia et al. 2006a). Why do breeding birds of this particular species from distant populations increase their care when assisted? Maybe the outcome of increased food delivery from assisted breeding birds may not entirely be intended to enhance nestling body condition but could also have a different purpose such as manipulating the helpers (Alexander 1974). Breeding birds may increase their provisioning in the presence of helpers to enhance breeding success compared to a breeding pair alone, through benefits from extra alertness and workforce of helpers to detect and deter predators (Rabenold 1984, Carranza et al. 2008). Therefore, breeding birds may strategically have increased feeding rates to motivate and keep helpers at the nest. In turn, a helpers' regular 
presence around the nest may reduce nest predation, and extra provisioning from helpers would accelerate nestling development, allowing them to fledge earlier. Indeed, our results are in line with the prediction of the model by Carranza et al. (2008), which states that breeding birds should not reduce but instead respond with additive provisioning towards nestlings if the helpers' contribution is largely to reduce predation rather than prevent starvation. Moreover, reduced investment by breeding birds in nest defense due to helper presence may allow breeders to invest more time in foraging thus leading to increased food delivery.

In most bird species, breeding females have to forage by themselves, thus making their nests vulnerable to predation. In the case of the Khonin Nuga breeding colony, no temporal differences in nest attentiveness were found between helped and unhelped nests during the incubation stage. On the contrary, helped nests had much longer nest attentiveness time during the chick-rearing stage. This difference in duration is mainly due to extra allo-feeding from the helpers towards breeding females and provisioning nestlings that allowed females to stay longer at the nest during chick-rearing. Reduced foraging time of the breeding females allows them to invest more time in anti-predator activities (Martin 1987, 1992b, Lima 1998, Nagy and Holmes 2005, Rastogi et al. 2006). If females are at the nest, they can defend the nest more effectively (Montgomerie and Weatherhead 1988, Martin 1992b) thus reducing the predation risk (Fontaine and Martin 2006b). The fact that the breeding females were fed by their mates or helpers nearly in all cases could explain the roughly equal nest attentiveness time from our study during the incubation stage. Therefore, they did not forage by themselves regularly, spending most of the time at the nest in both helped and unhelped nests. Even if breeding females spent the same amount of time at the nests during the incubation stage, helpers could still increase alertness by spending more time around a nest to feed females.

In this paper we discussed the effect of food availability and nest predation on the expression of helping behaviour. Both reduced food availability and the risk of nest predation likely increase the benefits of helping behaviour, favouring the expression of this behaviour. 
Helpers appeared to increase nesting success via increasing nestling body condition and decreasing nest predation. We suggest that nest predation may also be one of the selective factors that promote the evolution of helping behaviour. Therefore, to understand the evolution of cooperative breeding fully, the nest predation hypothesis should receive more empirical attention in future studies. Variation of cooperative breeding among populations within species and among species of the same genus could be exploited to assess the importance of nest predation risk more comprehensively.

\section{ACKNOWLEDGEMENTS}

We are grateful to the Mongolian Ornithological Society for providing us with field equipment and thank all students from the National University of Mongolia, the Mongolian State University of Education, the Mongolian University of Life Sciences, Georg-August University Goettingen, Jena University in Germany, and Sterling College in USA for assistance in field work. This research has been made possible thanks to financial support from the German Academic Exchange Service (DAAD), Mike Madder's Field Research Award and the Heinrich-Böll Foundation (DK).

Author Gantulga Bayandonoi received a research grant 'Mike Madder's Field Research Award' in 2013 from Natural Research Limited (with registered number SC209393), registered in Great Britain, and a scholarship from the German Academic Exchange Service (DAAD). 


\section{CHAPTER 3}

RESPONSIVE ADAPTATION TO ANTI-PREDATOR STRATEGIES OF

THE AZURE-WINGED MAGPIE (CYANOPICA CYANUS PALLAS, 1776)

BREEDING COLONIES IN NORTHERN MONGOLIA

Gantulga Bayandonoi, Peter M. Kappeler, Eckhard W. Heymann, Matthias Waltert, Denis Kupsch, Gombobaatar Sundev, Michael Mühlenberg 


\section{ABSTRACT}

Birds have developed different anti-predator strategies in response to predators and environmental conditions. However, how flexible birds are in adopting suitable strategies against sudden and varying pressures from nest predators is not well explored. We studied breeding colonies of the azure-winged magpie (Cyanopica cyanus) in northern Mongolia, one for eight years and three others for two years. Azure-winged magpies experienced intense nest predation, mostly from corvids, that at on average of 56\% magpie nests $(n=163)$ were preyed upon. We investigated the nest concealment, distance to the main nest predator's (carrion crow) nest, number of helpers at the nest, breeding pair experience and nest distance on nest success separately to reveal specific effects and also comprehensively using GLM to explore the relative effects of each factor. Azure-winged magpies increased their nest concealment, nested closer to each other gradually and consistently moved their colony further away from the main predator's nest over eight-year study period. Also within one breeding season they relocated their colony with a longer distance to the main predator after experiencing high nest predation. Moreover, magpies built their later nests much closer to neighbouring nests, especially experienced pairs, and nesting was more synchronized after experiencing high nest predation. Nest concealment, distance to crow nest, number of helpers at the nest had strong positive effect on nest success. Breeding pair experience also appeared to have a positive effect on nest success. Our study showed that some of those strategies are interrelated and are integral elements of elaborate joint strategies. Plasticity of azure-winged magpies in implementing anti-predator strategies not only decreased the nest predation rate but also improved group cohesiveness due to closer nests and promoted cooperation. The data suggests that azure-winged magpies have a high cognitive ability to assess predation risk and respond adaptively by implementing a variety of interrelated anti-predator strategies.

Key words: Antipredator strategy, nest predation, nest concealment, nest location, pair experience, azure-winged magpie 


\section{INTRODUCTION}

Nest predation is recognized as the most common cause of reproductive failure for the great majority of birds, particularly passerines (Ricklefs 1969, Martin 1993, 1995b, Grzybowski and Pease 2005, Thompson 2007, Lima 2009). It is also seen as a significant selective factor favouring group living and cooperation (Alexander 1974, Vehrencamp 1978, Rubenstein and Wrangham 1986, Ford et al. 1988, McGowan and Woolfenden 1989, Rabenold 1990, Du Plessis et al. 1995, Poiani and Pagel 1997). Lima (2009) emphasised the fact that many aspects of bird ecology and biology, such as breeding, behaviour, sociality, and reproductive decision making may be influenced by predation risk. In many cases, different anti-predator strategies are required to reduce predation rates effectively, depending on predator type and its behaviour, for example nest concealment, elaborate nest design, protective nesting association, colonial or dispersed breeding and use of cavities (Kruuk 1964, Hoogland and Sherman 1976, Collias and Collias 1984, Brunton 1997).

Plasticity in response towards predation will undoubtedly increase reproductive fitness of birds since the predation risk can vary greatly during a bird's lifetime (Lima and Dill 1990, Lima 2009). Many studies indicated that birds have a significant capacity to assess and respond adaptively to changes in predation risk, specific predator types and improve the effectiveness of the anti-predator strategies (Doligez and Clobert 2003, Quinn et al. 2003, Doligez et al. 2004, Eggers et al. 2006, Fontaine and Martin 2006b, Mönkkönen et al. 2007, Ueta 2007, Emmering and Schmidt 2011). Therefore, birds may also be able to implement multiple anti-predator strategies simultaneously or switch from one strategy to another or to deploy multiple strategies under complex and suddenly emerging situations. In order to maximize reproductive fitness, they may often have to trade off between different antipredator strategies and optimal breeding conditions, such as better microclimate for the nest, foraging efficiency and reproductive investments in favour of optimal anti-predator strategies (see Götmark et al. 1995; Komdeur and Kats 1999; Burhans and Thompson 2001; Eggers et 
al. 2006; Lima 2009). However, studies that deal with different anti-predator strategies and their complexity are exceptionally rare (see Colombelli-Négrel and Kleindorfer 2009; Valcarcel and Fernández-Juricic 2009), and most studies have focused on olny a specific antipredator strategy and might, therefore, neglect cumulative or confound effects of several interrelated strategies. Some anti-predator strategies such as nesting closer to each other may only serve as a prerequisite for the active strategies, in particular, behavioural responses. We may find no effect from the strategy when we inspect separately. Nevertheless, some seemingly non-influental strategies could actually reduce the predation in association with other strategies as a part of complex strategy.

The azure-winged magpies (Cyanopica cyanus) may implement various anti-predator strategies to deal with nest predation risk. First, individuals may obtain parenting skills including optimal nest site selection through own breeding attempts (e.g. Marzluff 1988), observation of others (Boulinier 1996), and helping (Brown 1987, Hatchwell 1999). These experiences should contribute to reduced nest predation, but also decreased hatching failure, nestling starvation, increased number of fledglings. Indeed, few studies have provided empirical evidence showing the positive effect of experience regarding the breeding performance (Marzluff 1988, Komdeur 1996, Hatchwell et al. 1999). Second, superior nest concealment should reduce the probability of being detected by vision-oriented predators (Filliater et al. 1994, Lima 2009). Although, studies on artificial nests generally suggest that well concealed nests tend to suffer less nest predation (Weidinger 2002, Remeš 2005, Colombelli-Négrel and Kleindorfer 2009, Michalski and Norris 2014) and that this is also the case in some natural nests (Finch 1989, Segura et al. 2012), a notable number of studies on natural nests is not in line with this hypothesis, possibly due to habitat variation, active nest defense and predator types (see Filliater et al. 1994; Howlett and Stutchbury 1996; Burhans and Thompson III 1998; Peak 2003; Goławski and Mitrus 2008; reviewed by Lima 2009). Third, changing the nesting site to different location within a breeding territory may have 
benefits in response to specific nest predators and may therefore be widespread (Lima 2009). The traits of species which would avoid nest predation spatially may be typically those specied that experience high nest predation, are single brooded, have a certain ability to assess predation risk prior to breeding by a variety of cues, have a later breeding phase than predator species, and face main predators that have easily identifiable small foraging territories (Roos 2006). Finally, many studies revealed a positive effect of helpers on lowering nest predation for various cooperative breeding bird species (Brown 1987, Emlen and Wrege 1991, Mumme 1992, Schaub et al. 1992, Innes and Johnston 1996, Cockburn 1998, Hatchwell 2004, Lloyd et al. 2009). If breeding in colony is driven by increased predation, reproductive activities are expected to be synchronized within the colony (Elgood and Ward 1963, Kruuk 1964, Patterson 1965). Birds should therefore synchronize reproductive activities under predation pressure.

In this paper, we use data from four Mongolian breeding colonies of the azure-winged magpie to investigate the plasticity of anti-predator strategies of this species under differing predation risk. Nest predation was the main cause of nest failure in these breeding colonies and it appeared to promote helping behaviour (see chapter 2). We predicted that experienced breeding pairs will have better nest site selection (Tinbergen et al. 1967, Andersson and Wiklund 1978). As the species is a flexible cooperative breeding bird and helping decreases nest predation in its Iberian sister population (Valencia et al. 2003), we expected the same pattern in the Mongolian population. Since nest concealment is more effective against visually hunting nest predators (Weidinger 2002, Lima 2009) like the main nest predator - the carrion crow (Corvus corone) and common magpie (Pica pica) in our study, we predict that the azure-winged magpies prefer to build their nests in well concealed locations when corvids are present. We also predicted that azure-winged magpies synchronize reproductive activities under predation risk. Furthermore, since azure-winged magpies in northern Mongolia meet Roos (2006)'s criteria fully, we would expect the azure-winged magpies to respond to their 
main predator, the carrion crow, to increase the distance between the their nests and the crow nest.

\section{METHODS}

\section{Study area and breeding colonies}

The study was conducted on one breeding colony of the azure-winged magpie, namely Khonin Nuga $(\mathrm{KhN})$ along the Yuruu river basin $\left(49^{\circ} 05^{\prime} \mathrm{N}, 107^{\circ} 17^{\prime} \mathrm{E}\right)$ in West Khentii, northern Mongolia, between May and July in 2007-2014. Moreover, other three breeding colonies were incorporated in our study during 2013 and 2014 breeding seasons along the Tuul $\left(47^{\circ} 86^{\prime} \mathrm{N}, 106^{\circ} 69^{\prime} \mathrm{E}\right)$ and Sugnugur $\left(48^{\circ} 40^{\prime} \mathrm{N}, 106^{\circ} 91^{\prime} \mathrm{E}\right)$ river basins, called Songino-1 and Songino-2 breeding colonies (together SON) and Sugnugur (SUG) (see more detail in chapter 2). The climate in northern Mongolia is continental with hot summers and cold, severe winters with average annual temperature of $0.7^{0} \mathrm{C}$ (von Velsen-Zerweck 2002). Snow covers the ground from early October to mid-April. Generally, habitats of the breeding colonies are similar to each other and include open river flats, riparian woodland and scrubland (see habitat description in detail from chapter 2).

\section{Nest predators}

We considered a species as a main nest predator if: (1) we observed predation on the nest; (2) detected species-specific clues around preyed nests; (3) azure-winged magpies responded aggressively to this species around their breeding territory (see details in chapter 2). A pair of carrion crow was the main predator in the Khonin Nuga breeding colony during the eight-year study period (see chapter 2). The Yuruu river serves as a natural border between the breeding territory of the azure-winged magpies and the pair of carrion crow. Azure-winged magpies showed defensive behaviour towards crows and other potential predators only if they are detected at the site of the river where azure-winged magpies breed 
(Gantulga Bayandonoi, personal observation). In 2014, common magpies and carrion crows were the main nest predators at Songino breeding colonies (see details from chapter 2), while an unidentified mammalian species (likely a member of the Mustelidae) was the sole predator in Songino-1 breeding colony in 2013. Although potential terrestrial and avian predators from corvids and raptors were common in Sugnugur, we have not observed any nest predator that could be regarded as a main nest predator.

Besides direct observation records, we also considered nests as being preyed when entire clutches or broods disappeared in one day and clues of predators or remains of nestlings are found at or nearby the nest. We used a term "high nest predation" for the incidences if more than half of the current nests were lost to predators in less than two weeks at the onset of the breeding seasons in breeding colonies. Such incidences occurred in all breeding colonies in most of the year except during 2011 and 2013 in Khonin Nuga, 2013 in Songino-1 and 2014 in Sugnugur. These incidences were always followed by new sub-colony(s) formation by late breeders and second attempt-breeders at relatively far distances and/or different time periods from the initial colony or another newly formed sub-colony.

\section{Data collection}

Results are primarily focused on data collected from the Khonin Nuga over eight years. Data from Sugnugur and Songino breeding colonies are used to investigate specific anti-predator strategies. We located nests by searching the breeding sites once every three days during the egg-laying and the incubation stage, and more intense directly after nest predation incidences to check for second nesting attempts. Birds were ringed at the onset of the breeding seasons with unique combinations of one numbered metal and one or several coloured plastic rings (see detailed method in chapter 2). The number of helpers at nests were verified and identified after at least six hours of nest observation during late egg-laying and chick rearing stages (see detailed method in chapter 2). 
We measured the distance between azure-winged magpie nests (ND) as well as between crow and each azure-winged magpie nests (DC) using GPS coordination of the nests. We took five photos at each nest (one from the top and four from the side in square angles) and averaged the coverage by branches and leaves as a measure of nest concealment (NC) after leaf growth was completed in early June. We categorized breeding pair experience (PE) at Khonin Nuga as experienced when we could identify at least one individual from the pair that had attempted to breed in previous years, as inexperienced when both breeding birds attempted to breed for the first time or both birds were unbanded. The error with regard to unbanded individuals as inexperienced which might have bred before is expected to be reasonably low, owing that the average proportion of unbanded adults in Khonin Nuga was 20\% during seven breeding seasons (2007-2013), and some of which are immigrants (Gantulga Bayandonoi, unpubl. data). Pairs of the azure-winged magpie tend to be stable and unlikely emigrate from the breeding colony. Moreover, immigrants are usually young birds which had no experience with breeding.

We tested the effect of pair experience during high predation risk on feeding rates. Feeding rate refers to food delivery (provisioning) to the nest per hour, resulting in actual feeding of nestlings. All nests that failed due to other causes except nest predation were excluded from the analyses. We recorded mobbing behaviour of the azure-winged magpie towards potential nest predators, especially crows, during $646 \mathrm{~h}$ of nest observation (see details in chapter 2) at the nests in Khonin Nuga during 6 breeding seasons in order to reveal any interaction between azure-winged magpies and their predator species.

\section{Data analyses}

We analysed the effects of a set of parameters on nest success in Khonin Nuga breeding colony by Generalized Linear Models (GLM) in R project using "arm" package and its bayesglm function with binomial distribution (link: logit). Mean distance of each nest of 
the azure-winged magpie to neighbouring nests (MD), distance to crow nest, nest concealment, number of helpers at the nest $(\mathrm{NH})$, breeding pair experience, breeding colony size (CS), identity of the sub-colony (SC) within breeding season, and breeding season (BS) were used as explanatory variables. As recommended for the small sample size if the ratio between sample and parameters $(\mathrm{n} / \mathrm{k})$ is less than 40 , Akaike Information Criterion with a correction for finite sample sizes $\left(\mathrm{AIC}_{\mathrm{c}}\right.$ ) were used to rank the models (Sugiura 1978, Hurvich and Tsai 1995). We did multi-model inference in the full set of models using MuMIn-package (Bartoń 2016) in $\mathrm{R}$, considering that best approximating models cannot explain the results solely in our analyses because of lower Akaike weight $\left(\Delta_{i}\right)$ than the recommended threshold value of $0.9 \Delta_{i}$ (Burnham and Anderson 2002, Lukacs et al. 2010, Symonds and Moussalli 2011). We did not use GLM analyses in Sugnugur breeding colony due to its small sample size and in Songino breeding colonies due to different set of predator species and implementation of "protector species" strategy (see below). Because of those unique circumstances multi-variance analyses would have been unsuitable, we preferred to analyze parameters separately with non-parametric tests in Songino and Sugnugur breeding colonies.

To fit the data of Khonin Nuga for the GLM analyses on nest success, each nest required single distance to neighbouring nests. Therefore, mean distance (MD) from given nest to other nests represented a distance for that given nest. Regression analysis was used to tests any changes in nest distances of the azure-winged magpie along breeding seasons in Khonin Nuga. Mann-Whitney $U$-test (MWU) was used to test effect of pair experience on nest distances, number of helpers at the nest, nest concealment, distance to crow nest and differences in distance between initial and later formed colony/sub-colonies within breeding season in Khonin Nuga. We used relative mean distances (not to be confused with MD) of each nest instead of actual mean distances for the MWU test on nest distance regarding pair experience to account for variations between breeding seasons, which might have occurred 
due to adaptation against nest predators, effects between years and different habitats of new breeding site in some years.

In order to acquire relative mean distance, we averaged distances between all nests from six breeding seasons, but separately in old and new breeding sites, to obtain total mean distance which was regarded as a mean distance between nests in each breeding season. Thus, we can separate variations between breeding seasons and breeding sites from the variation of the breeding pair experiences and nests from initial and late colony/sub-colonies, while retaining the proportional variation between nests. Afterwards, we corrected actual mean distances of each nest by the difference between mean distances in each breeding season and total mean distance to acquire relative mean distance of each nest. Breeding seasons without sub-colony establishment were omitted from the analyses to test difference between initial and later formed colony/sub-colonies within breeding seasons.

In Khonin Nuga, we divided distances between crow and azure-winged magpie nests into two sections by the north bank of the Yuruu river, which is the natural border between the breeding territories of these two species, to examine the avoidance of the azure-winged magpie from the crow nest. We used a Wilcoxon matched-pair test to examine the effect of pair experience under high predation risk on feeding rate. We represented nesting synchronization by the difference of each nest in days prior or later to the mean day of first egg-laying dates of initial colony nests and later formed sub-colony nests respectively in each breeding colony in a given breeding season. Egg-laying day was counted from the day of the first egg in colony to the day of the first egg in last nest. We combined data from Songino-1 and Songino-2 breeding colonies for the analyses on synchronous nesting and nest concealment because of their similarities being essentially in the same habitat that two colonies were located close to each other (nearest nest distance of two colonies was $320 \mathrm{~m}$ apart), timing of breeding, same set of predator individuals and frequent individual movements between colonies. 
Spearman rank order correlation was used to examine nest synchronization over breeding seasons and the relationship between breeding colony size and mobbing rate (in percentage) of magpies against crows during crow intrusion in Khonin Nuga breeding group. We tested difference in nest success of the experienced and inexperienced breeding pairs and difference in mobbing rate of magpies against crows based on crow vocalization by Fisher's exact test in Khonin Nuga. Yates corrected Chi-squared test was used to assess crow's intrusion rate differences before and after crow nestlings are fledged.

\section{RESULTS}

\section{Predation rate}

In total, $56 \%$ of all nests $(\mathrm{n}=163)$ from breeding colonies were preyed upon by predators. Since 2008 the Khonin Nuga breeding group has experienced serious nest failure rates due to predation mostly by a pair of crows that started to breed next to azure-winged magpies breeding site directly on the other river side since 2007. On average, $42 \%$ (ranging from $0 \%-63 \%)$ of the nests in Khonin Nuga $(n=72)$ were lost to nest predation between 2008 and 2014.

The area surrounding the Songino-2 breeding colony was occupied by three breeding colonies of the rook (Corvus frugilegus) during the 2013 breeding season. Presumably due to the rook's intense nest defense, carrion crows and common magpies, the main nest predators of the azure-winged magpies, did not breed close to the breeding site of the Songino-2 breeding colony and were rarely observed in 2013, resulting in a low nest predation rate of $24 \%$. In contrast, breeding colonies of the rook abandoned their former breeding sites in 2014 . Three pairs of carrion crow and two individuals of resident common magpie occupied the area that has been left unoccupied by rooks. As a result, azure-winged magpies in Songino-2 experienced a $100 \%$ nest predation rate. In addition, the Songino-1 breeding colony started to nest near the Songino-2 breeding colony after losing two of their early nests due to predation 
in their former breeding site in 2014, experiencing high nest predation rate of $64 \%$ from probably the same individuals of carrion crow and common magpie. All but one preyed nest from Songino-1 was lost likely by a mammalian predator in the same night in 2013 breeding season, and one day after the last remaining nest was also preyed upon, resulting in $100 \%$ predation rate. In Sugnugur, birds experienced $74 \%$ nest predation in old breeding site which is located closer to human settlement that provides large number of corvids, while the colony had low nest predation in its new breeding site which was further located from the settlement.

\section{Nest distance}

Since 2008, when high nest predation at Khonin Nuga breeding site started, breeding birds continuously reduced the distance between nests over years $\left(\mathrm{R}^{2}=0.06, F_{1,178}=11.55, P\right.$ $=0.00084$, Fig. 6). This pattern has observed not only between but also within breeding seasons, meaning that distances between nests from sub-colonies formed after high nest predation incidences were significantly closer than initial colony nests (see chapter 2).

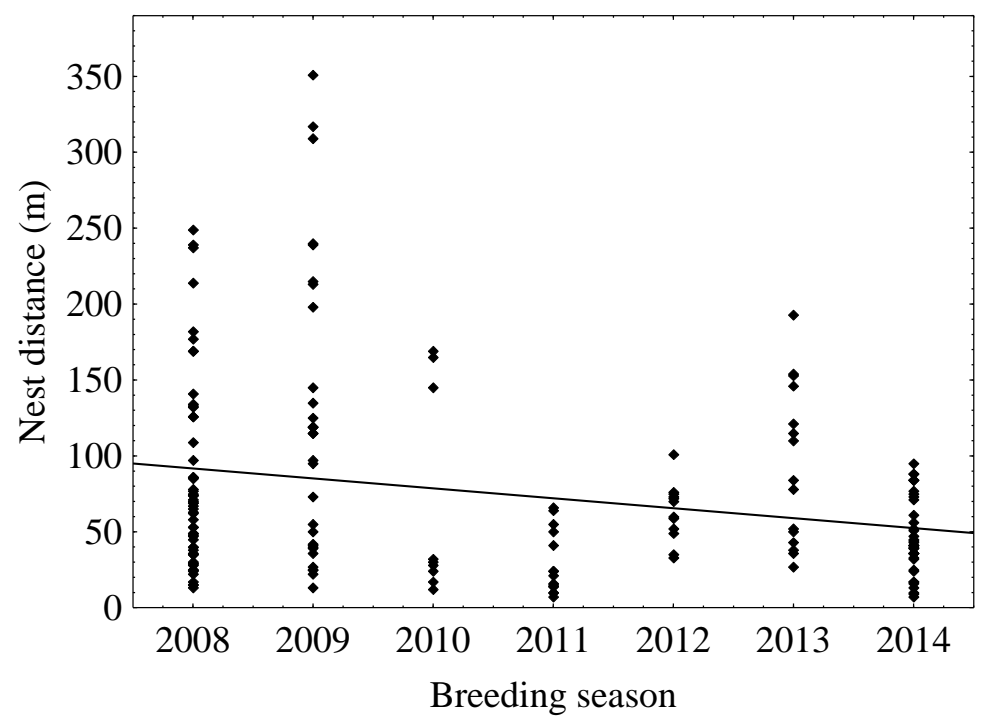

Figure 6 Mean distance between nests during seven breeding seasons in Khonin Nuga 


\section{Nest concealment}

Nest concealment gradually increased over the breeding seasons in Khonin Nuga (Correlation coefficient, $r=0.32, \mathrm{R}^{2}=0.104, F_{1,62}=7.185, P<0.0094$, Fig. 7). It was higher in later formed sub-colony nests than initial colony nests in years where sub-colonies were formed in all breeding colonies (pooled data, MWU: $U=1355, \mathrm{n}_{1}=65, \mathrm{n}_{2}=62, P=0.0012$ ).

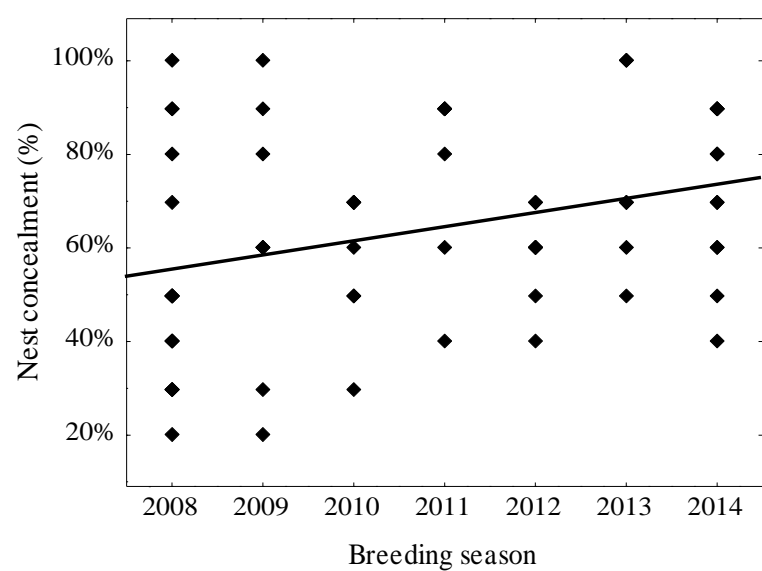

Figure 7 Difference of the nest concealment during seven breeding seasons in Khonin Nuga

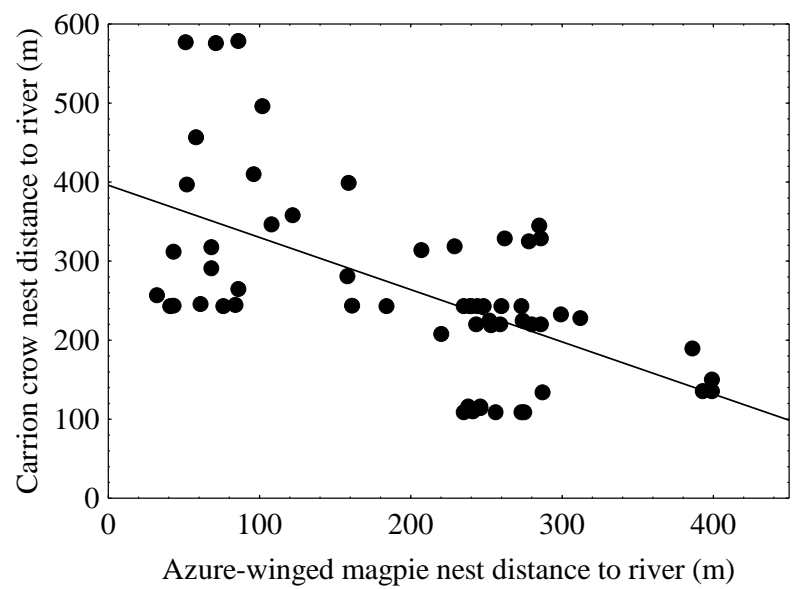

Figure 8 Relation between azure-winged magpie nests and carrion crow nests to the river during six breeding seasons in Khonin Nuga

\section{Effect of breeding pair experience on anti-predator strategies}

During six breeding seasons, experienced breeding pairs built their nests closer to neighbouring nests than inexperienced pairs (total $\mathrm{MD}_{\exp }=59.8 \pm 28.5 \mathrm{~m}$; total $\mathrm{MD}_{\text {inexp }}=$ 91.2 $\left.\pm 30.6 \mathrm{~m} ; \mathrm{MW} U, U=77, n_{1}=27, n_{2}=14, P<0.0022\right)$. Whereas, pair experience had no effect on nest concealment, distance to crow nest and number of helpers at the nest (MWU, $n_{1}$ $=27, n_{2}=14$, nest concealment: $U=132, P<0.12$, distance to crow nest: $U=184, P<0.9$, number of helpers: $U=180, P<0.77)$. In addition, experienced pairs tended to feed nestlings less frequently than inexperienced pairs (tested by average daily feeding rate per hour, Wilcoxon matched-pair test, feeding rate in experienced: $2.5 \pm 0.6$, inexperienced: $3.2 \pm 1.1, T=$ 
$31, n=16, P=0.056$; total feeding rate including helpers' feeding in experienced: $2.8 \pm 0.7$, inexperienced: $3.4 \pm 1.2, T=33, n=16, P=0.07)$.

\section{Avoidance from the carrion crow nest}

There was a significant negative correlation between the distance of crow and magpie nest to the river (Correlation coefficient, $r=-0.59, \mathrm{R}^{2}=0.347, F_{1,57}=30.31, P<0.00001$, Fig.8). Furthermore, the later formed sub-colony nests were much further located from the carrion crow nest than initial colony nests (mean distance of initial nests: $433 \pm 89 \mathrm{~m}$, later nests: $\left.671 \pm 364 \mathrm{~m}, \mathrm{MW} U: U=255, n_{1}=33, n_{2}=27, P<0.005\right)$.

\section{Synchronous breeding}

Nests from later formed sub-colonies in all breeding colonies tended to have more synchronized egg-laying than nests at the beginning of the breeding season (initial nests: $1.92 \pm 1.60$ days, later nests: $1.39 \pm 1.04$ days, MWU: $\left.U=2347, \mathrm{n}_{1}=99, \mathrm{n}_{2}=56, P=0.11\right)$. Especially in Songino where nest predation risk was higher than in other breeding colonies, nesting was more synchronized (initial nests: $2.30 \pm 1.71$ days, later nests: $1.32 \pm 0.79$ days, MWU: $\left.U=354, \mathrm{n}_{1}=36, \mathrm{n}_{2}=28, P=0.04\right)$. In case of the Khonin Nuga breeding colony, nesting gradually became more synchronous over years (Spearman rank order correlation $\rho=$ $-0.76, \mathrm{n}=8, P=0.028)$

\section{Impacts on nest success}

The main cause of nest failure was nest predation throughout the eight breeding seasons ( $86 \%$ of failed nests) in Khonin Nuga. The rest are attributed to a forest fire in 2009, either through direct destruction (up to 5 nests) or nestling starvation (one nest) after food shortage. 
Results from GLM analysis showed that the nest success of the Khonin Nuga breeding colony is strongly affected by nest concealment, distance to crow nests, and number of helpers at the nest (Table. 5, 6). Breeding pair experience also increased nest success, though this was a not a strong effect. Breeding season, nesting in sub-colonies, mean distance of each magpie nest, and breeding colony size had not been of much influence on the nest success (Table 5, 6).

Table 5. Results of the best-ranked models (within $\Delta \mathrm{i}<2$ ) of the nest success in the Khonin Nuga breeding colony during 2008-2014 breeding seasons. $\mathrm{k}$ - number of parameters, $\Delta i$ - difference between the $\mathrm{AIC}_{\mathrm{c}}$ value of the best model and the $\mathrm{AIC}_{\mathrm{c}}$ value of the i model, $\mathrm{w}_{i}$ - Akaike weight of the i model, ER - evidence ratio, $\mathrm{NC}$ Nest concealment, DC - Distance from the crow nest, NH - Helpers at the nest (number of helpers), PE Breeding pair experience, SC - Sub-colonies formed during same breeding season, BS - Breeding season, MD Mean distance from the other nests of the sub-colony. Sample size is 64 nests

\begin{tabular}{|c|c|c|c|c|c|c|c|c|c|c|c|c|c|c|}
\hline Rank & Candidate models & $\mathrm{NC}$ & DC & $\mathrm{NH}$ & PE & $\mathrm{SC}$ & BS & MD & k & $\log \mathrm{Lik}$ & $\mathrm{AIC}_{\mathrm{c}}$ & $\Delta i$ & $w_{i}$ & ER \\
\hline \multicolumn{2}{|c|}{ Full Model average } & 7.46 & 0.01 & 4.00 & 2.17 & -0.08 & -0.15 & -0.00 & 9 & & & & & \\
\hline 1 & $\mathrm{NC}+\mathrm{DC}+\mathrm{NH}+\mathrm{PE}+\mathrm{SC}$ & 7.64 & 0.01 & 4.07 & 2.33 & -0.19 & & & 6 & -11.41 & 36.3 & 0.00 & 0.17 & \\
\hline 2 & $\mathrm{NC}+\mathrm{DC}+\mathrm{NH}+\mathrm{PE}+\mathrm{BS}$ & 7.95 & 0.01 & 4.15 & 2.30 & & -0.36 & & 6 & -11.44 & 36.4 & 0.05 & 0.17 & 1.02 \\
\hline 3 & $\mathrm{NC}+\mathrm{DC}+\mathrm{NH}+\mathrm{PE}$ & 6.09 & 0.01 & 4.31 & 2.84 & & & & 5 & -13.03 & 37.1 & 0.79 & 0.12 & 1.49 \\
\hline
\end{tabular}


Table 6. Model averaging estimates for the parameters of the models within $95 \%$ confidence set (cumulative Akaike weight $\leq 0.95$ ) from the final GLM of the Nest success in the Khonin Nuga breeding colony during 2008-2014 breeding seasons. Sample size is 64 nests

\begin{tabular}{llllll}
\hline & Estimate & Std. Error & Adjusted SE & z value & $\operatorname{Pr}(>|z|)$ \\
\hline Intercept) & -12.790 & 3.643 & 3.720 & 3.440 & $\mathbf{0 . 0 0 0 6} * * *$ \\
Nest concealment & 7.374 & 2.760 & 2.815 & 2.619 & $\mathbf{0 . 0 0 9} * *$ \\
Distance from the carrion crow nest & 0.015 & 0.006 & 0.006 & 2.492 & $\mathbf{0 . 0 1 3}{ }^{* *}$ \\
Number of helpers at the nest & 4.029 & 1.715 & 1.749 & 2.304 & $\mathbf{0 . 0 2 1} *$ \\
Breeding pair experience & 2.270 & 1.273 & 1.291 & 1.758 & $\mathbf{0 . 0 7 9}$ \\
Sub-colonies within breeding season & -0.091 & 0.143 & 0.144 & 0.629 & 0.529 \\
Breeding season & -0.100 & 0.206 & 0.209 & 0.477 & 0.633 \\
Mean distance of each nests & -0.001 & 0.005 & 0.006 & 0.142 & 0.887 \\
Colony size & 0.002 & 0.030 & 0.030 & 0.054 & 0.957 \\
\hline
\end{tabular}

Highly concealed nests were more successful than less concealed nests in all breeding colonies (MWU, KhN: $U=207.5, n_{1}=33, n_{2}=31, P<0.0004$, Fig. 9A; SUG: $U=30, n_{1}=12$, $n_{2}=11, P<0.027 ;$ SON: $\left.U=99.5, n_{1}=37, n_{2}=16, P<0.00009\right)$. The nests at Khonin Nuga breeding site that were located closer to neighbouring nests tended to be preyed upon less often than nests which were distantly located from neighbouring nests (MD, MWU: $U=$ 418.5, $n_{1}=33, n_{2}=31, P<0.21$; Fig. 9B). Successful azure-winged magpie nests in Khonin Nuga breeding colony were much further located from the crow nests compared to preyed nests (MWU: $U=169.5, n_{1}=33, n_{2}=31, P<0.000004$; Fig. 9C). Moreover, none of the preyed nests from Khonin Nuga had a helper, while $39 \%$ of all successful nests had (MWU: $U$ $=310, n_{1}=33, n_{2}=31, P<0.007$; Fig. 9D). Experienced breeding pairs were more likely to be successful than inexperienced pairs in Khonin Nuga (successful pairs, experienced: 24 out of 33; inexperienced: 13 out of 31, Fisher's exact test: $P<0.022$ ). 

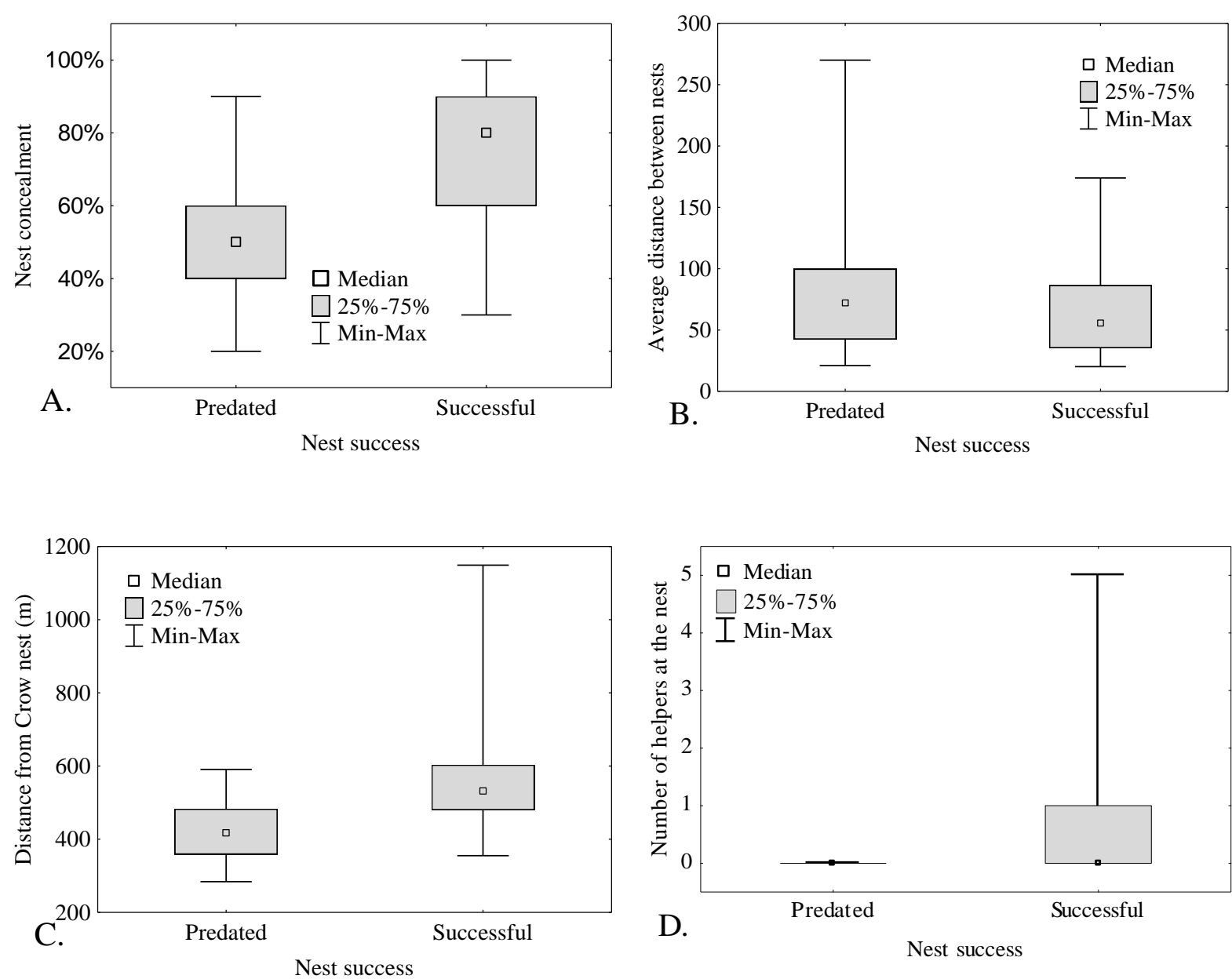

Figure 9 Relation between nest success of the azure-winged magpies and Nest concealment (A), Mean distance from colony nests (B), Distance from azure-winged magpie nests to carrion crow nest (C), Number of helpers (D) in the Khonin Nuga breeding colony, pooled data from seven breeding seasons

\section{Behavioural responses against predators}

Breeding colony size was only weakly correlated with the anti-predator response rate of magpies against crows (Spearman rank order correlation $\rho=0.70, P=0.1881$ ). Moreover, azure-winged magpies chased crows that entered silently into their breeding territory more frequently than vocalized crows (crows were chased, 93/113 during silent intrusion, 6/20 during non-silent, Fisher's exact test: $P<0.00001)$. The crows significantly reduced flight events over the magpie breeding territory after the crow's chick rearing stage (before the crow's chick rearing stage: 141 times in 514 hours nest observation; after: 12 times in 132 
hours nest observation; Yates corrected Chi-squared: $\left.\chi^{2}=12.43, P=0.0004\right)$. The azurewinged magpies generally ignored the crows after the crow's chicks fledged. However, they continued to be aware of sparrow hawks, and other potential predators.

\section{Protector species}

All four successful nests including two failed nests formed a separate sub-colony within Songino-1 breeding colony and were located in the vicinity $(29.2 \pm 25.4 \mathrm{~m})$ of an active nest of the Amur falcon (Falco amurensis). All four successful nests were located much closer to the Amur falcon nest than preyed nests (successful nests: $30 \pm 30 \mathrm{~m}$, failed nests: $\left.380 \pm 125 \mathrm{~m}, \mathrm{MW} U: U=4, n_{1}=31, n_{2}=4, P<0.0005\right)$. Moreover, those six nests were located much closer to the crow nest $(60.5 \pm 22 \mathrm{~m})$ than rest of the 31 failed nests $(232.7 \pm 39 \mathrm{~m})$.

\section{DISCUSSION}

Nest predation was the main cause of nest failure of the azure-winged magpie in this Mongolian population, which is in line with findings on various other populations (Cruz et al. 1990, Muñoz-Pulido et al. 1990, Valencia et al. 2003, Bayandonoi et al. 2013). As a response, the azure-winged magpies implemented a combination of flexible strategies to deal with nest predation risk, such as avoidance from the predators in terms of space and time, improved safety of the nest in terms of nest location, concealment, enhanced defense, behavioural responses and individual experience.

\section{Nest concealment}

Nesting in well concealed locations was the most effective anti-predator strategy for the azure-winged magpies, which is in line with Ueta (1998)'s study on a Japanese population. Our results support the nest concealment hypothesis that well concealed nest are less prone to be preyed (Filliater et al. 1994, Weidinger 2002). An increase of nest concealment over eight 
years in Khonin Nuga implies that birds are able to improve their strategy based on their experience from previous years. The main disadvantage of highly concealed nest locations is that it could also lower the breeding bird's view, which in turn might decrease early detection of approaching predators (Finch 1989, Götmark et al. 1995). In our case, this disadvantage likely has been compensated by alarm calling from neighbouring and guarding birds in almost all cases. Therefore, higher nest concealment will likely be favoured by azure-winged magpies under predation risk since it has diminutive negative aspects.

\section{Effect of helpers}

Helpers at the nest reduce nest predation directly by enhancing the nest defense and indirectly by speeding up the nestling development and, therefore, shortening the time window nestlings might be preyed (see chapter 2). Also, helpers contribute to feeding, which in turn allows breeding birds themselves to show longer attendance at the nests and dedicate more time to nest defense (see chapter 2).

\section{Effect of breeding pair experience}

Our result from the Khonin Nuga breeding colony that the experienced breeding birds built their nests considerably closer to neighbouring nests than inexperienced pairs suggests that new breeding birds may lack the experience to implement this strategy and experienced pairs may have learnt the benefits of the closely located neighbours under pressure from specific nest predators. However, experienced pairs seem not to perform better in regard to nest concealment, number of helpers at the nest (higher in experienced nests, though not significantly), distance to crow nest than counterparts. Breeding pair experience had a positive effect on nest success, largely explained by that experienced pairs build their nests close to neighbouring nests, thus likely reducing nest predation through the extra vigilance and swift collaboration with the neighbours. Some other studies also revealed an advantage of 
experience in selecting better nest sites. For example, in the Pinyon Jay (Gymnorhinus cyanocephalus) where birds selected more concealed sites after experiencing nest predation (Marzluff 1988). Hatchwell et al. (1999) also found that not the breeders, but the helpers that assisted successful breeders built their subsequent nest in low locations, which is assumed to have less risk of predation, and more successful than helpers assisted unsuccessful breeders in their long-term study on the Long-tailed tits (Aegithalos caudatus). Moreover, in study on the Seychelles warbler (Acrocephalus seychellensis) where birds with helping and breeding experiences built their nests in more stable locations than inexperienced birds, which resulted in significantly higher hatching success (Komdeur 1996). Besides nesting close to each other, experienced pairs may also have acquired fine-tuned behavioural responses and skills from previous breeding attempts which is required to improve nest conditions and prevent nest predation. In fact, we observed that some of the yearling breeders had clumsy thinner nests with less soft materials inside and even one of them had a hole at the bottom of the nest, while experienced pair always had well-crafted nests with tightly packed inner linings, which would certainly improve microclimate and safety at the nest. Also, experienced pairs seem to have decreased their feeding visit rate at the nest suggesting that they may avoid attracting predators by their visits. Hence, it ought to reduce nest predation given that the main predator in our study is the visually oriented carrion crow. Although, this behavioural response is well known in birds under high predation risk, especially against visually oriented avian predators (Eggers et al. 2005, Fontaine and Martin 2006b, Massaro et al. 2008, Peluc et al. 2008, Zanette et al. 2011, Ghalambor et al. 2013), none of those studies took into account the effect of individual experience. Our results indicate that birds may have learned this anti-predator strategy from their previous experiences. 


\section{Synchronous breeding}

Breeding synchronization promotes joint nest defense, cumulative parental investments, social foraging and reduced breeding length (Elgood and Ward 1963, Emlen and Demong 1975, Hoogland and Sherman 1976), and, therefore, also contributes to reduce nest predation. Birds from the Khonin Nuga breeding colony continuously increased nesting synchronization ever since they started experiencing high nest predation from carrion crows in 2008, which suggests that there is an active and ongoing adaptation process over years. Moreover, azure-winged magpies seem to assess predation risk within breeding season based on recent nest predation events and adapt their nesting activities by synchronizing their later formed sub-colony nests more than initial colony nests, likely to maximize the benefit from effective anti-predator strategies as a reaction to steadily high nest predation rates during the first breeding attempt. However, the synchronization of the later formed sub-colony nests might have been a result of time constraint since breeding season is relatively short due to short summer and seasonally changing main food sources that may limit breeding season.

\section{Nest avoidance from the predator nest}

Azure-winged magpies have likely started breeding in Khonin Nuga valley in 2005 (pers. comm. with staff and researchers from the permanent manned Khonin Nuga research station, located approximately $100 \mathrm{~m}$ from the current breeding site of the Khonin Nuga breeding colony but opposite site of the river). Exceptionally large group size (83 individuals at the peak in 2007) during the first years after the breeding site establishment indicates that predation pressure was low. Since 2008, the pair of carrion crow started to inflict high nest predation on the nests of the azure-winged magpies in Khonin Nuga. Our study showed that the azure-winged magpies implement predator-specific avoidance of nest dispersal within breeding territory. Azure-winged magpies possibly locate the crow nest during foraging flights already before their own nesting starts since crows start breeding around a month 
before the azure-winged magpies. Breeding birds from Khonin Nuga were deliberately keeping distance from crow nest over eight-year study period by nesting further to the north of their breeding territory until the edge of steep slopes that limit the breeding territory when crow nest are close to the border of their breeding territory, the Yuruu river, and vice versa. A number of studies suggest that birds actually avoid specific nest predators by nesting further away or in "less risk" locations, for example, in European blackbird Turdus merula (Møller 1988), Atlantic puffin Fratercula arctic (Finney et al. 2003), (Roos and Pärt 2004, Roos 2006), Siberian jay Perisoreus infaustus (Eggers et al. 2006) and Orange-crowned warbler Vermivora celata sordida (Peluc et al. 2008). To this point, only studies from Roos and Pärt (2004) and Roos' (2006) on Red-backed shrike Lanius collurio have documented consistent avoidance in spatial distribution in regard to predation risk and predator type over several breeding seasons, similar to our study results. Azure-winged magpies also built their nests further from the crow nest after high nest predation incidences within same breeding season, which suggests their plasticity to react quickly to predation risk. Until today, such rapid reaction to disperse within one breeding season is known to occur only in a few bird species, mostly with multiple broods, for example, Stonechats Saxicola torquata (Greig-Smith 1982), Prairie warblers Dendroica discolor (Jackson et al. 1989), Orange-breasted sunbirds Anthobaphes violacea (Gregoire and Cherry 2007), Grey fantails Rhipidura albiscapa (Beckmann et al. 2015), but absent in other species, for example, Wood thrush Hylocichla mustelina (Gow and Stutchbury 2013). Azure-winged magpies are capable for both proactive as well as rapid responses to predation events regarding breeding site selection.

\section{Temporary shift of breeding sites}

Azure-winged magpies relocated their breeding site temporarily in Khonin Nuga. Following year of the forest fire that diminished food source greatly (see chapter 2), four breeding pairs (including two pairs that failed in old site) separated from the rest of the 
breeding colony and established a sub-colony around one month later in a new breeding site which is approximately $1.2 \mathrm{~km}$ far from the old site in small pocket of the river basin unaffected by fire. We assume it was likely because of both food shortage and high nest predation risk due to lack of suitable nesting locations in old breeding site that forced some birds to seek out a new breeding site, though we cannot verify exactly which one was the main triggering cause. The dense bushes in the unburnt area likely provided protection that breeding pairs could not obtain from the old burnt breeding site. The following breeding season, 2011, all breeding pairs relocated to the new breeding site where they experienced $100 \%$ nest success, though it was not as suitable as old breeding site due to its considerably smaller size with much denser vegetation which may have been not large enough and not optimal for foraging. However, breeding group again divided between two breeding sites in 2012 and all returned to the old breeding site by 2013, the year old breeding site recovered and food availability had surpassed the food supply before forest fire in 2009 (see chapter 2). This short-term shift of breeding sites suggests that azure-winged magpies are able to respond towards sudden devastating changes in their environment. Although, most of the nest failure attributed to nest predation instead of nestling starvation, it is hard to argue that high predation risk due to lack of well concealed locations for the nests in old breeding site was the leading cause for the temporary breeding territory shift. Because breeding birds returned to the old breeding site even though they were enjoying less predation in new breeding site, especially in 2011 (nest predation rate, in old site: 48\% during 6 breeding seasons, in new site: $38 \%$ during 3 breeding seasons). Food shortage may increase a nest predation indirectly since breeding birds and helpers would have to spend more time for foraging thus likely reduce the nest attentiveness leaving nest vulnerable to the predation. (see Martin 1992a; Komdeur and Kats 1999; Rastogi et al. 2006). Therefore, we cannot rule out the predation risk from the possible cause of the breeding site shift not only because of possible reduced foraging time but also due to further away from the crow nest. On the other hand, only food 
shortage may have triggered it, but low predation could be an unexpected benefit of the better food source and further distance to crow nest in the new breeding site.

\section{Re-nesting}

Re-nesting within the same breeding season is a widespread anti-predator strategy in many bird species, especially in non-cavity nesting passerines (Jackson et al. 1989, Martin 1992a, Grzybowski and Pease 2005). Azure-winged magpies generally produce only one clutch each year (Cramp and Perrins 1994). Second brood after successful breeding is rarely recorded in Iberian population (Valencia et al. 2000), but second clutch after failure has been recorded in Japanese, Iberian and Mongolian populations of the azure-winged magpies (Komeda et al. 1987, Valencia et al. 2000, 2003, Canario et al. 2004, Bayandonoi et al. 2013). Re-nesting after unsuccessful attempt was common and effective anti-predator strategy in Mongolian azure-winged magpie population (over 54\% of the failed breeding pairs re-nested). It not only increases the probability of successful breeding in the same breeding season, but also allows birds to implement other strategies, such as nesting close to each other and forming subcolonies in the same breeding season and synchronization of nesting. Under high nest predation rate, birds should initiate later reproductive attempts in same season directly after failure of their first attempt (Segura 2011, Segura et al. 2012). Given that breeding season of the azure-winged magpies are relatively short in Mongolia due to adverse climate with short summer, between mid-May and late July, we thus expect that magpies should maximize their reproductive fitness by attempting to breed as quickly as possible after failure of first reproductive attempt. Indeed, most of the azure-winged magpies re-nested as short as 6-10 days following failure of their first reproductive attempts, thus they could be able to have more likelihood to increase their reproductive fitness during short breeding season. 


\section{Nest distance}

Likewise, increased nest concealment and synchronous nesting, birds from the Khonin Nuga breeding colony also optimized the strategy to nest closer to each other, over the years. These changes in anti-predator strategies imply that azure-winged magpies are able to learn from previous experiences and improve different strategies over long time periods. Although, there was a positive tendency from separate non-parametric analysis, the results from the GLM analyses on data from Khonin Nuga showed no effect on nest success from the nest distance. The outcome likely have resulted from the data fitting of the GLM analyses on nest success that each nest required single distance to other nests. Therefore, mean distance of each nest was used instead of every distance between nests. This approach has reduced a sample size greatly, thus may have curtailed the statistical power of the data on distances between nests. For that reason, we investigated the effect of nest distance on nest success and related behavioural responses in depth in chapter 4 using all distances between nests from all breeding colonies. As a result, true effect of the nest distance may have obscured from the GLM analyses on data from Khonin Nuga. We assume that nest distance also has a compound effect on nest success along with other factors, since it serves as a prerequisite condition to the behavioural responses along with the nest synchronization and differs by individual experience.

\section{Protector species}

The nest predation risk of the Songino colony was expected to have extremely high in 2014 given that three pairs of carrion crow and two resident common magpie, the main predators, have been much closer located to azure-winged magpie nests (see chapter 2). Azure-winged magpies from Songino seemed to be unable to defend their nest by themselves owing that all except four nests were lost to predation. Under those circumstances six breeding pairs from Songino-1 may have strategically chosen to nest close to a "protector" 
species to benefit from its aggressive anti-predator activities. Although, such association is common in birds (Greeney et al. 2015), benefits of this association is demonstrated only in few studies (Wiklund 1982, Ueta 1994, Blanco and Tella 1997, Bogliani et al. 1999, Greeney et al. 2015). In our case, the Amur falcon, known as a vicious nest defender during its breeding season, was the "protector" species. As a result of being neighbours with an aggressive raptor, four out of those six pairs had successful breeding attempts even though a nest of crow with three nestlings was just in 31-87 m distance. Although, it is observational record during one breeding season, it suggests that azure-winged magpies possibly are able to assess that the vigorous protection from the Amur falcon would prevent crows to prey on their nests even in close proximity of the crow nest. Same behaviour of the Japanese azure-winged magpie is studied extensively, where they associated with Japanese lesser sparrow hawks (Accipiter gularis) to reduce nest predation from Jungle crows (Corvus macrorhynchos) (Uchida 1986, Ueta 1994, 1998b, 2001, 2007). Studies from Ueta (1994, 1998, 2001) demonstrated that azure-winged magpies prefer to nest as close as possible to Japanese lesser sparrowhawk nests and those of closely located nests were more successful, less concealed and less defended by hosts themselves than further located nests. He concluded that magpies rely on "protector" species extensive nest defense, thus they even ignore their own nest concealment and greatly reducing nest defense activities. Whether it was accidental or intentional, those of six breeding females which built their nests right in vicinity of the Amur falcon nest laid their first eggs one to three days after the Amur falcon's first egg, which was highly synchronous. In general, azure-winged magpies lay first egg the same day or even before they complete inner soft line of their nest (Gantulga Bayandonoi, pers. observation). Interestingly, those of six nests were already completed 4 to 6 days before the first egg of the Amur falcon appears. It seems that the azure-winged magpies purposely waited for several days to synchronize their egg-laying with Amur falcon, which would maximize their nest protection from the Amur falcons, or to make sure that Amur falcons really occupy the old 
common magpie nest. Ueta (2001) found that Japanese azure-winged magpies also synchronize their incubation phase along with Japanese lesser sparrowhawk. To this point, handful of studies have empirical evidence suggesting that birds have the ability to assess advantages of this strategy and implement it accordingly (Ueta 1994, 1998b, 2001, Bogliani et al. 1999, Quinn et al. 2003, Bang et al. 2005, Mönkkönen et al. 2007).

\section{Behavioural responses}

Azure-winged magpies seem to respond differently against intruding crows based on their colony size and crow's behaviour. They reduced their mobbing rate when colony size is small and when crows vocalize during intrusion. The reason for changing their behaviour against predators is perhaps due to breeding colony structure, size and new breeding site (Gantulga Bayandonoi, unpubl. data). For example, there were no non-breeding individuals in 2011, except helpers. The role of non-breeders in chasing predators and guarding breeding site in previous years was lost. Shortage of recruits against predator would have increased breeding bird's extra mobility resulting increased unattended time at the nest and decrease the likelihood of successful eviction, which in turn may increase predation risk if breeding birds had showed same level of aggressiveness they used to in previous years. On the other hand, it may be because of $53 \%$ less intrusion rate of crows from previous years due to far located new breeding site from crow nest in 2011 that has allowed the magpies to reduce their alertness thus resulting low mobbing rate. Decreased mobbing from azure-winged magpies when crow vocalize during intrusion suggests that the azure-winged magpie may have an ability to assess an intention of the predators based on predator behaviour. The ignorance of the azure-winged magpies after the crow's nestlings left the nest suggests that crows are dangerous possibly only during their breeding season and azure-winged magpie could differentiate the danger from the crows in different periods of time. 
In summary, consistent adjustment on nest concealment, nest distance and avoidance from the main predator's nest over high predation risk years, proactive and rapid responses to the recent nest predation events on nest concealment, nest distance, nest synchronization, opportunistic exploitation of the protector species within breeding season, and breeding site changes of breeding colonies possibly to reduce nest predation, all of those results suggest the high adaptive and cognitive ability of the azure-winged magpies to deal with nest predation risk. Azure-winged magpies have highly flexible mechanisms to reduce predation based on their cognitive ability to assess predation risk and to implement complex anti-predator strategies adaptively according to the predation risk and predator type and over long time period. Some of those strategies are interrelated to each other that they can be the integral element of elaborated joint strategies. These anti-predator strategies not only decreased the nest predation rate but also improved the colony cohesiveness and promoted the cooperation.

\section{ACKNOWLEDGEMENTS}

We are grateful to the Khonin Nuga Field Station and Mongolian Ornithological Society for providing us with field equipment and logistic supports, students from the National University of Mongolia, the Mongolian State University of Education, the Mongolian University of Life Sciences, Georg-August University Goettingen, Jena University in Germany, Sterling College in USA for assistance in field work. This research has been made possible thanks to financial support from the German Academic Exchange Service (DAAD) and Mike Madder's Field Research Award. 


\section{CHAPTER 4}

\section{NESTING CLOSE TOGETHER AND SPLITTING IN SUB-COLONIES}

AS ADAPTIVE ANTI-PREDATOR STRATEGIES OF THE AZUREWINGED MAGPIE (CYANOPICA CYANUS PALLAS, 1776)

Gantulga Bayandonoi, Eckhard W. Heymann, Matthias Waltert, Peter M. Kappeler, Gombobaatar Sundev, Michael Mühlenberg 


\section{ABSTRACT}

Birds gain diverse advantages by breeding colonially or in colonies in regard to reducing nest predation. Although, edge effect, breeding colony size and clustered nests have received substantial investigation concerning nest predation, plasticity of the nest distance and its adjustment associated with varying predation risk is less known. We investigated the effect of nest distance on nest success of the azure-winged magpie, a flexible cooperative breeding species, and its flexibility on adjusting nest distances according to varying predation risks. We predicted that nest distance would be closer under high predation risk, since it facilitates efficient group responses against predators. Between 2007 and 2014, we examined four breeding colonies of the azure-winged magpie in northern Mongolia with varying predation pressures using non-parametric tests and GLM analyses. The best models from the GLM analyses demonstrated that both nest distance and sub-colony (nest clustering) formation have a positive effect on nest success. Nests from later formed sub-colonies after high nest predation incidences were much closer to each other and more successful than those from initial colony nests within breeding season. Moreover, nest distance was closer in years that have higher predation risk. These results reveal the notable plasticity of the azure-winged magpies in response to predation pressure by adjusting nest distances that resulted in higher nest success, thus it supports that predation can be one of the selective factors for group living.

Key words: nest predation, nest distance, nest clustering, sub-colony formation, azure-winged magpie, anti-predator strategy 


\section{INTRODUCTION}

In accordance with a predator type and its behaviour and habitat variety prey species have evolved two opposing anti-predator strategies that are aggregation and scattering (Saito et al. 2008). Decision to disperse and dispersing further than successful counterparts after experiencing nest predation is a common anti-predator strategy in solitary breeding birds (Greig-Smith 1982, Jackson et al. 1989, Powell 1998, Powell and Frasch 2000, Gregoire and Cherry 2007). Whereas, colonial breeding and group living birds may show opposing strategy, the aggregation, that can compensate the advantages of dispersion by increased vigilance, joint group defense, dilution and confusion effects that usually reduce the predation risk (reviewed in: Krause and Ruxton 2002; Caro 2005). Such effects may reduce predation at high nest density in group living birds if it increases the effectiveness of group responses (Wittenberger and Hunt 1985, Picman et al. 1988). Social groups of some species become increasingly compact and individual distance decreases in the presence of predators, suggests it has benefits (Lima and Dill 1990). There are nearly no studies (but see Hogstad 1995) that provide empirical evidence for that the birds assess and adjust their nest density and spacing of nests in accordance with nest predation risk and type of predators (Lima 2009). Highly mobile predators, such as corvids, gulls and canids, are more likely to exhibit density dependent nest predation, i.e. intensified search in an area where nest are detected, through their ability to detect and scan an area at large scale (Schmidt and Whelan 1999). Against such predators, group living birds should counter in two contrary ways depending on type of predators during high predation risk assuming that birds are capable of assessing nest predation risk and predator type. Firstly, similar to most solitary bird species, group living birds should space out their nests in case of nocturnal and large predators, when direct confrontation of host birds in group response is practically ineffective (Picman 1988). Spacing out would increase a search area and time for the predators and decrease the detection probability (e.g. Tinbergen et al. 1967; Treisman 1975; Gottfried and Thompson 1978; 
Chamberlain et al. 1995). Lastly, cohesive group living birds should space their nest in dense formation in case of evadable predators that host birds could succeed defending their nests in most cases by group response, assuming that advantages of the anti-predator strategies associated with neighbours overweight the disadvantages, particularly, the attraction of predators and density dependent nest predation (see Andersson and Wiklund 1978; Page et al. 1983; Wittenberger and Hunt 1985).

In this paper, we investigate the effect of nest distance and nest clustering on nest predation using data from four breeding colonies of the azure-winged magpie in Mongolia. We predict that the azure-winged magpies would decrease the distance between their nests under high predation risk, because the primary nest predators, corvids, can be evicted easily by group response, but not in individual response. If there is such a relationship, we may also expect that nest clustering would appear within breeding territory (see Hirsch and Morrell 2011). Since predation is the main cause of nest failure in great majority of the bird species (Ricklefs 1969), it is potentially one strong selective factor for group living as it allows birds to implement a variety of anti-predator strategies in association with conspecifics (Martin 1988). Under high predation risk we would expect increased cohesiveness between individuals in the same group.

\section{METHODS}

\section{Study area and breeding colonies}

The study was carried out on four breeding colonies of the azure-winged-magpie, namely Khonin Nuga (KhN), Sugnugur (SUG), Songino-1 and Songino-2 breeding colonies (together SON, separately SON-1 and SON-2) along the Yuruu $\left(49^{\circ} 05^{\prime} \mathrm{N}, 107^{\circ} 17^{\prime} \mathrm{E}\right)$, Sugnugur $\left(48^{\circ} 40^{\prime} \mathrm{N}, 106^{\circ} 91^{\prime} \mathrm{E}\right)$ and Tuul $\left(47^{\circ} 86^{\prime} \mathrm{N}, 106^{\circ} 69^{\prime} \mathrm{E}\right)$ river basins respectively in West Khentii, northern Mongolia. We studied the Khonin Nuga breeding colony between 2007 and 2014 and the rest of the breeding colonies in 2013 and 2014 breeding seasons (see description 
of the breeding colonies in detail from Chapter 2). The breeding season of the azure-winged magpie in northern Mongolia starts mid-May and ends around mid-July. The climate in northern Mongolia is continental with hot summers and cold, severe winters with average annual temperature of $0.7^{0} \mathrm{C}$ (von Velsen-Zerweck 2002). Generally, habitats of the breeding colonies are similar to each other and include open river flats, riparian woodland and scrubland (see habitat description in detail from chapter 2).

\section{Nest predators}

We considered a species as a main nest predator if: (1) we observed predation on the nest; (2) detected species-specific clues around preyed nests; (3) azure-winged magpies responded aggressively to this species around their breeding territory (see details in chapter 2). A pair of carrion crow was the main predator in the Khonin Nuga breeding colony during the eight-year study period (see chapter 2). Common magpies and carrion crows were the main nest predators at Songino breeding colonies (see details from chapter 2), except 2013 in Songino-1 where unidentified mammalian (likely a species of Mustelidae) was the sole predator. Although potential terrestrial and avian predators from corvids and raptors were common in Sugnugur area, there was no defined main predator in Sugnugur breeding colony. We regarded predation risk as low in 2014 and high in 2013 in Sugnugur based on distance to the human settlement that provides large number of resident corvids. The human settlement was closer in 2013 (approx. $0.4 \mathrm{~km}$ ) and further in 2014 (approx. $2.5 \mathrm{~km}$ ). We considered predation risk as highest in Songino, intermediate in Khonin Nuga and lowest in Sugnugur based on predator intrusion rate and number of resident predators for the 2014 breeding season (see in detail from chapter 3). Predation risk was lower in 2013 than 2014 in Songino-2 because of lack of resident predators near the breeding site (see chapter 3), whereas, predation risk in Songino-1 was high in both breeding seasons (see chapter 2). In case of Khonin Nuga, we regarded predation risk not by breeding seasons due to presence of the same pair of carrion crow, 
the main nest predator, during entire study period. Instead, we differentiated the predation risk by new and old breeding sites because of further location of new breeding site from the carrion crow nest which was assumed to have less risk of predation. Beside direct observation records, we also considered nests as being preyed when entire clutches or broods disappeared in one day and clues of predators or remains of nestlings were found at or nearby the nest. We used a term "high nest predation" for the incidences that more than half of the current nests are lost to predators in less than two weeks at the onset of the breeding seasons in breeding colonies. Such incidences occurred in all breeding colonies during most of the year except during 2011 and 2013 in Khonin Nuga, 2013 in Songino-1 and 2014 in Sugnugur. These incidences were always followed by new sub-colony formation (nest clustering) by late breeders and second attempt-breeders at relatively far distances and/or different time periods from the initial colony or another newly formed sub-colony.

\section{Data collection and analyses}

We located nests by searching the breeding sites once in every three days during the egg-laying and the incubation stage, and more intense directly after nest predation incidences to check for second nesting attempts. We measured the distance between azure-winged magpie nests (ND) using GPS coordination of each nest in all four breeding colonies. We recorded mobbing behaviour of the azure-winged magpie towards nest predators and number of defenders during chasing predators from the $1084 \mathrm{~h}$ of nest observation at the nests in all breeding colonies (see detailed method from chapter 2).

We combined data from Songino-1 and Songino-2 breeding colonies, except for analyses on nest distance between years and sub-colonies within year, because of their similarities due to several reasons: being essentially in the same habitat, being located close to each other (nearest nest distance of two colonies was $320 \mathrm{~m}$ apart), timing of breeding, same set of predator individuals and frequent individual movements between colonies. The Mann- 
Whitney $U$-test (MWU) was used to test difference in relative distances (RD) between initial and later formed colony/sub-colonies within breeding season in all breeding colonies. Relative distance of each nest to other nests was preferred over actual distances (ND) to account for variations between breeding seasons, which might have occurred due to adaptation against nest predators, and different habitats of new breeding site in some years (see chapter 2). In order to acquire relative distance, we averaged all ND from each colony and from all breeding seasons, but separately in old and new breeding sites in case of Khonin Nuga, to obtain mean distance of each breeding season and total mean distance. Total mean distance was then regarded as a mean distance of each breeding season. Thus, we can separate variations between breeding seasons and breeding sites from the variation of the nests from initial and late colony/sub-colonies, while retaining the proportional variation between nests. Afterwards, we corrected ND of each nest by difference between mean distances in each breeding season and total mean distance to calculate RD of each nest. Breeding seasons without sub-colony establishment were omitted from the analyses to test difference between initial and later formed colony/sub-colonies within breeding seasons. Mean distances of each nest to neighbouring nests were used only to test nest distance differences between breeding colonies. We tested differences in nest success between initial and later formed sub-colonies using Fisher's exact test.

We performed GLM analyses using the glm function of the R-package "lme4" (Bates et al. 2015) with Gaussian distribution in $\mathrm{R}$ (version 3.3.0) on data from all breeding colonies to reveal any compound effects on nest success and nest distance by using ND. For the GLM analysis on nest success, we considered the breeding colony (BC), initial and later formed sub-colonies within breeding season (SC), breeding season (BS), distance between nests (ND) as explanatory variables for the response variable, nest success (NS). For the GLM analysis on nest distance, we considered $\mathrm{BC}, \mathrm{SC}$ and $\mathrm{BS}$ as explanatory variables for the response variable, ND. Akaike Information Criterion (AIC) was used to rank the models. We did multi- 
model inference in the full set of models using MuMIn-package (Bartoń 2016) in R, considering that best approximating models ranked by AIC cannot explain the results solely in our analyses because of lower Akaike weight $\left(\Delta_{i}\right)$ than the recommended threshold value of $0.9 \Delta_{i}$ (Burnham and Anderson 2002, Lukacs et al. 2010, Symonds and Moussalli 2011). All nest distances of the nests that failed due to other causes except nest predation were excluded from the analyses. For all analyses, significance levels were set at 5\% and means are reported \pm 1 SD unless otherwise stated.

\section{RESULTS}

\section{Effects from the predation risk on nest distance}

Nests were much closer to each other in the new breeding site in Khonin Nuga which is approximately 12 times smaller in size (approx. $0.005 \mathrm{~km}^{2}$ ) and located roughly 2.5 times further (approx. $1150 \mathrm{~m}$ ) from the carrion crow nest than the old site, thus regarded as low predation risk site (mean RD in old site: $81 \pm 55 \mathrm{~m}$; in new site: $36 \pm 21 \mathrm{~m}$; MWU, $U=855, n_{1}=156, n_{2}=24$, $P<0.00002)$. Sugnugur breeding colony has experienced relatively high nest predation in high predation risk year, 2013 (45\% higher than in the following year). The following year, the breeding colony moved their breeding site $2.1 \mathrm{~km}$ far from the old site, further away from the human settlement, where few numbers of corvids were present. There was no difference between breeding seasons in regard to nest distances in Sugnugur, though nests were slightly closer to each

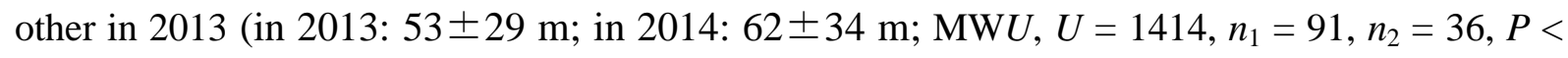
0.23). Nests from Songino-2 breeding colony were considerably closer to each other in 2014 , a year with high nest predation risk, compared to nests in 2013 (in 2013: 49 $\pm 30 \mathrm{~m}$; in 2014: $\left.33 \pm 19 \mathrm{~m} ; \mathrm{MW} U, U=4324, n_{1}=165, n_{2}=76, P<0.0001\right)$. All but one nest were lost in the same night to an unidentified predator (likely mammalian) in the Songino-1 breeding colony in 2013. 
Birds built their nests closer to each other in 2013 than 2014 in Songino-1 (in 2013: 29 \pm 19 m; in 2014: $42 \pm 25 \mathrm{~m}$; MWU, $\left.U=190, n_{1}=36, n_{2}=28, P<0.00002\right)$.

\section{Nest clustering in sub-colonies}

Nests in later established sub-colonies were much closer to each other than nests from initial colony that is preyed upon heavily in all breeding colonies (Table 7, 8). Moreover, distances between nests were considerably different between breeding seasons, while it was not between breeding colonies (Table 7. 8).

Table 7 Results of the best-ranked models of the distance between nests within $\Delta i<2$ range and full average of the full set of models. $k$ number of parameters , $\Delta i$ difference between the $\mathrm{AIC}_{\mathrm{c}}$ value of the best model and the $\mathrm{AIC}_{\mathrm{c}}$ of the $i$ model, $\mathrm{w}_{i}$ Akaike weight indicating the relative support for each of the $i$ model, acc $\mathrm{w}_{i}$ cumulative Akaike weight, ER evidence ratio. Sample size is 388 nest distances from the four breeding colonies

\begin{tabular}{llllllllllll}
\hline Rank & Best models & $\mathrm{SC}$ & $\mathrm{BS}$ & $\mathrm{BC}$ & $k$ & $\operatorname{logLik}$ & $\mathrm{AIC}_{\mathrm{c}}$ & $\Delta i$ & $\mathrm{w}_{i}$ & $\mathrm{acc}_{i}$ & $\mathrm{ER}$ \\
\hline & Full average & -28.18 & -9.12 & 0.46 & 5 & & & & & & \\
1 & & SC+BS & -28.13 & -8.96 & & 4 & -1995.75 & 3999.6 & 0 & 0.73 & 0.73 \\
2 & SC+BS+BC & -28.35 & -9.76 & 2.17 & 5 & -1995.71 & 4001.6 & 1.98 & 0.27 & 0.99 & 2.69
\end{tabular}

SC - sub-colonies (initial colony at the beginning of the breeding season vs. later established sub-colonies in same breeding season), BS - breeding season, BC - breeding colony

Table 8 Distance between nests: result from the GLM models, All-Subset average estimates of the models within $95 \%$ confidence set. Sample size is 388 nest distances from the four breeding colonies

\begin{tabular}{llllll}
\hline Parameters & Estimate & Std. Error & Adjusted SE & z value & $\operatorname{Pr}(>|\mathrm{z}|)$ \\
\hline (Intercept) & 118.70 & 5.84 & 5.86 & 20.25 & $0.000 * * *$ \\
Initial vs. later sub-colony(s) & -28.18 & 4.66 & 4.67 & 6.03 & $0.000 * * *$ \\
Breeding season & -9.12 & 1.96 & 1.97 & 4.63 & $0.000 * * *$ \\
Breeding colony & 0.46 & 4.58 & 4.59 & 0.10 & 0.92 \\
\hline
\end{tabular}


As shown in GLM analyses, nests from later formed sub-colonies were significantly closer to each other than initial colony nests in Khonin Nuga and Sugnugur from the separate analyses (mean RD in $\mathrm{KhN}$, initial nests: $95 \pm 58 \mathrm{~m}$, later nests: $53 \pm 39 \mathrm{~m}, \mathrm{MW} U, U=1478$, $n_{1}=91, n_{2}=59, P<0.000003$, Fig. $10 \mathrm{~A}$; mean ND in SUG, initial nests: $69 \pm 31 \mathrm{~m}$, later nests: $42 \pm 21 \mathrm{~m}, \mathrm{MW} U, U=78, n_{1}=21, n_{2}=15, P<0.011$, Fig. 10B), but not in Songino-2 (mean RD, initial nests: $43 \pm 27 \mathrm{~m}$, later nests: $36 \pm 21 \mathrm{~m}, \mathrm{MW} U, U=4377, n_{1}=186, n_{2}=55, P<$ 0.10, Fig. 10C). Sub-colonies were formed in Songino-1 only in 2014, though initial colony nests consisted of only two nests which were not sufficient for the analysis.
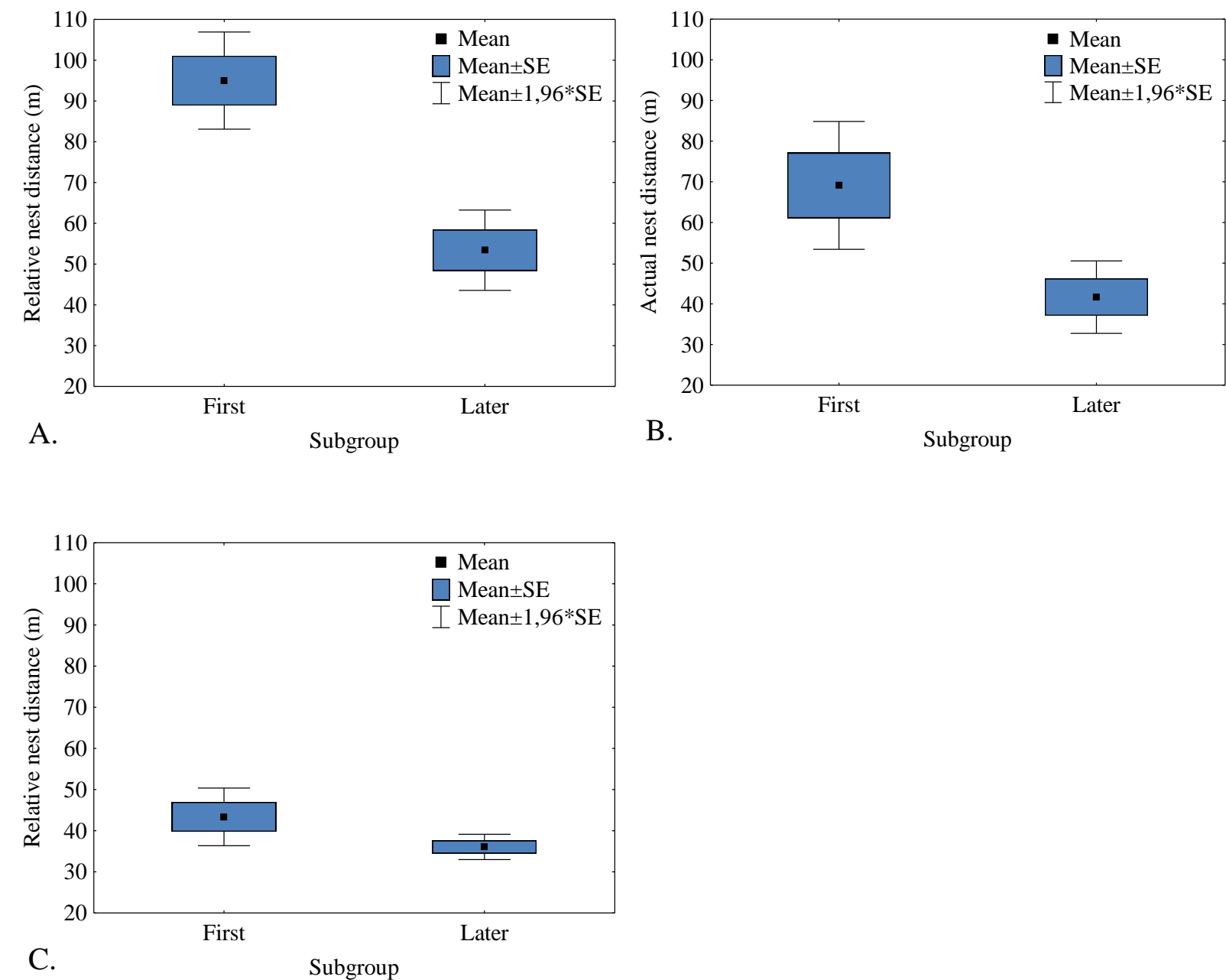

Figure 10 Difference between nest distances of the nests from initial and later formed colony/sub-colonies in Khonin Nuga (A), Sugnugur (B) and Songino-2 (C) breeding colonies. 
Nests from Songino breeding colonies were closest to each other compared to other two breeding colonies during last two breeding seasons (mean ND, SON: $39 \pm 18 \mathrm{~m}, \mathrm{KhN}$ : $62 \pm 28 \mathrm{~m}$, SUG: $58 \pm 18$ m; MWU, SON vs. KhN: $U=268, \mathrm{n}_{1}=64, \mathrm{n}_{2}=18, P=0.0006 ;$ SON vs. SUG: $U=$ $\left.319, \mathrm{n}_{1}=64, \mathrm{n}_{2}=27, P=0.000002\right)$.

\section{Effects from nest distance on nest success}

Nests from later formed sub-colonies were less affected by predation than nests from initial colonies (nest success rate, initial nest: $17 \%, \mathrm{n}=50$; later nests: $17 \%, \mathrm{n}=59$; Fisher's exact test: $P=0.0017)$.

GLM analysis using ND within colony/sub-colonies revealed that both nest distance and nesting in sub-colonies had an effect on nest success (Table 9, 10). Breeding season also had an effect but not significantly so, while breeding colonies had no effect on nest success.

Table 9 Results of the best-ranked models of the effect of distance between nests on nest success within $\Delta i<2$ range and full average of the full set of models. $k$ number of parameters, $\Delta i$ difference between the $\mathrm{AIC}_{\mathrm{c}}$ value of the best model and the $\mathrm{AIC}_{\mathrm{c}}$ of the $i$ model, $\mathrm{w}_{i}$ Akaike weight indicating the relative support for each of the $i$ model, acc $\mathrm{w}_{i}$ cumulative Akaike weight, ER evidence ratio. Sample size is 544 nest distances from the four breeding colonies

\begin{tabular}{|c|c|c|c|c|c|c|c|c|c|c|c|c|}
\hline Rank & Best models & ND & $\mathrm{BC}$ & $\mathrm{SC}$ & $\mathrm{BS}$ & $k$ & logLik & $\mathrm{AIC}_{\mathrm{c}}$ & $\Delta i$ & $\mathrm{w}_{i}$ & $\operatorname{acc~}_{i}$ & ER \\
\hline & Full average & -0.001 & 0.011 & 0.128 & 0.022 & 6 & & & & & & \\
\hline 1 & $\mathrm{ND}+\mathrm{SC}+\mathrm{BS}$ & -0.001 & & 0.139 & 0.024 & 5 & -347.295 & 704.7 & 0.00 & 0.58 & 0.58 & \\
\hline 2 & $\mathrm{ND}+\mathrm{BC}+\mathrm{SC}+\mathrm{BS}$ & -0.001 & -0.015 & 0.148 & 0.027 & 6 & -347.267 & 706.7 & 1.99 & 0.21 & 0.80 & 2.71 \\
\hline
\end{tabular}


Table 10 Effect of distance between nests on nest success: result from the GLM models, All-Subset average estimates of the models within $95 \%$ confidence set. Sample size is 544 nest distances from the four breeding colonies

\begin{tabular}{lccccc}
\hline Parameters & Estimate & Std. Error & Adjusted SE & $\mathrm{z}$ value & $\operatorname{Pr}(>|\mathrm{z}|)$ \\
\hline (Intercept) & 0.298 & 0.104 & 0.104 & 2.863 & $0.004^{* *}$ \\
Distance between nests & -0.001 & 0.001 & 0.001 & 2.881 & $0.004^{* *}$ \\
Sub-colony within breeding season & 0.130 & 0.057 & 0.057 & 2.289 & $0.022^{*}$ \\
Breeding season & 0.022 & 0.012 & 0.012 & 1.749 & 0.080. \\
Breeding colony & 0.011 & 0.050 & 0.050 & 0.222 & 0.824 \\
& & & & & \\
\hline
\end{tabular}

Separate analyses on each breeding colony showed that successful nests were located closer to neighbouring nests in Khonin Nuga and Sugnugur, though not in Songino where the breeding seasons with $100 \%$ predation rate are excluded (MWU, in SUG, preyed: $67 \pm 36 \mathrm{~m}$, successful: $53 \pm 26 \mathrm{~m}, U=6377.5, n_{1}=135, n_{2}=119, P<0.0005$; in $\mathrm{KhN}$, preyed: $81 \pm 53 \mathrm{~m}$, successful: $62 \pm 44 \mathrm{~m}, U=13059, n_{1}=198, n_{2}=172, P<0.0001$; in SON, preyed: $49 \pm 35 \mathrm{~m}$, successful: $\left.47 \pm 27 \mathrm{~m}, U=2763, n_{1}=152, n_{2}=37, P<0.87\right)$.

\section{Number of defenders}

Mean number of azure-winged magpies that successfully evicted the predators, mostly corvids ( $90 \%$ of the predators), were $5.7 \pm 3.3$ individuals $(n=88)$ during breeding season in all breeding colonies. In total, $83 \%$ of the mobbing cases were required three or more individuals during chasing part of the defense behaviour, not including individuals involved in defense that did not join in chasing. 


\section{DISCUSSION}

\section{Nest distance in respect to the predation risk and predator types}

Birds often apply different anti-predator strategies to reduce predation rate effectively depending on predator type and its behaviour (Kruuk 1964, Hoogland and Sherman 1976, Brunton 1997). Anti-predator strategies can be complex interrelated strategies that one strategy may serve as a condition for the other one (chapter 3). If birds are able to deter specific nest predators successfully in most cases by colony response, such as carrion crow and common magpie, nesting close to each other would clearly improve the nest defense by defending their nests together in large numbers. Indeed, a single pair of azure-winged magpie appears not to stand against carrion crow during confrontation, instead they keep distance (Gantulga Bayandonoi, personal observation). Concerning our results, it seems at least three to five individuals of the azure-winged magpie are required for successful eviction of the predators, mostly carrion crows, in breeding colonies. Thus, closer neighbours who could respond and gather quickly to assemble minimum number of birds to inhibit predators are crucial for the successful defense under circumstances that predation happens within few seconds. This condition necessitates birds to stay close to each other and respond cooperatively against predators, which in turn enhances cooperation and nest success (see Krams et al. 2010). Krams et al. (2009) found that mobbing behaviour of the host Pied Flycatcher (Ficedula hypoleuca) intensified when number of defending conspecifics increases suggesting that birds become more confident, perhaps due to dilution and confusion effects. In our study, nests were consistently closer to each other in years that are assumed to have higher predation risk in three breeding colonies, whereas it was not the case in Khonin Nuga. Old and new breeding sites were preferred over breeding seasons in Khonin Nuga because the main nest predator, the same pair of crow, was present during entire study resulting less variation in predation risk, while the new breeding site was considerably far from the crow nest and low frequency of intrusion by crows indicated low predation risk (see chapter 2). We could justify the 
result from Khonin Nuga based on specific conditions of the breeding sites. New breeding site in Khonin Nuga was much smaller with dense vegetation than the old site that may have allowed and/or strained birds to nest closer to each other in confined area regardless of the predation risk. Nesting in same distance like in new site is practically impossible in old site due to relatively sparsely located suitable bushes and trees, thus limiting the strategy. Nesting close to each other could improve nest defense (Krebs and Davies 1978), but it also could attract specific predators more due to density of birds around nests and more detectability for the close nests by predators, thus predation may be higher (Andersson and Wiklund 1978, Hogstad 1983, 1995, Page et al. 1983, Martin 1988). In Sugnugur, Songino-1 and Songino-2 breeding colonies, breeding birds suffered highest rate of nest predation in years where nests were close to each other in each breeding colonies (SUG: $81 \%$ in 2013, SON-1: $100 \%$ in 2013, SON-2: $100 \%$ in 2014, see chapter 3). We assume that the outcome is probable because of the response from the neighbouring azure-winged magpies against predators was here not enough to prevent nest predation effectively under the high pressure from predators in Sugnugur (large number of corvids associated with nearby settlement) and exceptionally high pressure (three neighbouring pairs of carrion crow and two common magpies, see chapter 3) in Songino-2. Whereas, it may have given an advantage to the specific predator to locate nests easily, since nests are close to each other. Nest distances were closest in Songino-1 (28.8 $\pm 19.4 \mathrm{~m})$ in 2013 in comparison to all other breeding colonies during eight-year study, possibly due to their breeding habitat which is a small patch of densely located bushes and trees. As a result, nests are assumed to be more vulnerable to the density dependent and olfactory oriented predators. All nests, except one, were destroyed (mostly inner line of the nests) in the same night from the Songino-1 in 2013. That lone surviving nest was isolated 2.5 times far from the average distance of other nests at the edge of the breeding site and located at the main stem in upmost position differing to any other nest, which would make it difficult to locate and to reach by mammalian predators. Although avian predators were common, the 
scenario strongly suggests that the predator was not a bird, but likely a terrestrial species, most likely a mustelid, because several mustelid species are common in the area and they are known to hunt during night and are more olfactory oriented hunters (Zielinski 2000). It is uncertain whether azure-winged magpies had cues to assess predation risk of that particular predator. In that particular case in Songino-1, nesting close to each other was likely not a suitable strategy against nocturnal and terrestrial predators like mustelids. Nests from the Songino-2 breeding colony had occupied almost every neighbouring tree leaving no more opportunity to nest closer to each other during exceptionally high predation pressure in 2014 . Up to now, there is no record of more than one active nests of the azure-winged magpie at the same tree during our eight-year study period. It seems imperative that pairs occupy the tree by themselves alone. Distance between nests were much closer in Songino breeding colonies than other two breeding colonies showing that the strategy, nesting close to each other, was already implemented in best possible way in Songino. Moreover, birds from the Khonin Nuga breeding colony also enhanced the strategy, nesting close to each other, over years (see chapter 3).

\section{Effect of nest distance on nest success}

Our result showed that closer clustered nests were less likely to be preyed upon by predators than further located nests in all breeding colonies. Although, this result has not taken into account of other factors which had strong effect on nest success, for example, in case of Khonin Nuga (see chapter 3), it would still suggest that birds benefit from closer neighbours under high nest predation pressure concerning evadable nest predators. Similar results were documented in several species and simulation approaches, for example, in Redwinged blackbird (Agelaius phoeniceus) where breeding birds with closer conspecific neighbours were more effective defending their nests against March wrens (Cistothorus palustris), the main predator (Ritschel 1985, Picman et al. 1988); in waterfowl nests (mostly Mallard Anas platyrhynchos and Gadwall Anas strepera) where nest survival appear to 
increase when nearest-neighbor distances are short (Ringelman et al. 2012), and from the simulation model of Hirsch and Morrell (2011) which predicts that nest predation would decrease as nest density increases. This strategy is also widespread in colonial breeding seabirds, in most cases resulting in lowered nest predation (e.g. Hill et al. 1997; Phillips et al. 1998; Hötker 2000; Forster and Phillips 2009).

\section{Effect of nest clustering in sub-colonies}

Distinct cluster of territories (breeding pairs) can be seen as an anti-predator strategy that birds could benefit from presence of neighbours (Lima 2009). The study on least flycatcher (Empidonax minimus) from Perry \& Andersen (2003) showed intriguing results that supported the hypothesis of predator deterrence where predation led to the territory clustering. In this study, clustered birds responded towards predators with more intense alarm calls and quicker in large numbers than outside birds, consequently, less predators were detected inside the cluster than outside. As a result of joint responses, the interior nests in that cluster territories were more successful than nests at the edge of clusters (Perry et al. 2008), though Tarof \& Ratcliffe (2004)'s later work on the same species, but different population, did not reveal any benefits from the territory clustering in lowering the nest predation. Similarly to the study on Least flycatchers from Perry \& Andersen (2003), azure-winged magpies from our study consistently showed nest clustering that resulted in formation of sub-colonies after high nest predation incidences. The parameters, sub-colonies within breeding season (clustered nests in terms of the distance and time period) and nest distance were the part of the effective anti-predator strategies that possibly have enhanced nest defenses in combination with other strong factors. Even though parameters appeared to be not important to the nest success from the GLM analyses of the Knonin Nuga breeding colony from the results in chapter 3 , it is possibly the result of combined effects because nesting close to each other is a prerequisite condition that facilitates joint behavioural responses against predators and data 
treatment that averaged nest distance for each nest may have greatly reduced the statistical power of the nest distance data. The GLM analyses using every distance between nests in this paper, instead of average distance for each nest used in chapter 3, revealed that nesting closer and forming sub-colonies had a positive effect on nest success. Our results answer the question from Lima (2009) "Do birds assess the local risk of predation and space their nests relative to each other such that this risk is lowered?". Azure-winged magpies indeed space their nests relative to each other depending on predation risk. In all three breeding colonies in every breeding season, nests were persistently closer located to each other in later sub-colonies that established directly after high nest predation incidences than nests from initial colony within breeding season. These results strongly suggest that birds are highly flexible in implementing the strategy by adjusting the nest distances swiftly and clustering their nests in response to current predation risk. This strategy, in fact, resulted in low nest predation. This adaptive response was observed not only within breeding season, but also over years (see chapter 3). Hamilton (1971) proposed that animal clustering is evolved in favour of reducing predation by implementing a variety of anti-predator strategies in association with neighbours. Forming sub-colonies by building nests in cluster could reduce the cost of guarding and vigilance per individual (Birkhead 1977, Hoogland 1981, Brown 1987, Jungwirth et al. 2015), and further reduces the detection time of predators (Hoogland and Sherman 1976, Brown and Brown 1987, Møller 1987) and decreases the predator's anticipation due to lack of surprise elements (Curio 1978, Hasson 1991), and increases the probability of successful eviction through large number of recruitments in rapid deployment against predators (e.g. Perry and Andersen 2003). Active nest defense is costly, such as mobbing (Montgomerie and Weatherhead 1988, Brunton 1990, Krams et al. 2007), thus birds should adapt anti-predator strategies that would allow them to reduce energetic cost while maintaining optimal number of recruits for the effective nest defense in case of specific predator. If predator can be evicted without requiring large number of recruits in defense, active involvement of birds in large numbers against 
predators may not only have energetic consequences but also it could concentrate the defenders in small area while increasing risk of predation on rest of the breeding territory. Nest clustering and formation of sub-colonies could be the most effective anti-predator strategies to deal with such condition, where birds from clustered nests (closely located) can defend their nest much faster and effectively in association with neighbours without suffering high energetic cost and time for defense of far located nests while leaving their own nest unguarded. In our study, sub-colonies functioned as an independent unit that breeding birds foraged separately by sub-colonies (Gantulga Bayandonoi, personal observation), which may enhance foraging efficiency and minimize travelling time (Marzluff and Balda 1992). The sub-colony also increases the time for nest attendance, and generally responded against intruders disjointedly. Its members also appeared to restrict their defensive behaviour to the vicinity of their own sub-colony. For instance, carrion crow was chased from the vicinity of first post-fire sub-colony in 2009 by the azure-winged magpies belonged to same sub-colony in Khonin Nuga. As the crow approaches the second post-fire sub-colony the birds stopped chasing the crow, in replace, birds from second post-fire sub-colony met with crow and took over the chase. We observed dozens of similar independent responses from sub-colonies towards predators throughout the breeding seasons in all breeding colonies. Although, we didn't measure cohesiveness, high predation risk appeared to strengthen colony cohesiveness and cooperation by nesting close to each other and forming sub-colonies, which in turn facilitated synchronous foraging and rapid and coordinated defense responses.

In summary, our results revealed the remarkable plasticity of the azure-winged magpies in response to varying predation risks by adjusting nest distances and forming subcolonies that resulted in low nest predation. Results also suggests that azure-winged magpies have substantial cognitive ability to assess predation risk based on recent predation events and adopt suitable strategies accordingly. The effect of predation risk on strengthening cooperation and colony living via decreased nest distance and nest clustering implies that it 
might be the substantial selective factor to explain the evolution of cooperation along with other traits.

\section{ACKNOWLEDGEMENTS}

We are grateful to the Khonin Nuga Field Station and Mongolian Ornithological Society for providing us with field equipment and logistic supports, students from the National University of Mongolia, the Mongolian State University of Education, the Mongolian University of Life Sciences, Georg-August University Goettingen, Jena University in Germany, Sterling College in USA for assistance in field work. This research has been made possible thanks to financial support from the German Academic Exchange Service (DAAD) and Mike Madder's Field Research Award. 
Chapter 4 


\section{CHAPTER 5}

SUMMARY OF THE MAIN FINDINGS AND CONCLUSION 


\section{SUMMARY OF THE MAIN FINDINGS AND CONCLUSION}

In this study, I investigated the proximate mechanisms underlying an expression of the helping behaviour by examining feeding rate and frequency of helpers under varying food availability and predation risk in different breeding colonies (see chapter 2). Many hypotheses have developed to explain the underlying mechanisms of the cooperative breeding. However, it appears to have no single hypothesis that can explain it, instead several hypotheses can be applied for the evolution of cooperative breeding. The kin-selection, life-history and ecological constraints hypotheses are widely accepted, though none of them can explain the evolution of the cooperative breeding exclusively.

The nest predation hypothesis was underlined because the main cause of nest failure among cooperative breeding birds is nest predation (Brown 1987, Stacey and Ligon 1991), suggesting its potential selective factor for evolution of cooperative breeding (Poiani and Pagel 1997). Yet, not much empirical evidence has been found to support it. I could show that both low food availability and high predation risk increase the benefits of helping behaviour, thus they lead to expression of the helping behaviour. Our findings support the nest predation hypothesis that high nest predation pressure over ecological time favours the cooperative breeding (see Poiani and Pagel 1997). However, nest predation hypothesis cannot explain the evolution of cooperative breeding solely, it is one of the selective factors that work in conjunction with other selective factors such as ecological constraints and kin-selection.

Helpers at the nest have long been assumed to increase nestling survival through enhancing nestling's body condition. But in last two decades many studies have documented for some species that helpers at the nest appear to reduce nest predation (e.g. Austad and Rabenold 1985, Emlen and Wrege 1991, Mumme 1992, Schaub et al. 1992, Innes and Johnston 1996, Boland 1998, Valencia et al. 2003, Hatchwell 2004). The data on nestling 
body mass, nest attentiveness and egg-laying period along with observational records of helpers' active involvement in nest defense in this study showed that helpers improved nestling condition and reduced chick rearing time period at the nest, which both in turn reduce nest predation (see chapter 2). Therefore, helping behaviour appeared to be an effective antipredator strategy since it reduces nest predation substantially (see chapter 2 and 3). Besides that, our findings revealed several other anti-predator strategies that azure-winged magpies employ under high predation risk. Greater concealment of the nest, proactive avoidance of the nest location from the predator nest along with involvement of helpers at the nest were the most effective anti-predator strategies in our study (see chapter 3).

Although, nest concealment is arguably the widespread anti-predator strategy not only for birds but for many other animal groups, most field studies found no evidence of which nest concealment reduced nest predation (reviewed by Borgmann and Conway 2015). Borgmann and Conway (2015) concluded that lack of evidence of nest-concealment hypothesis, i.e. birds prefer nest sites enclosed by dense foliage to reduce the likelihood of detection by predators and brood parasites (Martin et al. 1988, Martin and Li 1992), in large quantity of studies largely caused by morphological traits and methods used to measure concealment which in turn likely resulted in lack of support. Benefits through nest concealment may be traded-off by consequences associated with greater concealed nest site (Morosinotto et al. 2010, Borgmann and Conway 2015) or compensated by active defense in some bird species (Götmark et al. 1995, Cresswell 1997, Weidinger 2002, Remeš 2005, Fontaine and Martin 2006a). Thus, other anti-predator strategies may have cancelling effect on nest concealment, leading to lack of support of nest-concealment hypothesis. But my study with the comprehensive analyses of several factors which may affect nest predation showed strong support on nest-concealment hypothesis (see chapter 3).

Crows are the well-known nest predators in many avian species (Shields and Parnell 1986). Some studies revealed that the nest predation rate increased as nest distance of prey 
species decreased to the crow nest (Shields and Parnell 1986, Sullivan and Dinsmore 1990). In this study, I found that azure-winged magpies consistently tried to avoid spatially the crow nests both within and between breeding season and those of distant nests were preyed much less than nests closer to the crow nest (see chapter 3). Moreover, breeding pair experience appeared to reduce nest predation as well. So far, very little work exists regarding the effect of individual experience on nest predation. In this study, pair experience largely appeared to affect decision to build the nest closer to colony neighbours, which indeed reduced nest predation through joint nest defense of neighbouring birds (see chapter 3 ).

Individuals may respond by two opposing ways regarding nest density of both conspecifics and interspecifics in response to predator type. In case of evadable predators, collective nest defense of neighbours often increases the success of their common predators' eviction, thus, individuals are expected to nest closer to each other. Also other studies showed that nesting in high density resulted in decreased nest predation (Ritschel 1985, Picman et al. 1988), though much work is needed to understand what factors affect the decision whether to space out or space in their nests. The data on nest distance in this study indicated that azurewinged magpies prefer to nest closer to each other, probably to gain anti-predator benefits from neighbours (see chapter 4). Azure-winged magpies decreased distance between their nest in accordance with predation risk and nest closer to each other were more successful than nests further apart located (see chapter 4). It leads to nest clustering and independent subcolony formations in terms of nest defense activities. Distinct clustering may have evolved as means of reducing predation to facilitate variety of collective defenses of neighbours and it can be regarded as proactive anti-predator strategy (Hamilton 1971, Lima 2009). Nest clustering may have several benefits: by reducing per individual vigilance and time spent for it (Birkhead 1977, Hoogland 1981, Brown 1987, Jungwirth et al. 2015), by increased detectability of predators (Hoogland and Sherman 1976, Brown and Brown 1987, Møller 1987), by decrease of the predator's incentive (Curio 1978, Hasson 1991) and by increase of 
the likelihood of successful defense (e.g. Perry and Andersen 2003). Very little studies found an empirical evidence for the predator deterrence hypothesis that predation promotes the nest clustering (Perry and Andersen 2003, Perry et al. 2008). Our findings that closer nests and later formed cluster nests experienced less predation support the predator deterrence hypothesis (see chapter 4).

Our findings demonstrated that azure-winged magpies have high cognitive capacity to assess predation risk in short time period. It was also shown that azure-winged magpies have a plasticity to execute complex and appropriate anti-predator strategies immediately after the nest predation events in accordance with changing predation risk and predator type (see chapter 3 and 4). The findings of gradual changes in nest concealment, nest distances, nest synchronization suggest that the adaptive behaviour of the azure-winged magpies inherits from generation to generation over long time period. 


\section{REFERENCES}

Alarcos, S., De La Cruz, C., Solís, E., Valencia, J. and García-Baquero, M. J. 2007. Sex determination of Iberian Azure-winged Magpies Cyanopica cyanus cooki by discriminant analysis of external measurements. - Ringing Migr 23: 211-216.

Alexander, R. D. 1974. The evolution of social behavior. - Annu Rev Ecol Syst 5: 325-383.

Álvarez, F. and Aguilera, E. 1988. Sobre el dimorfismo sexual en el rabilargo, Cyanopyca cyanea Pall. - Ardeola 35: 269-295.

Andersson, M. and Wiklund, C. G. 1978. Clumping versus spacing out: Experiments on nest predation in Fieldfares (Turdus pilaris). - Anim Behav 26: 1207-1212.

Araujo, J. 1975. Estudios sorbe el rabilargo (Cyanopica cyanea) en una colonia de cria de Avila. - Ardeola 21: 469-485.

Arnold, K. E. and Owens, I. P. F. 1998. Cooperative breeding in birds: a comparative test of the life history hypothesis. - Proc R Soc B 265: 739.

Arnold, K. E. and Owens, I. P. F. 1999. Cooperative breeding in birds: the role of ecology. Behav Ecol 10: 465-471.

Austad, S. N. and Rabenold, K. N. 1985. Reproductive enhancement by helpers and an experimental inquiry into its mechanism in the bicolored wren. - Behav Ecol Sociobiol 17: 19-27.

Avilés, J. M. and Parejo, D. 2006. Nest defense by Iberian azure-winged magpies (Cyanopica cyanus): do they recognize the threat of brood parasitism? - Ethol Ecol Evol 18: 321333.

Baglione, V. 2003. Kin selection in cooperative alliances of Carrion crows. - Science (80- ) 300: 1947-1949. 
Baglione, V., Marcos, J. M. and Canestrari, D. 2002a. Cooperatively breeding groups of carrion crow (Corvus corone corone) in Northern Spain. - Auk 119: 790.

Baglione, V., Canestrari, D., Marcos, J. M., Griesser, M. and Ekman, J. 2002b. History, environment and social behaviour: experimentally induced cooperative breeding in the carrion crow. - Proc R Soc B 269: 1247-1251.

Bang, J., Jensen, B. and Sunde, P. 2005. Woodpigeons Columba palumbus breeding in open land associate with Kestrel Falco tinnunculus nests. - Bird 52: 93-95.

Bartoń, K. 2016. Multi-Model Inference “MuMIn.” - R package.

Bates, D., Maechler, M., Bolker, B. M. and Walker, S. 2015. Fitting Linear Mixed-Effects Models using lme4. - J Stat Softw 67: 1-48.

Bayandonoi, G., Gombobaatar, S., Wilson, K.-J. and Muehlenberg, M. 2013. Impacts of forest fire and predation to the breeding biology of Azure-winged magpie (Cyanopica cyanus Pallas, 1776), Mongolia. - Ornis Mongolica 2: 3-9.

Beckmann, C., Biro, P. A. and Martin, K. 2015. Hierarchical analysis of avian re-nesting behavior: mean, across-individual, and intra-individual responses. - Behav Ecol Sociobiol 69: 1631-1638.

Birkhead, T. R. 1977. The effect of habitat and density on breeding success in the Common guillemot (Uria aalge). - J Anim Ecol 46: 751-764.

Blanco, G. and Tella, J. L. 1997. Protective association and breeding advantages of choughs nesting in lesser kestrel colonies. - Anim Behav 54: 335-42.

Bogliani, G., Sergio, F. and Tavecchia, G. 1999. Woodpigeons nesting in association with hobby falcons: advantages and choice rules. - Anim Behav 57: 125-131.

Boland, C. R. J. 1998. Helpers improve nest defense in cooperatively breeding White-winged choughs. - Emu 98: 320-324.

Boland, C. R. J., Heinsohn, R. and Cockburn, A. 1997. Experimental manipulation of brood reduction and parental care in cooperatively creeding White-winged Choughs. - J Anim 
Ecol 66: 683-691.

Bold, A. 1973. Birds of Mongolia. - J Mong Acad Sci in press.

Bold, A. 1977. The practical importance of the birds of Khentey mountain region.

Boldbaatar, S. 1999. The occurrence of Corvidae birds among Tuul river. - J Natl Univ Mong 9: $122-133$.

Boldbaatar, S. 2006. The results of vertebrates in the Eg river basin. - J Mong Acad Sci 26: $82-100$

Borgmann, K. L. and Conway, C. J. 2015. The Nest-concealment hypothesis: new insights from a comparative analysis. - Wilson J Ornithol 4: 646-660.

Borgo, J. 2008. Effects of olfactory and visual predators on nest success and nest-site selection of waterfowl in North Dakota.

Brown, J. L. 1987. Helping and communal breeding in birds ecology and evolution. Princeton University Press.

Brown, C. R. and Brown, M. B. 1987. Group-living in Cliff Swallows as an advantage in avoiding predators. - Behav Ecol Sociobiol 21: 97-107.

Brunton, D. H. 1990. The effects of nesting stage, sex, and type of predator on parental defense by killdeer (Charadrius vociferous): testing models of avian parental defense. Behav Ecol Sociobiol 26: 181-190.

Brunton, D. H. 1997. Impacts of predators: center nests are less successful than edge nests in a large nesting colony of Least terns. - Condor 99: 372-380.

Burhans, D. E. and Thompson III, F. R. 1998. Effects of time and nest-site characteristics on concealment of songbird nests. - Condor 100: 663-672.

Burhans, D. E. and Thompson, F. R. 2001. Relationship of songbird nest concealment to nest fate and flushing behavior of adults. - Auk 118: 237-242.

Burnham, K. P. and Anderson, D. R. 2002. Model Selection and Multimodel Inference: A Practical Information-Theoretic Approach (2nd ed). - Springer. 
Canario, F., Matos, S. and Soler, M. 2004. Environmental constraints and cooperative breeding in the Azure-winged Magpie. - Condor 106: 608-617.

Canestrari, D., Marcos, J. M. and Baglione, V. 2005. Effect of parentage and relatedness on the individual contribution to cooperative chick care in carrion crows. - Behav Ecol Sociobiol 52: 422-428.

Canestrari, D., Marcos, J. M. and Baglione, V. 2007. Costs of chick provisioning in cooperatively breeding crows: an experimental study. - Anim Behav 73: 349-357.

Canestrari, D., Chiarati, E., Marcos, J. M., Ekman, J. and Baglione, V. 2008a. Helpers but not breeders adjust provisioning effort to year-round territory resource availability in carrion crows. - Anim Behav 76: 943-949.

Canestrari, D., Marcos, J. M. and Baglione, V. 2008b. Reproductive success increases with group size in cooperative carrion crows, Corvus corone corone. - Anim Behav 75: 403416.

Canestrari, D., Marcos, J. M. and Baglione, V. 2009. Cooperative breeding in carrion crows reduces the rate of brood parasitism by great spotted cuckoos. - Anim Behav 77: 13371344.

Canestrari, D., Marcos, J. M. and Baglione, V. 2011. Helpers at the nest compensate for reduced maternal investment in egg size in carrion crows. - J Evolution Biol 24: 18701878.

Caro, T. M. 2005. Antipredator defenses in birds and mammals. - The University of Chicago Press.

Carranza, J., Polo, V., Valencia, J., Mateos, C. and Cruz, C. 2008. How should breeders react when aided by helpers? - Anim Behav 75: 1535-1542.

Chamberlain, D. E., Hatchwell, B. J. and Perrins, C. M. 1995. Spaced out nests and predators: An experiment to test the effects of habitat structure. - J Avian Biol 26: 346-349.

Clutton-Brock, T. H. 2002. Breeding together: kin selection and mutualism in cooperative 
vertebrates. - Science (80- ) 296: 69-72.

Clutton-Brock, T. H., Russell, A. F., Sharpe, L. L., Young, A. J., Balmforth, Z. and Mcilrath, G. M. 2002. Evolution and development of sex differences in cooperative behavior in meerkats. - Science (80- ) 297: 253-256.

Cockburn, A. 1996. Why do so many Australian birds cooperate: social evolution in the Corvida? - In: Floyd, R. B. et al. (eds), Frontiers of Population Ecology. CSIRO Publishing, pp. 451-472.

Cockburn, A. 1998. Evolution of helping behavior in cooperatively breeding birds. - Annu Rev Ecol Syst 29: 141-177.

Cockburn, A. 2006. Prevalence of different modes of parental care in birds. - Proc R Soc B 273: 1375-1383.

Collias, N. E. and Collias, E. C. 1984. Nest building and bird behavior. - Princeton University Press.

Colombelli-Négrel, D. and Kleindorfer, S. 2009. Nest height, nest concealment, and predator type predict nest predation in superb fairy-wrens (Malurus cyaneus). - Ecol Res 24: 921928.

Covas, R. and Griesser, M. 2007. Life history and the evolution of family living in birds. Proc R Soc B 274: 1349-1357.

Cramp, S. and Perrins, C. M. 1994. Birds of the Western Palearctic (S Cramp and CM Perrins, Eds.). - Oxford university Press.

Cresswell, W. 1997. Nest predation rates and nest detectability in different stages of breeding in Blackbirds Turdus merula. - J Avian Biol 28: 296-302.

Cruz, C. D. la 1988. Contribución al conocimiento de la biología del rabilargo (Cyanopica cyanus Pall., 1776).

Cruz, C., Lope, F. and Silva, E. 1990. Exito reproductor del rabilargo (Cyanopica cyanea Pall.) en Extremadura. - Ardeola 37: 179-195. 
Curio, E. 1978. The adaptive significance of avian mobbing. - Zeitschrift fürTierpsychologie 183: 175-183.

Dally, J. M., Emery, N. J. and Clayton, N. S. 2006. Food-caching Western scrub-jays keep track of who was watching when. - Science (80- ) 312: 1662-1666.

Dickinson, J. L. 2004. A test of the importance of direct and indirect fitness benefits for helping decisions in Western Bluebirds. - Behav Ecol 15: 233-238.

Dickinson, J. L. and Hatchwell, B. J. 2004. The fitness consequences of helping. - In: Koenig, W. and Dickinson, J. L. (eds), Ecology and Evolution of Cooperative Breeding in Birds. Cambridge University Press, pp. 48-66.

Doligez, B. and Clobert, J. 2003. Clutch size reduction as a response to increased nest rredation rate in the Collared flycatcher. - Ecology 84: 2582-2588.

Doligez, B., Danchin, E., Clobert, J. and Gustafsson, L. 1999. The use of conspecific reproductive success for breeding habitat selection in a non-colonial, hole-nesting species, the collared flycatcher. - J Anim Ecol 68: 1193-1206.

Doligez, B., Pärt, T. and Danchin, E. 2004. Prospecting in the collared flycatcher: Gathering public information for future breeding habitat selection? - Anim Behav 67: 457-466.

Dow, B. Y. H. and Fredgat, S. 1983. Breeding and natal dispersal of the Goldeneye, Bucephala clangula. - J Anim Ecol 52: 681-695.

Du Plessis, M. A., Siegfried, W. R. and Armstrong, A. J. 1995. Ecological and life-history correlates of cooperative breeding in South African birds. - Oecologia 102: 180-188.

Eden, S. F. 1987. When do helpers help? Food availability and helping in the moorhen, Gallinula chloropus. - Behav Ecol Sociobiol 21: 191-195.

Eggers, S., Griesser, M. and Ekman, J. 2005. Predator-induced plasticity in nest visitation rates in the Siberian jay (Perisoreus infaustus). - Behav Ecol 16: 309-315.

Eggers, S., Griesser, M., Nystrand, M. and Ekman, J. 2006. Predation risk induces changes in nest-site selection and clutch size in the Siberian jay. - Proc Biol Sci 273: 701-706. 
Ekman, J. and Ericson, P. G. . 2006. Out of Gondwanaland; the evolutionary history of cooperative breeding and social behaviour among crows, magpies, jays and allies. - Proc R Soc B 273: 1117-1125.

Elgood, J. H. and Ward, P. 1963. A snake attack upon a Weaver-bird colony: Possible significance of synchronous breeding activity. - Bull Br Ornithol Club 83: 71-73.

Emery, N. J. and Clayton, N. S. 2004. The mentality of crows: convergent evolution of intelligence in corvids and apes. - Science 306: 1903-1907.

Emlen, S. T. 1982. The evolution of helping . I . An ecological constraints model. - Am Nat 119: 29-39.

Emlen, S. T. and Demong, N. J. 1975. Adaptive significance of synchronized breeding in a colonial bird: a new hypothesis. - Science (80- ) 8: 1029-1031.

Emlen, S. T. and Wrege, P. H. 1991. Breeding biology of White-fronted Bee-eaters at Nakuru: the influence of helpers on breeder fitness. - J Anim Ecol 60: 309-326.

Emmering, Q. C. and Schmidt, K. A. 2011. Nesting songbirds assess spatial heterogeneity of predatory chipmunks by eavesdropping on their vocalizations. - J Anim Ecol 80: 13051312.

Filliater, T. S., Breitwisch, R. and Nealen, P. M. 1994. Predation on Northern cardinal nests: does choice of nest site matter? - Condor 96: 761-768.

Finch, D. M. 1989. Relationships of surrounding riparian habitat to nest-box use and reproductive outcome in House wrens. - Condor 91: 848-859.

Finke, M. D. 2005. Nutrient Content of Insects. - In: Capinera, J. L. (ed), Encyclopedia of Entomology. Springer, pp. 1563-1575.

Finney, S. K., Harris, M. P., Keller, L. F., Elston, D. A., Monaghan, P. and Wanless, S. 2003. Reducing the density of breeding gulls influences the pattern of recruitment of immature Atlantic puffins Fratercula arctica to a breeding colony. - J Appl Ecol 40: 545-552.

Fok, K. W., Wade, C. M. and Parkin, D. T. 2002. Inferring the phylogeny of disjunct 
populations of the azure-winged magpie Cyanopica cyanus from mitochondrial control region sequences. - Proc Biol Sci 269: 1671-1679.

Fontaine, J. J. and Martin, T. E. 2006a. Habitat selection responses of parents to offspring predation risk: An experimental test. - Am Nat 168: 811-818.

Fontaine, J. J. and Martin, T. E. 2006b. Parent birds assess nest predation risk and adjust their reproductive strategies. - Ecol Lett 9: 428-434.

Fontaine, J. J., Martel, M., Markland, H. M., Niklison, A. M., Decker, K. L. and Martin, T. E. 2007. Testing ecological and behavioral correlates of nest predation. - Oikos 116: 18871894.

Ford, H. A., Bell, H., Nias, R. and Noske, R. 1988. The relationship between ecology and the incidence of cooperative breeding in Australian birds. - Behav Ecol Sociobiol 22: 239249.

Forster, I. P. and Phillips, R. A. 2009. Influence of nest location, density and topography on breeding success in the Black-browed Albatross Thalassarche melanophris. - Mar Ornithol 37: 213-217.

Francis, A. M., Hailman, J. P. and Woolfenden, G. E. 1989. Mobbing by Florida scrub jays: behaviour, sexual asymmetry, role of helpers and ontogeny. - Anim Behav 38: 795-816.

Gantigmaa, C. 2004. Butterfly communities in the natural landscape of West Khentej, northernMongolia: diversity and conservation value.

Ghalambor, C. K., Peluc, S. I. and Martin, T. E. 2013. Plasticity of parental care under the risk of predation : how much should parents reduce care? - Biol Lett 9: 1-4.

Goławski, A. and Mitrus, C. 2008. What is more important: Nest-site concealment or aggressive behaviour? A case study of the red-backed shrike, Lanius collurio. - Folia Zool 57: 403-410.

Gombobaatar, S. and Monks, E. M. 2011. Mongolian red list of birds (R Seidler, D Sumiya, N.Tseveenmyadag, S Bayarkhuu, JEM Baillie, S Boldbaatar, and C Uuganbayar, Eds.). - 
Zoological Society of London, National University of Mongolia and Mongolian Ornithological Society.

Gonzalez, J.-C. T., Sheldon, B. C. and Tobias, J. A. 2013. Environmental stability and the evolution of cooperative breeding in hornbills. - Proc R Soc B 280: 20131297.

Goodwin, D. 1986. Crows of the World. - Comstock Publishing Associates.

Götmark, F., Blomqvist, D., Johansson, O. C. and Bergkvist, J. 1995. Nest site selection: A trade-off between concealment and view of the surroundings? - J Avian Biol 26: 305312.

Gottfried, B. M. and Thompson, C. F. 1978. Experimental analysis of nest predation in an old-field habitat. - Auk 95: 304-312.

Gow, E. A. and Stutchbury, B. J. M. 2013. Within-season nesting dispersal and molt dispersal are linked to habitat shifts in a Neotropical migratory songbird. - Wilson J Ornithol 125: 696-708.

Greeney, H. F., Meneses, M. R., Hamilton, C. E., Lichter-Marck, E., Mannan, R. W., Snyder, N., Snyder, H., Wethington, S. M. and Dyer, L. A. 2015. Trait-mediated trophic cascade creates enemy-free space for nesting hummingbirds. - Sci Adv 1: 1:e1500310.

Gregoire, A. and Cherry, M. I. 2007. Nesting success and within-season breeding dispersal in the Orange-breasted Sunbird Anthobaphes violacea. - Ostrich 78: 633-636.

Greig-Smith, P. W. 1982. Dispersal between nest-sites by Stonechats Saxicola torquata in relation to previousbreeding success. - Ornis Scand 13: 232-238.

Groenewoud, F., Frommen, J. G., Josi, D., Tanaka, H., Jungwirth, A. and Taborsky, M. 2016. Predation risk drives social complexity in cooperative breeders. - Proc Natl Acad Sci U S A 113: 4104-4109.

Grzybowski, J. A. and Pease, C. M. 2005. Renesting determines seasonal fecundity in songbirds: what do we know? what should we assume? - Auk 122: 280.

Hailman, J. P., McGowan, K. J. and Woolfenden, G. E. 1994. Role of helpers in the sentinel 
behaviour of the Florida Scrub Jay (Aphelocoma c. coerulescens). - Ethology 97: 119140.

Hakkarainen, H., Ilmonen, P., Koivunen, V. and Korpimäki, E. 2001. Experimental increase of predation risk induces breeding dispersal of Tengmalm's owl. - Oecologia 126: 355359.

Hamilton, W. D. D. 1964. The genetical evolution of social behaviour. I. - J Theor Biol 7: 116.

Hamilton, W. D. 1971. Geometry for the selfish herd. - J Theor Biol 31: 295-311.

Hanski, I. K., Fenske, T. J. and Niemi, G. J. 1996. Lack of edge effect in nesting success of breeding birds in managed forest landscapes. - Auk 113: 578-585.

Haojin, T. 2011. Habitat use and population dynamics of the Azure-winged magpie, Cyanopica cyanus, and their response to fire in Northern Mongolia.

Hasson, O. 1991. Pursuit-deterrent signals: communication between prey and predator. Trends Ecol Evol 6: 325-329.

Hatchwell, B. J. 1999. Investment strategies of breeders in avian cooperative breeding systems. - Am Nat 154: 205-219.

Hatchwell, B. J. 2004. Helpers increase long-term but not short-term productivity in cooperatively breeding long-tailed tits. - Behav Ecol 15: 1-10.

Hatchwell, B. J. 2009. The evolution of cooperative breeding in birds: kinship, dispersal and life history. - Philos Trans R Soc B Biol Sci 364: 3217-3227.

Hatchwell, B. J. and Komdeur, J. 2000. Ecological constraints, life history traits and the evolution of cooperative breeding. - Anim Behav 59: 1079-1086.

Hatchwell, B. J., Russell, A. F., Fowlie, M. K. and Ross, D. J. 1999. Reproductive success and nest-site selection in a cooperative breeder: effect of experience and a direct benefit of helping. - Auk 116: 355-363.

Haydock, J., Koenig, W. D. and Stanback, M. T. 2001. Shared parentage and incest avoidance 
in the cooperatively breeding acorn woodpecker. - Mol Ecol 10: 1515-1525.

Heg, D. and Taborsky, M. 2010. Helper response to experimentally manipulated predation risk in the cooperatively breeding cichlid Neolamprologus pulcher. - PLoS One 5: e10784.

Hill, W. L., Jones, K. J., Hardenbergh, C. L. and Browne, M. 1997. Nest distance mediates the costs of coloniality in Eared Grebes. - Colon Waterbirds 20: 470-477.

Hirsch, B. T. and Morrell, L. J. 2011. Measuring marginal predation in animal groups. Behav Ecol 22: 648-656.

Hogstad, O. 1983. Is nest predation really selecting for colonial breeding among Fieldfares Turdus pilaris? - Ibis (Lond 1859) 125: 366-369.

Hogstad, O. 1995. Do avian and mammalian nest predators select for different nest dispersion patterns of fieldfares Turdus pilaris? A 15-year study. - Ibis (Lond 1859) 137: 484-489.

Hoogland, J. L. 1981. The evolution of coloniality in White-tailed and Black-tailed prairie dogs (Sciuridae: Cynomys Leucurus and C.Ludovicianus). - Ecology 62: 252-272.

Hoogland, J. L. and Sherman, P. W. 1976. Advantages and disadvantages of Bank swallow (Riparia riparia) coloniality. - Ecol Monogr 46: 33-58.

Hosono, T. 1966a. A study of the life history of the Blue magpie (3). Chick foods. - Misc Rep Yamashina Inst Ornithol 4: 4811-487.

Hosono, T. 1966b. A life history study of the Blue magpie (1). Breeding biology. - Misc Rep Yamashina Inst Ornithol 4: 327-347.

Hosono, T. 1968. A study of the life history of the Blue magpie (5). Roost and roost-flock distribution in winter. - Misc Rep Yamashina Inst Ornithol 5: 278-286.

Hosono, T. 1983. A study of the life history of the Blue Magpie (2). Breeding helpers and nest-parasitism by cuckoos. - J Yamashina Inst Ornithol 15: 63-71.

Hötker, H. 2000. Intraspecific variation in size and density of Avocet colonies: effects of nestdistances on hatching and breeding success. - J Avian Biol 31: 387-398. 
Howlett, J. S. and Stutchbury, B. J. 1996. Nest concealment and predation in Hooded warblers: Experimental removal of nest cover. - Auk 113: 1-9.

Hurvich, C. M. and Tsai, C.-L. 1989. Regression and time series model selection in small samples. - Biometrika 76: 297-307.

Hurvich, C. M. and Tsai, C. L. 1995. Model selection for extended quasi-likelihood models in small samples. - Biometrics 51: 1077-1084.

Innes, K. E. and Johnston, R. E. 1996. Cooperative breeding in the white-throated magpie-jay. How do auxiliaries influence nesting success? - Anim Behav 51: 519-533.

Iwaniuk, A. N. and Arnold, K. E. 2004. Is cooperative breeding associated with bigger brains? A comparative test in the Corvida (Passeriformes). - Ethology 110: 203-220.

Jackson, W. M., Rohwer, S. and Nolan, V. 1989. Within-season breeding dispersal in Prairie warblers and other passerines. - Condor 91: 233-241.

Jesus M. Aviles 2004. Egg rejection by Iberian azure-winged magpies Cyanopica cyanus in the absence of brood parasitism. - J Avian Biol 35: 295-299.

Jetz, W. and Rubenstein, D. R. 2011. Environmental uncertainty and the global biogeography of cooperative breeding in birds. - Curr Biol 21: 72-78.

Jungwirth, A., Josi, D., Walker, J. and Taborsky, M. 2015. Benefits of coloniality: Communal defense saves anti-predator effort in cooperative breeders. - Funct Ecol 29: 1218-1224.

Kingma, S. A., Santema, P., Taborsky, M. and Komdeur, J. 2014. Group augmentation and the evolution of cooperation. - Trends Ecol Evol 29: 476-484.

Klett, A. T., Shaffer, T. L. and Johnson, D. H. 1988. Duck nest success in the Prairie Pothole region. - J Wildl Manage 52: 431-440.

Koenig, W. D. and Stacey, P. B. 1990. Acorn woodpeckers: group-living and food storage under contrasting ecological conditions. - In: Cooperative breeding in birds long term studies of Ecology and Behaviour. Cambridge University Press, pp. 413-453.

Koenig, W. and Dickinson, J. 2004. Ecology and evolution of cooperative breeding in birds. - 
Cambridge University Press.

Koenig, W. D. and Dickinson, J. L. 2016. Cooperative breeding in vertebrates. - Cambridge University Press.

Koenig, W. D., Pitelka, F. A., Carmen, W. J., Mumme, R. L. and Stanback, M. T. 1992. The evolution of delayed dispersal in cooperative breeders. - Q Rev Biol 67: 111-150.

Kokko, H., Johnstone, R. A. and T. H., C.-B. 2001. The evolution of cooperative breeding through group augmentation. - Proc R Soc B 268: 187-196.

Komdeur, J. 1996. Influence of helping and breeding experience on reproductive performance in the Seychelles warbler: A translocation experiment. - Behav Ecol 7: 326-333.

Komdeur, J. and Kats, R. K. H. 1999. Predation risk affects trade-off between nest guarding and foraging in Seychelles warblers. - Behav. Ecol. 10: 648-658.

Komeda, S., Yamagishi, S. and Fujioka, M. 1987. Cooperative breeding in Azure-winged magpies, Cyanopica cyana, living in a region of heavy snowfall. - Condor 89: 835-841.

Kozlova, N. A. 1930. Birds of South Baikal, Northern Mongolia and Central Gobi.

Krams, I., Krama, T., Igaune, K. and Mänd, R. 2007. Long-lasting mobbing of the pied flycatcher increases the risk of nest predation. - Behav Ecol 18: 1082-1084.

Krams, I., Berziņš, A. and Krama, T. 2009. Group effect in nest defense behaviour of breeding pied flycatchers, Ficedula hypoleuca. - Anim Behav 77: 513-517.

Krams, I., Berzins, A., Krama, T., Wheatcroft, D., Igaune, K. and Rantala, M. J. 2010. The increased risk of predation enhances cooperation. - Proc R Soc B 277: 513-518.

Krause, J. and Ruxton, G. D. 2002. Living in Groups. - Oxford university Press.

Krebs, J. R. and Davies, N. B. 1978. Behavioural ecology: An evolutionary approach.

Kruuk, H. 1964. Predators and anti-predator behaviour of the Black-headed gull (Larus Ridibundus L.). - Behav Suppl 11: 1-129.

Kryukov, A., Iwasa, M. a., Kakizawa, R., Suzuki, H., Pinsker, W. and Haring, E. 2004. Synchronic east-west divergence in azure-winged magpies (Cyanopica cyanus) and 
magpies (Pica pica). - J Zool Syst Evol Res 42: 342-351.

Kuznetsova, A., Brockhoff, P. B. and Christensen, R. H. B. 2016. ImerTest: Tests in Linear Mixed Effects Models. in press.

Lima, S. L. 1998. Nonlethal effects in the ecology of predator-prey interactions. - Bioscience 48: $25-34$.

Lima, S. L. 2009. Predators and the breeding bird: behavioral and reproductive flexibility under the risk of predation. - Biol Rev 84: 485-513.

Lima, S. L. and Dill, L. M. 1990. Behavioral decisions made under the risk of predation: a review and prospectus. - Can J Zool 68: 619-640.

Lloyd, P., Andrew Taylor, W., Du Plessis, M. A. and Martin, T. E. 2009. Females increase reproductive investment in response to helper-mediated improvements in allo-feeding, nest survival, nestling provisioning and post-fledging survival in the Karoo scrub-robin Cercotrichas coryphaeus. - J Avian Biol 40: 400-411.

Lukacs, P. M., Burnham, K. P. and Anderson, D. R. 2010. Model selection bias and Freedman's paradox. - Ann Inst Stat Math 62: 117-125.

Madge, S. and Burn, H. 1994. Crows and jays: A guide to crows, jays and magpies of the world. - Christopher Helm.

Martin, T. E. 1987. Food as a limit on breeding birds: A life-history perspective. - Annu Rev Ecol Syst 18: 453-487.

Martin, T. E. 1988. Processes organizing open-nesting bird assemblages: competition or nest predation? - Evol Ecol 2: 37-50.

Martin, T. E. 1992a. Breeding productivity considerations: what are the appropriate habitat features for management? - In: Hagen III, J. M. and Jonston, D. W. (eds), Ecology and conservation of Neotropical migrant birds. Smithsonian Institution Press, pp. 455-473.

Martin, T. E. 1992b. Interaction of nest predation and food limitation in reproductive strategies. - In: Current Ornithology. Springer US, pp. 163-197. 
Martin, T. E. 1993. Nest predation and nest sites: new perspectives on old patterns. Bioscience 43: 523-532.

Martin, T. E. 1995a. Avian life history evolution in relation to nest sites, nest predation, and food. - Ecol Monogr 65: 101-127.

Martin, T. E. 1995b. Avian life history evolution in relation to nest sites, nest predation, and food. - Ecol Monogr 65: 101-127.

Martin, T. E. and Li, P. 1992. Life history traits of open- vs. cavity-nesting birds. - Ecology 73: 579-592.

Martin, T. E., Roper, J. J., Condor, T., Feb, N., Martin, E. and Roper, J. 1988. Nest predation and nest-site selection of a western population of the Hermit thrush. - Condor 90: 51-57.

Marzluff, J. M. 1988. Do pinyon jays alter nest placement based on prior experience? - Anim Behav 36: 1-10.

Marzluff, J. M. and Balda, R. P. 1992. The Pinyon jay: Behavioral ecology of a colonial and cooperative Corvid. - T. \& A. D. Poyser.

Massaro, M., Starling-Windhof, A., Briskie, J. V. and Martin, T. E. 2008. Introduced mammalian predators induce behavioural changes in parental care in an endemic New Zealand bird. - PLoS One 3: e2331.

McGowan, K. J. and Woolfenden, G. E. 1989. A sentinel system in the Florida scrub jay. Anim Behav 37: 1000-1006.

McGowan, K. J. and Woolfenden, G. E. 1990. Contribution to fledgling feeding in the florida scrub jay. - J Anim Ecol 59: 691-707.

Michalski, F. and Norris, D. 2014. Artificial nest predation rates vary depending on visibility in the eastern Brazilian Amazon. - Acta Amaz 44: 393-396.

Møller, A. P. 1987. Advantages and disadvantages of coloniality in the swallow, Hirundo rustica. - Anim Behav 35: 819-832.

Møller, A. P. 1988. Nest predation and nest site choice in Passerine birds in habitat patches of 
different size: A study of magpies and blackbirds. - Oikos 53: 215-221.

Mönkkönen, M., Husby, M., Tornberg, R., Helle, P. and Thomson, R. L. 2007. Predation as a landscape effect: The trading off by prey species between predation risks and protection benefits. - J Anim Ecol 76: 619-629.

Montgomerie, R. D. and Weatherhead, P. J. 1988. Risks and rewards of nest defense by parent birds. - Q Rev Biol 63: 167.

Morosinotto, C., Thomson, R. L. and Korpimäki, E. 2010. Habitat selection as an antipredator behaviour in a multi-predator landscape: All enemies are not equal. - J Anim Ecol 79: $327-333$.

Muehlenberg, M., Slowik, J., Samiya, R., Dulamsuren, C., Gantigmaa, C. and Woyciechowski, M. 2000. The conservation value of West Khentii, North Mongolia: evaluation of plant and butterfly communities. - Fragm Florist Geobot 45: 63-90.

Mumme, R. L. 1992. Do helpers increase reproductive success? An experimental analysis in the Florida scrub jay. - Behav Ecol Sociobiol 31: 319-328.

Muñoz-Pulido, R., Bautista, L. M. and Alonso, J. C. 1990. Breeding success of Azure-winged Magpies Cyanopica cyana in Central Spain. - Bird Study 37: 111-114.

Nagy, L. R. and Holmes, R. T. 2005. Food limits annual fecundity of a migratory songbird: An experimental study. - Ecology 86: 675-681.

O’Brien, T. G. 1997. Behavioural ecology of the north Sulawesi Tarictic hornbill Penelopides exarhatus exarhatus during the breeding season. - Ibis (Lond 1859) 139: 97-101.

Page, G. W., Stenzel, L. E. and Winkler, D. W. 1983. Spacing out at Mono lake: Breeding success, nest density, and predation in the Snowy plover. - Am Nat 100: 13-24.

Patterson, I. J. 1965. Timing and spacing of broods in Black-headed gull Larus rudibundus. Ibis (Lond 1859) 107: 433-459.

Peak, R. G. 2003. An experimental test of the concealment hypothesis using American goldfinch nests. - Wilson Bull 115: 403-408. 
Peluc, S. I., Sillett, T. S., Rotenberry, J. T. and Ghalambor, C. K. 2008. Adaptive phenotypic plasticity in an island songbird exposed to a novel predation risk. - Behav Ecol 19: 830835.

Perkins, D. W. and Vickery, P. D. 2007. Nest success of grassland Birds in Florida dry prairie. - Southeast Nat 6: 283-292.

Perry, E. F. and Andersen, D. E. 2003. Advantages of clustered nesting for least flycatchers in north-central Minnesota. - Condor 105: 756-770.

Perry, E. F., Manolis, J. C. and Andersen, D. E. 2008. Reduced predation at interior nests in clustered all-purpose territories of Least flycatchers (Empidonax minimus). - Auk 125: $643-650$.

Phillips, R. A., Furness, R. W. and Stewart, F. M. 1998. The influence of territory density on the vulnerability of Arctic skuas Stercorarius parasiticus to predation. - Biol Conserv 86: $21-31$.

Picman, J. 1988. Experimental study of predation on eggs of ground-nesting brids: effects of habitat and nest distribution. - Condor 90: 124-131.

Picman, J., Leonard, M. and Horn, A. 1988. Antipredation role of clumped nesting by marshnesting red-winged blackbirds. - Behav Ecol Sociobiol 22: 9-15.

Pitman, J. C., Hagen, C. A., Jamison, B. E., Robel, R. J., Loughin, T. M. and Applegate, R. D. 2006. Nesting ecology of Lesser Prairie-Chickens in sand sagebrush prairie of southwestern Kansas. - Wilson J Ornithol 118: 23-35.

Poiani, A. and Pagel, M. 1997. Evolution of avian cooperative breeding: comparative tests of the nest predation hypothesis. - Evolution (N Y) 51: 226-240.

Powell, L. A. 1998. Experimental analysis and simulation modeling of forest management impacts on wood thrushes, Hylocichla mustelina.

Powell, L. A. and Frasch, L. L. 2000. Can nest predation and predator type explain variation in dispersal of adult birds during the breeding season ? - Behav Ecol 11: 437-443. 
Quinn, J. L., Prop, J., Kokorev, Y. and Black, J. M. 2003. Predator protection or similar habitat selection in red-breasted goose nesting associations: extremes along a continuum. - Anim Behav 65: 297-307.

R Core Development Team 2016. R: a language and environment for statistical computing. in press.

Rabenold, K. N. 1984. Cooperative enhancement of reproductive success in tropical wren societies. - Ecology 65: 871-885.

Rabenold, K. N. 1990. Campylorhynchus wrens: the ecology of delayed dispersal and cooperation in the Venezuelan savanna. - In: Stacey, P. B. and Koenig, W. D. (eds), Cooperative breeding in birds: long-term studies of ecology and behaviour. Cambridge University Press, pp. 157-196.

Raby, C. R., Alexis, D. M., Dickinson, a and Clayton, N. S. 2007. Planning for the future by western scrub-jays. - Nature 445: 919-21.

Rastogi, A. D., Zanette, L. and Clinchy, M. 2006. Food availability affects diurnal nest predation and adult antipredator behaviour in song sparrows, Melospiza melodia. - Anim Behav 72: 933-940.

Remeš, V. 2005. Nest concealment and parental behaviour interact in affecting nest survival in the blackcap (Sylvia atricapilla): An experimental evaluation of the parental compensation hypothesis. - Behav Ecol Sociobiol 58: 326-332.

Reyer, H.-U. 1984. Investment and relatedness: a cost/benefit analysis of breeding and helping in the pied kingfisher (Ceryle rudis). - Anim Behav 32: 1163-1178.

Ricklefs, R. E. 1969. An analysis of nesting mortality in birds. - Smithson Contrib to Zool: 148.

Ridley, A. R. 2007. Factors affecting offspring survival and development in a cooperative bird: social, maternal and environmental effects. - J Anim Ecol 76: 750-760.

Ringelman, K. M., Eadie, J. M. and Ackerman, J. T. 2012. Density-dependent nest predation 
in waterfowl: The relative importance of nest density versus nest dispersion. - Oecologia 169: 695-702.

Ritschel, S. 1985. Breeding ecology of the Red-winged blackbird (Agelaius phoeniceus); tests of models of polygyny.

Roos, S. 2006. Habitat selection and reproduction of red-backed shrikes (Lanius collurio) in relation to abundance of potential avian nest predators. - J Appl Ecol: 167-173.

Roos, S. and Pärt, T. 2004. Nest predators affect spatial dynamics of breeding red-backed shrikes (Lanius collurio). - J Anim Ecol 73: 117-127.

Rubenstein, D. I. 1978. On Predation, Competition, and the Advantages of Group Living. - In: Bateson, P. P. G. and Klopfer, P. H. (eds), Perspectives in Ethology, Volume 3: Social Behaviour. Volume 3. Springer US, pp. 205-231.

Rubenstein, D. I. and Wrangham, R. W. 1986. Ecological aspects of social Evolution (DI Rubenstein and RW Wrangham, Eds.). - Princeton University Press.

Rubenstein, D. R. and Lovette, I. J. 2007. Temporal Environmental Variability Drives the Evolution of Cooperative Breeding in Birds. - Curr Biol 17: 1414-1419.

Saito, Y., Chittenden, A. R., Mori, K., Ito, K. and Yamauchi, A. 2008. An overlooked side effect of nest-scattering behavior to decrease predation risk (Acari: Tetranychidae, Stigmaeidae). - Behav Ecol Sociobiol 63: 33-42.

Schaub, R. O. N., Mumme, R. L. and Woolfenden, G. E. 1992. Predation on the eggs and nestlings of Florida scrub jays. - Auk 109: 585-593.

Schmidt, K. a and Whelan, C. J. 1999. Nest predation on woodland songbirds: When is nest predation density dependent? - Oikos 87: 65-74.

Schmidt, K. A., Ostfeld, R. S. and Smyth, K. N. 2006. Spatial heterogeneity in predator activity, nest survivorship, and nest-site selection in two forest thrushes. - Oecologia 148: $22-29$.

Seed, A. M., Clayton, N. S. and Emery, N. J. 2008. Cooperative problem solving in rooks 
(Corvus frugilegus). - Proc Biol Sci 275: 1421-9.

Seed, A., Emery, N. and Clayton, N. 2009. Intelligence in corvids and apes: A case of convergent evolution? - Ethology 115: 401-420.

Segura, L. N. 2011. Biología reproductiva del Cardenal Común (Paroaria coronata, Thraupidae) en talares del noreste de la provincia de Buenos Aires.

Segura, L. N., Masson, D. A. and Gantchoff, M. G. 2012. Microhabitat nest cover effect on nest survival of the Red-crested cardinal. - Wilson J Ornithol 124: 506-512.

Selander, R. K. 1964. Speciation in wrens of the genus Campylorhynchus. - Univ Calif publ zool 74: 1-224.

Shields, M. A. and Parnell, J. F. 1986. Fish crow predation on eggs of the white ibis at Battery Island, North Carolina. - Auk 103: 531-539.

Skutch, A. F. 1935. Helpers at the nest. - Auk 52: 257-273.

Snow, D. W., Perrins, C. M., Hillcoat, B., Gillmor, R. and Roselaar, C. S. 1997. The birds of the Western Palearctic. - Oxford university Press.

Sonerud, G. A. 1985. Nest hole shift in Tengmalm's owl Aegolius funereus as defense against nest predation involving long-term memory in the predator. - J Anim Ecol 54: 179-192.

Stacey, P. B. and Ligon, J. D. 1991. The Benefits-of-Philopatry hypothesis for the evolution of cooperative breeding: variation in territory quality and group size effects. - Am Nat 137: 831 .

Sugiura, N. 1978. Further analysis of the data by Akaike's Information Criterion and the finite corrections. - Commun Stat Theory A7: 13-26.

Sullivan, B. D. and Dinsmore, J. J. 1990. Factors affecting egg predation by American crows. - J Wildl Manage 54: 433-437.

Symonds, M. R. E. and Moussalli, A. 2011. A brief guide to model selection, multimodel inference and model averaging in behavioural ecology using Akaike's information criterion. - Behav Ecol Sociobiol 65: 13-21. 
Tarof, S. a and Ratcliffe, L. M. 2004. Habitat characteristics and nest predation do not explain clustered breeding in least flycatchers (Empidonax minimus). - Auk 121: 877-893.

Thompson, F. R. 2007. Factors affecting nest predation on forest songbirds in North America. - Ibis (Lond 1859) 149: 98-109.

Tinbergen, N., Impekoven, M. and Franck, D. 1967. An experiment on spacing out as a defense against predation. - Behaviour 28: 307-321.

Tiralla, N. 2007. An examination of the infestation of wood with Lymantria dispar asiatica in Northern Mongolia.

Treisman, M. 1975. Predation and the evolution of gregariousness. I. Models for concealment and evasion. - Anim Behav 23: 779-800.

Tugarinov, A. Y. 1929. Status of birds in Northern Mongolia. in "introductory report of zoology expedition in Northern Mongolia in 1926."

Uchida, H. 1986. Passerine birds nesting close to the nests of birds of prey. - Japanese J Ornithol 35: 25-32.

Ueta, M. 1994. Azure-winged magpies, Cyanopica cyana, "parasitize" nest defense provided by Japanese lesser sparrowhawks, Accipiter gularis. - Anim Behav 48: 871-874.

Ueta, M. 1998a. Crow related low nesting success of small open nesting birds in Tokyo area. Strix 16: 67-71.

Ueta, M. 1998b. Azure-winged magpies avoid nest predation by nesting near a Japanese lesser sparrowhawk's nest. - Condor 100: 400-402.

Ueta, M. 2001. Azure-winged magpies avoid nest predation by breeding synchronously with Japanese lesser sparrowhawks. - Anim Behav 61: 1007-1012.

Ueta, M. 2007. Effect of Japanese lesser sparrowhawks Accipiter gularis on the nest site selection of azure-winged magpies Cyanopica cyana through their nest defending behavior. - J Avian Biol 38: 427-431.

Valcarcel, A. and Fernández-Juricic, E. 2009. Antipredator strategies of house finches: are 
urban habitats safe spots from predators even when humans are around? - Behav Ecol 63: 673-685.

Valencia, J., Cruz, C. and Carranza, J. 2000. Second broods in a Mediterranean cooperativelybreeding corvid: the Azure-winged Magpie. - Middle East 8: 25-28.

Valencia, J., Cruz, C. and Carranza, J. 2002. Timing of breeding in the azure-winged magpie in Spain. - Etologia 10: 17-22.

Valencia, J., Cruz, C. and Gonzalez, B. 2003. Flexible helping behaviour in the Azure-winged magpie. - Ethology 109: 545-558.

Valencia, J., Cruz, C., Carranza, J. and Mateos, C. 2006a. Parents increase their parental effort when aided by helpers in a cooperatively breeding bird. - Anim Behav 71: 1021-1028.

Valencia, J., Solís, E., Sorci, G. and Cruz, C. 2006b. Positive correlation between helpers at nest and nestling immune response in a cooperative breeding bird. - Behav Ecol Sociobiol 60: 399-404.

Vaurie, C. 1959. The Birds of the Palearctic fauna: Passeriformes.

Vehrencamp, S. L. 1978. The adaptive significance of communal nesting in Groove-billed anis (Crotophaga sulcirostris). - Behav Ecol Sociobiol 4: 1-33.

Velando, A. and Alonso-Alvarez, C. 2003. Differential body condition regulation by males and females in response to experimental manipulations of brood size and parental effort in the blue-footed booby. - J Anim Ecol 72: 846-856.

von Velsen-Zerweck, M. 2002. Socio-economic causes of forest loss in Mongolia.

Voous, K. H. 1960. Atlas of European birds.

Weidinger, K. 2002. Interactive effects of concealment, parental behaviour and predators on the survival of open passerine nests. - J Anim Ecol 71: 424-437.

Weimerskirch, H., Zimmermann, L. and Prince, P. a. 2001. Influence of environmental variability on breeding effort in a long-lived seabird, the yellow-nosed albatross. - Behav Ecol 12: 22-30. 
Weir, A. a S., Chappell, J. and Kacelnik, A. 2002. Shaping of hooks in New Caledonian crows. - Science 297: 981.

Wells, M. C. and Lehner, P. N. 1978. The relative importance of the distance senses in Coyote predatory behaviour. - Anim Behav 26: 251-258.

Wiklund, C. G. 1982. Fieldfare (Turdus pilaris) breeding success in relation to colony size, nest position and association with Merlins (Falco columbarius). - Behav Ecol Sociobiol 11: $165-172$.

Wittenberger, J. F. and Hunt, G. L. 1985. The adaptive significance of coloniality in birds. Avian Biol VIII: 1-78.

Woolfenden, G. E. 1975. Florida scrub jay helpers at the nest. - Auk 92: 1-15.

Woolfenden, G. E. 1978. Growth and survival of young Florida scrub jays. - Wilson Bull 90: $1-18$.

Zanette, L. Y., White, A. F., Allen, M. C. and Clinchy, M. 2011. Perceived predation risk reduces the number of offspring songbirds produce per year. - Science (80- ) 334: 13981401.

Zielinski, W. J. 2000. Weasels and Martens - Carnivores in northern latitudes. - In: Halle, S. and Stenseth, N. C. (eds), Activity Patterns in Small Mammals: An Ecological Approach. 1st ed.n. Springer-Verlag Berlin Heidelberg, pp. 322. 


\section{CURRICULUM VITAE}

\section{Gantulga Bayandonoi}

\section{EDUCATION}

Doctor of Philosophy (Biodiversity and Ecology), Department of Animal Ecology, GeorgAugust University Goettingen (Germany), October 2012 - July 2016

Master of Science (Zoology), Department of Zoology, Faculty of Biology, National University of Mongolia (Mongolia), September 2007 - July 2010

Bachelor of Art (Conservation biology and Ecology), Department of Ecology, Faculty of Biology, National University of Mongolia (Mongolia), September 2003 - June 2007

\section{EMPLOYMENT}

Database Officer, Library of the Georg-August University, Goettingen (Germany), February September 2013

Expert on Environmental Assessment, Wildlife Science and Conservation Center of Mongolia, subcontractor of the Flora and Fauna International, Umnugobi province (Mongolia), April - June 2012

Junior Researcher, Mongolian Ornithological Society, Ulaanbaatar (Mongolia), May 2008 - August 2012

Bird Guide, Oriental Nomads LLC., Ulaanbaatar (Mongolia), May 2010 - August 2012 
Lecturer (Ecology), Tushee University, Ulaanbaatar (Mongolia), September - November 2007

\section{RESEARCH EXPERIENCE}

Team leader and researcher on study "Sociobiology of azure winged magpie (Cyanopica cyanus)" in the Khonin Nuga research station, Sugnugur, Terelj, Bugant and Songino, June 2007 - July 2016

Expert on study "Surveys for Houbara bustards (Chlamydotis undulata) in infrastructure development areas related to the Oyu tolgoi project in southern Mongolia", Umnugobi province (Mongolia), April - June 2012

Team leader and researcher on census "National Saker falcon (Falco cherrug) census", April - June 2008 and 2010

Bird ringer on study "Monitoing research of the migrating birds" in the Khonin Nuga research station, in Mongolia, August -September 2007 - 2010

Assistant on study "Das Rebhuhnshutzprojekt im Landkreis Göttingen" at the Centre for Nature Conservation, Georg-August University, Goettingen, Germany, February - March in 2009, 2013 2016

Researcher on study "High power electric line survey and avian protection plans in the Mongolian steppe" in Mongolia, March - May 2009

Researcher on study "Breeding biology of Upland buzzard (Buteo hemilasius)" in Mongolia, April July 2007

Field assistant on study "Saker falcon in Mongolia: Research and Conservation" in Mongolia, March - July 2005 - 2007

Researcher on study "Breeding biology and density of some small birds of Alaudidae family" in Mongolia, May - July 2006 
Field assistant on study "The importance of North East Mongolia for Pacific Golden Plovers (Pluvialis fulva Gmelin., 1789)" in Mongolia, May - June 2005

\section{PRESENTATION AT PROFESSIONAL MEETINGS}

Talk, entitled "Responsive adaptation of the anti-predation strategies of the azure-winged magpie (Cyanopica cyanus Pallas, 1776) breeding groups under sudden predation risk" at the Department of Cognitive Biology, University of Vienna on $18^{\text {th }}$ April 2016 in Vienna, Austria

Talk, entitled "Cooperative breeding of the azure-winged magpie (Cyanopica cyanus Pallas, 1776) and its flexible anti-predation strategies" at the NGO, Biologische Schutzgemeinschaft, on $10^{\text {th }}$ March 2016 in Goettingen, Germany

10th meeting of the Ethological Society: "Causes and consequences of social behaviour" during 11th - 14th February 2015 in Hamburg with a poster presentation entitled "Does helping behaviour increase the quality of nestlings in varying environmental conditions? - Case study on the azurewinged magpies (Cyanopica cyanus Pallas, 1776) in northern Mongolia"

"Behaviour 2015" during the 9th - 14th August 2015 in Cairns Convention Centre, Cairns, Australia with a presentation entitled "How adaptive are the azure-winged magpies' (Cyanopica cyanus Pallas, 1776) defense strategies against nest predation in the Northern Mongolian population?: eight-year study results"

10th Conference of the European Ornithologists' union in Badajoz, 24-28 august 2015 with a poster presentation entitled "Nesting close together can be a flexible strategy against constant predation pressure in the azure-winged magpie"

Ecological Society of Germany, Austria and Switzerland (GfÖ) annual meeting during 8th - 12th September 2014 in Hildesheim with a poster presentation entitled "Flexible strategies of the azure- 
winged magpies (Cyanopica cyanus Pallas, 1776) against nest predation in northern Mongolia"

"Asian raptors science and conservation for present and future" $6^{\text {th }}$ International conference in Mongolia (2010.06.23-06.27) with poster presentation and as an organizer

"IUCN Bird Redlist data of the Mongolian birds" International workshop (2009.09.14-09.17) as an assessment expert

\section{HONOURS AND AWARDS}

DAAD scholarship for the $\mathrm{PhD}$ study during 2012-2016

Mike Madder's Field Research Award in 2013

Mongolian Korean friendship, Namjangju Scholarship in 2006

\section{PROFESSIONAL ORGANIZATIONS}

Member of the Mongolian Ornithological Society

Member of the British Ornithologists' Union

Member of the Wilson Ornithological Society

Member of the American Ornithologist' Union

\section{PUBLICATIONS}

Bayandonoi G., Waltert M., Kappeler P.M., Heymann E.W., Kupsch D., Gombobaatar S. and Mühlenberg M. (in review). Helping behaviour affects nestling condition and nest predation in a facultative cooperative breeding bird, the azure-winged magpie. Submitted to the Journal of Avian Biology 
Bayandonoi, G., Gombobaatar, S., Wilson, K.-J. and Muehlenberg, M. 2013. Impacts of forest fire and predation to the breeding biology of azure-winged magpie (Cyanopica cyanus Pallas, 1776), Mongolia. Ornis Mongolica 2: 3-9.

Gombobaatar S., Odkhuu B., Reuven Y., Bayandonoi G., Amartuvshin P., and Usukhjargal D. 2010. Reproductive Ecology of the Upland Buzzard (Buteo hemilasius) on the Mongolian Steppe. J. Raptor Research 44(3):196-201.

Gombobaatar S., Odkhuu B., Reuven Y., Gantulga B., Amartuvshin P., Usukhjargal, D. 2010. Do nest materials and nest substrates affect the breeding of Upland buzzard Buteo hemilasius in the Mongolian steppe. Efrorsch. Boil. Ress. Mongolei (Haale.Saale) 2010 (11):213-221.

Gombobaatar, S., Odkhuu, B., Gantulga, B and Yosef, R. 2008. A nest site selection of Upland Buzzards in the Mongolian steppe. Proceedings of the Biological Institute, Mongolian Academy of Sciences 27:47-51. (In Mongolian)

Gombobaatar, S. and Gantulga, B. 2008. A breeding biology of Alaudidae in the Mongolian steppe. Proceedings of the Biological Institute, Mongolian Academy of Sciences. 27:4346 (In Mongolian)

Gombobaatar, S., Munkhzaya, B., Gantulga, B., Odkhuu, B., Shane, M.P. 2007. A new finding for Mongolian bird species and unusual bird migration in the steppe. Proceedings of the Biological Institute, Mongolian Academy of Sciences 26:104-107. (In Mongolian)

Gantulga Bayandonoi. 2012. Birds, one of the wonders of Mongolia. Admon Printing House, Ulaanbaatar, Mongolia. p:160

Gantulga, B., Gombobaatar, S., Mühlenberg, M. 2010. Current status of raptors in the taiga forest, Northern Mongolia. In proceedings of the $6^{\text {th }}$ International Conference on Asian raptors. Ulaanbaatar, Mongolia. 23-27 June 2010. Asian Raptor Research and Conservation Network and Mongolian Ornithological Society. p. 79 
Gantulga Bayandonoi. 2010. Impacts of forest fire and predation to the breeding biology of azure-winged magpie (Cyanopica cyanus Pallas, 1776), Mongolia. In proceedings of the Master students' 2010 annual conference. National University of Mongolia. p: 41.

Gombobaatar, S., Yosef, R., Sumiya, D., Odkhuu, B., Gantulga, B., Amartuvshin, P., Usukjargal, D. 2009. The Ground Nesting Raptors on the Mongolian Steppe. Raptor research foundation 2009 Annual conference. Pitlochry, Scotland. 29 September - 4 October 2009. p: 49.

Gantulga Bayandonoi. 2006. "Migration study of Pacific Golden Plovers (Pluvialis fulva Gmelin., 1789)" In proceedings of the Bachelor students' 2006 annual conference. National University of Mongolia. p: 45.

Jan J. Wijmenga, Joop Jukema, Jeroen Reneerkens, Sundev Gombobaatar, B. Gantulga \& S. Tserennadmid. 2005. The importance of Northeastern Mongolia for migrating Pacific Golden Plovers. For the foundation Working Group International Waterbird \& Wetland Research (WIWO). 